\title{
CHANGE LEADERSHIP AND FEMALE SUPERINTENDENTS
}

\author{
A Dissertation submitted to the faculty of \\ San Francisco State University \\ As \\ 35 \\ 2015 \\ In partial fulfillment of \\ the requirements for \\ the Degree \\ EDD \\ .977 \\ Doctorate of Education \\ In
}

Educational Leadership

by

Mary Esther Streshly

San Francisco, California

May 2015 
Copyright by

Mary Esther Streshly

2015 
CERTIFICATION OF APPROVAL

I certify that I have read Change Leadership and Female Superintendents

by Mary Esther Streshly, and that in my opinion this work meets the criteria for approving a dissertation submitted in partial fulfillment of the requirement for the degree Doctorate of Education in Educational Leadership at San Francisco State University.
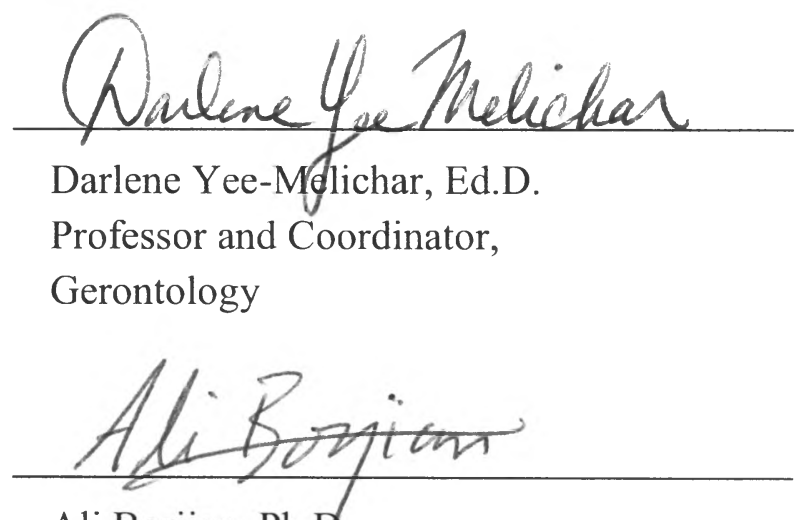

Ali Borjian, PhD.

Associate Professor, Elementary Education

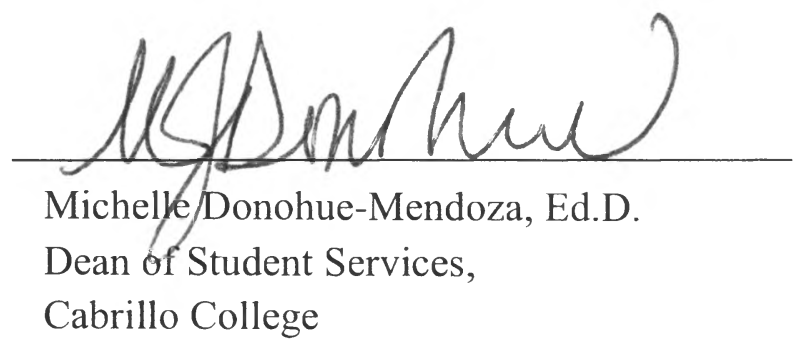




\title{
CHANGE LEADERSHIP AND FEMALE SUPERINDENDENTS
}

\author{
Mary Esther Streshly \\ San Francisco, California \\ 2015
}

This study highlights the underrepresentation of women in the $\mathrm{K}-12$ superintendency and explores barriers and facilitators for female educational leaders during their career trajectories. It investigates female leadership behaviors that have been linked to transformational leadership and change leadership attitudes that have had positive impacts on student achievement and school culture in order to facilitate women's career advancement and promote gender equity. Semistructured interviews and document reviews were employed to gain a more in-depth understanding of how and why these successful female educators lead the way they do. Key themes, including Relational Leadership, Social Justice Leadership, Leadership for Learning, Spiritual Leadership, Balanced Leadership, and Systems-Thinking Leadership frame an understanding of how women are redefining the role of the superintendent in order to realize system-wide, sustainable improvement in student achievement.

I certify that the Abstract is a correct representation of the content of this dissertation.
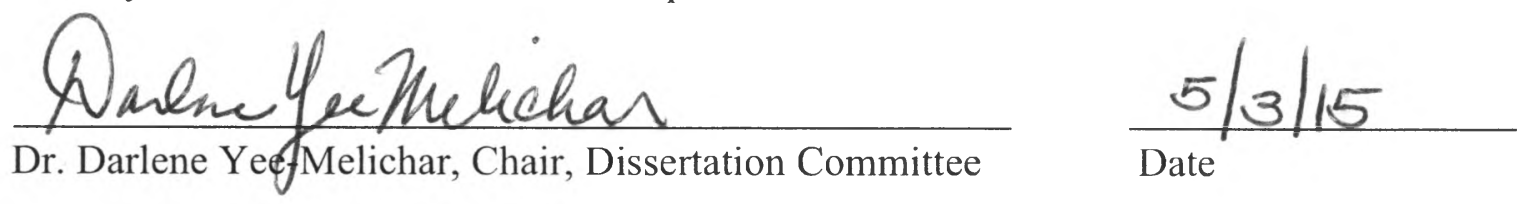


\section{ACKNOWLEDGMENTS}

As my father always said, doctorates are an endurance test and not just for the one in school, but for one's family and friends alike. The first person I must thank is Linette Edison: Your encouragement and support-your helpful presence by my side-made all of this possible. To Robyn Streshly, the best mom a daughter could ask for. I know many of the skills I have developed have come from your example and love. To William Streshly, You never had any doubt that I could accomplish this and you reminded me relentlessly until I got it done. Thank you for your staunch backing to pursue my most challenging dreams. To Carolyn Driscoll, since the day I became old enough not to ruin everything I borrowed, you have been my strongest ally and my best friend. To Allison Silvestri, we have seen each other through pivotal times during career milestones. Our lives and careers are now inextricably bound by mutual admiration and friendship. To Tanya Krause, I am grateful for your mentorship, professional advocacy, and what I hope to be a long-lasting friendship forged in mutual respect, shared values, and a love of wine and dancing! To Dr. Bobbie Plough, our chance reunion, combined with your generosity and your connections, allowed this research topic to take flight. I am eternally indebted. To Dr. Darlene Yee-Melichar, thank you for agreeing to take me on at the last minute and getting me on a structured schedule to finish on time. You worked miracles. To Dr. Michelle Donohue-Mendoza, your brilliant dissertation was influential and foundational in my research on female educational leaders. Thank you for your support. To Dr. Ali Borjian, you encouraged me to go deep, and this approach was deeply satisfying. 


\section{TABLE OF CONTENTS}

LIST OF TABLES ..................................................................................................... vii

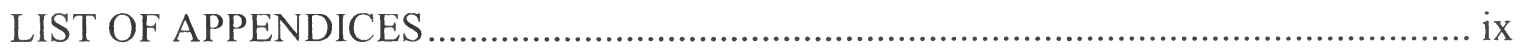

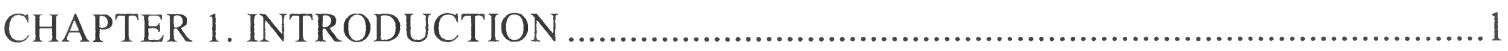

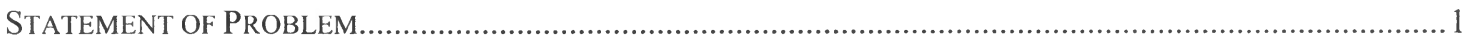

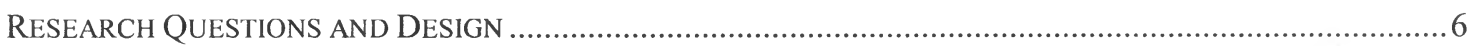

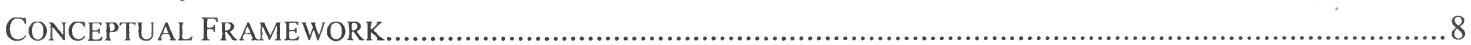

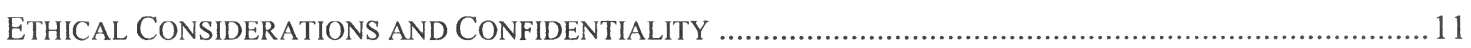

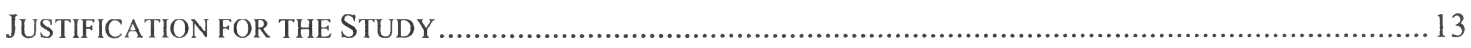

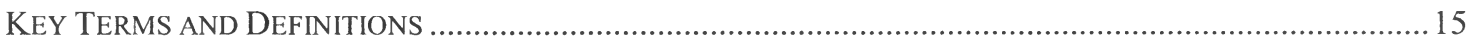

CHAPTER 2. REVIEW OF THE LITERATURE ………………………………...........18

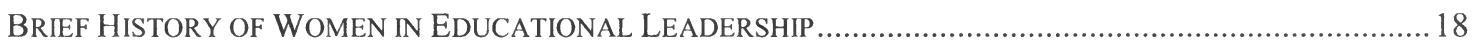

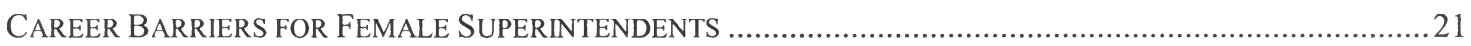

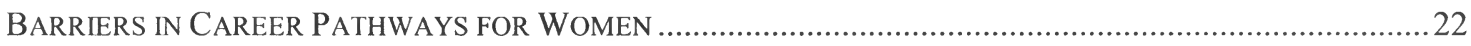

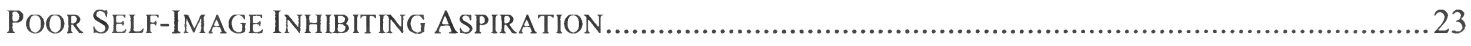

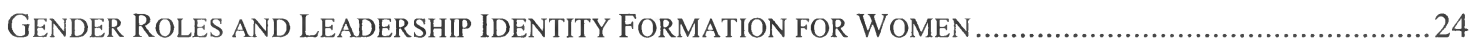

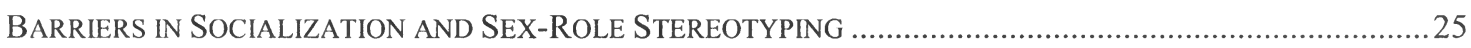

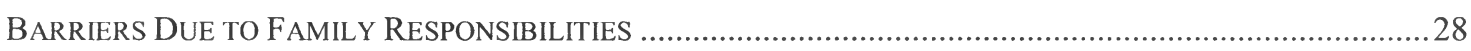

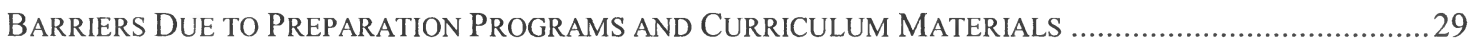

Barriers Due to Few Role Models, SPonsors, Mentors, AND NETWOrKS ..................................... 31

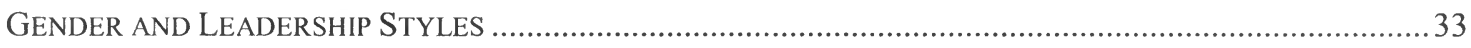

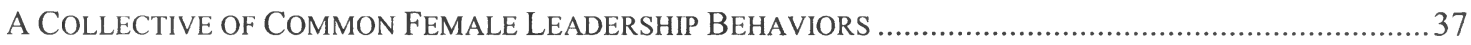

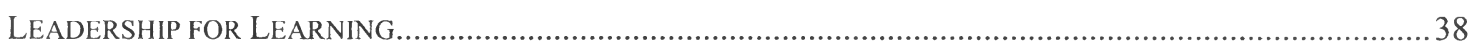

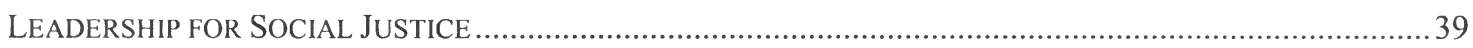

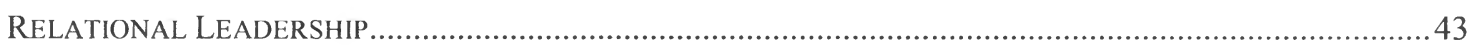

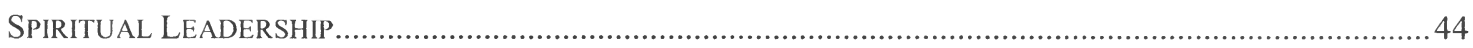

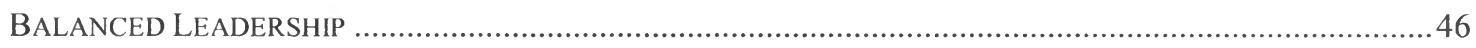

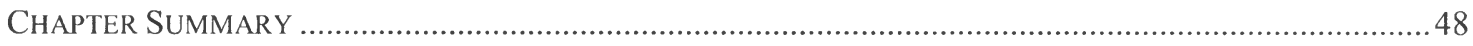

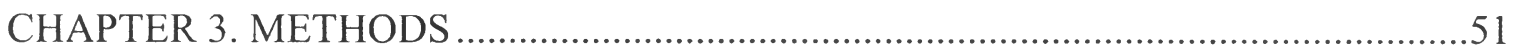

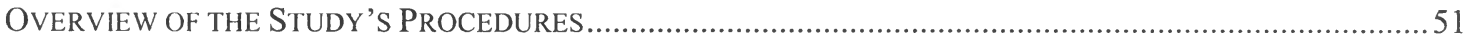

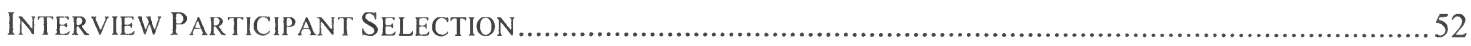

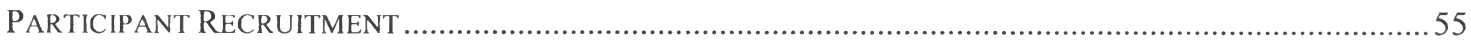

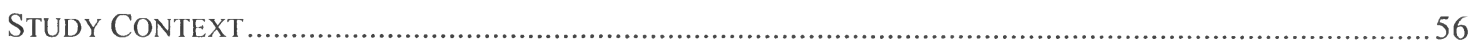

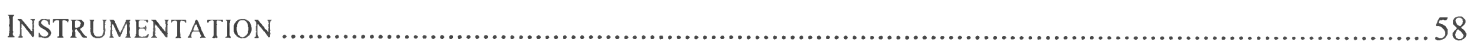

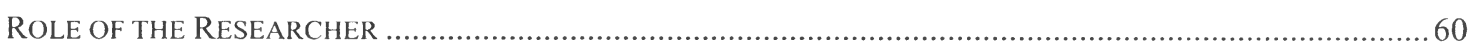

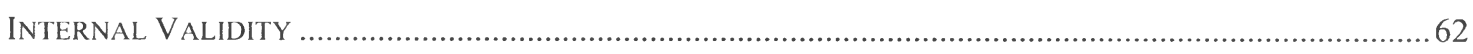

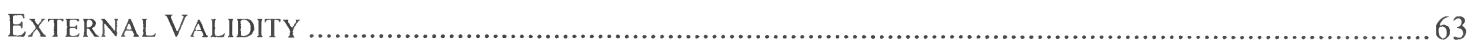




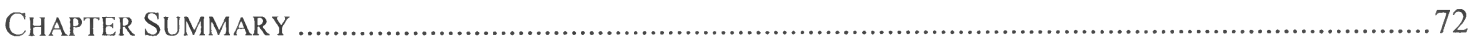

CHAPTER 4. PROFILES OF NINE FEMALE SUPERINTENDENTS ......................74

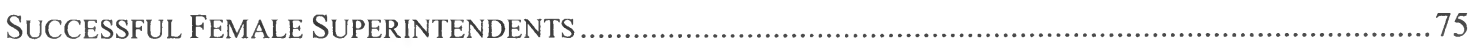

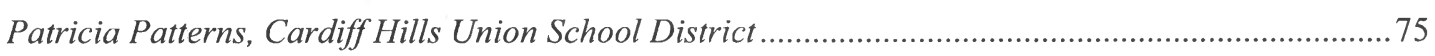

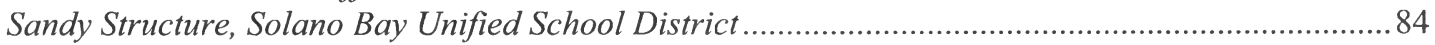

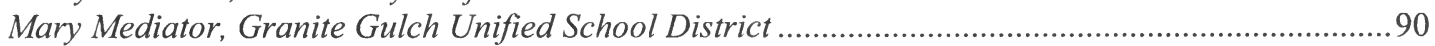

Constance Culture, El Capitan Union Elementary School District ..................................................96

Terry Teacherfirst, Freedom Valley Union High School District ..................................................... 104

Elizabeth Engager, Santa Vista Springs School District ……........................................................ 116

Carrie Community, Margarita Meadows Unified School District ..................................................... 124

Barbara Breakingthemold, Live Oak Unified School District ......................................................... 133

Susan Systems, Pilgrim Park Unified School District ............................................................... 145

CHAPTER 5. FINDINGS AND ANALYSIS ................................................. 154

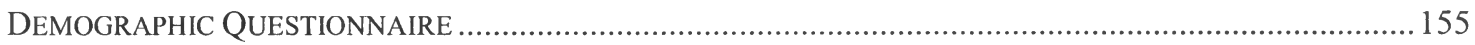

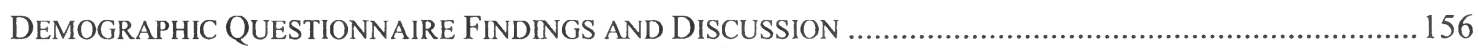

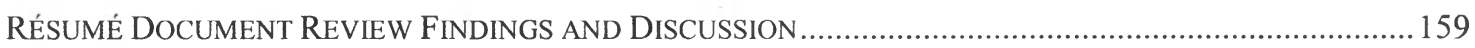

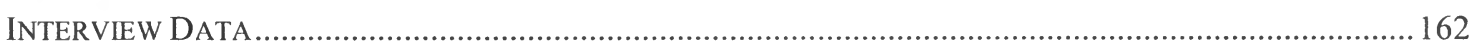

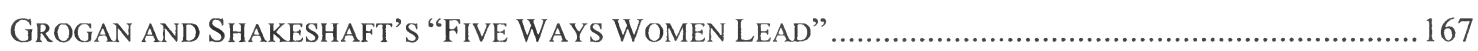

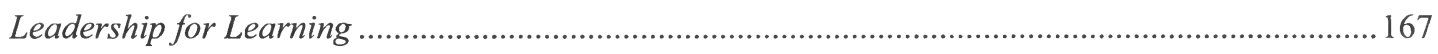

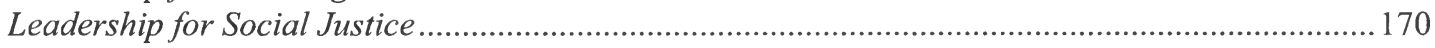

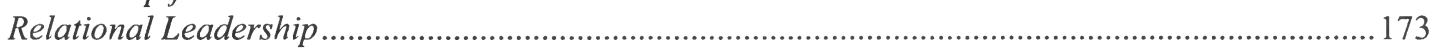

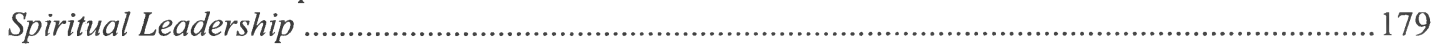

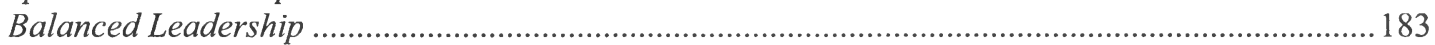

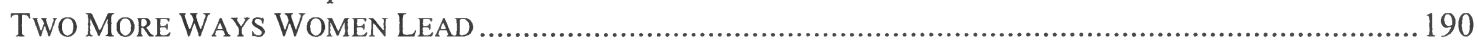

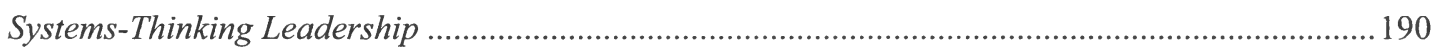

Change Leadership: Redefining the Role of Superintendent to Lead Change .................................. 196

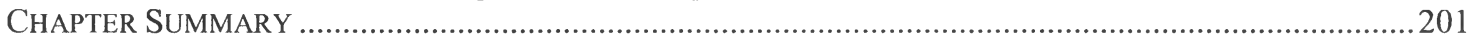

CHAPTER 6. CONCLUSIONS AND RECOMMENDATIONS .............................203

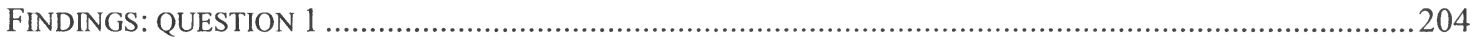

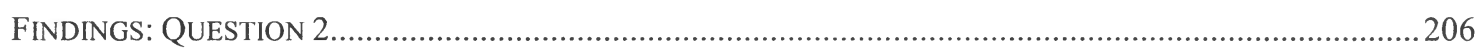

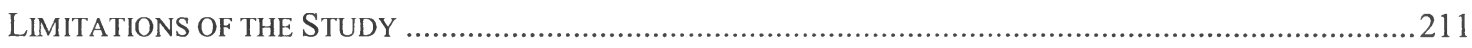

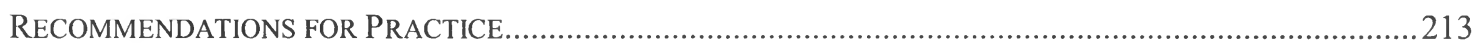

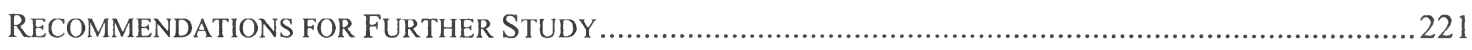

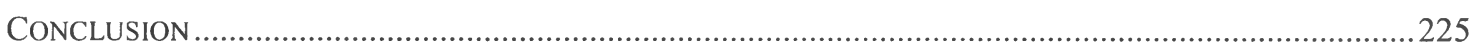

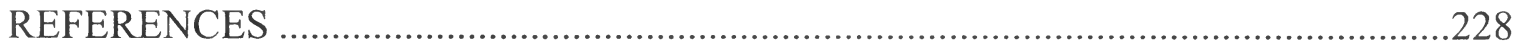

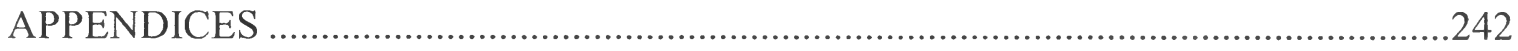

vii 


\section{LIST OF TABLES}

Table

1. Participant Selection from Four Bay Area Counties.......................................................53

2. District Performance Data.......................................................................................56

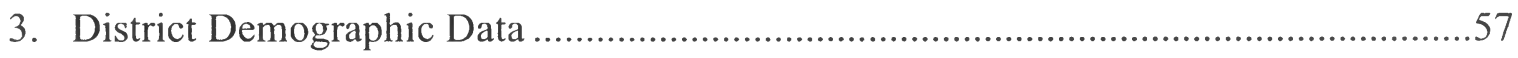

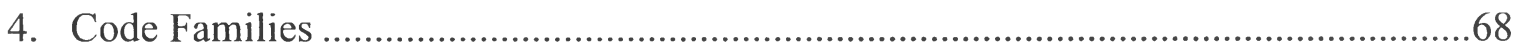

5. Participant Demographic Results Chart.....................................................................69

6. Career Pathway Chart: Curricula Vitae/Résumés .............................................................70

7. Demographics and Academic Performance, Cardiff Hills Union School District ......75

8. Demographics and Academic Performance, Solano Bay Unified School District......84

9. Demographics and Academic Performance, Granite Gulch Unified School District..90

10. Demographics and Academic Performance, El Capitan Union Elementary School District.

11. Demographics and Academic Performance, Freedom Valley Union High School District.

12. Demographics and Academic Performance, Santa Vista Springs School District ....116

13. Demographics and Academic Performance, Margarita Meadows Unified School District.

14. Demographics and Academic Performance, Live Oak Unified School District

15. Expectation Chart Provided by Barbara Breakingthemold. 142

16. Demographics and Academic Performance, Pilgrim Park Unified School District ..145

17. Summary of Highly Successful Female Superintendent Data Collected in the Questionnaire.

18. Responses Coded as Barriers or Facilitators to Successful Ascendancy to the Superintendency. 162

19. Responses Coded for Female Leadership Behaviors 166

20. Ranked Frequency of Leadership Themes 207 


\section{LIST OF APPENDICES}

\section{Appendix}

1. Appendix A: Protection of Human and Animal Subjects

2. Appendix B: Informed Consent Form and Letter of Introduction/E-Mail Letter Text

3. Appendix C: Semistructured Interview Question 249

4. Appendix D: Demographic Information: Superintendent .251 


\section{CHAPTER 1. INTRODUCTION}

\section{$\underline{\text { Statement of Problem }}$}

This study examined the underrepresentation of women in educational leadership, specifically those positioned as $\mathrm{K}-12$ superintendents in the U.S. public school system. The U.S. Bureau of Labor and Statistics reports that women make up 51.5\% of management, professional, and related occupations, but only $14 \%$ of executive officers and $4.6 \%$ of CEOs nationwide (Catalyst, 2014). Teaching and its field of K-12 education have long been considered a female profession because women have historically dominated the teaching ranks. As early as 1900 , over $70 \%$ of teachers were women, and the "role was considered feminized" (Brunner \& Grogan, 2007, p. 9). Furthermore, recent data from the National Center on Educational Statistics (2012) not only show the feminization of the teaching field rising steadily with $76 \%$ female employees in public education, but also that senior leadership preparation is also dominantly female with $67 \%$ of women receiving doctoral degrees in education alongside $77.3 \%$ of women completing masters of education programs (Brunner \& Grogan, 2007; NYTimes.com, 2010). Strong majorities of women are filling administrative credentialing programs as well (Shakeshaft et al., 2007). Yet standing as a stark reminder of the lingering glass ceiling, the position of $\mathrm{K}-12$ superintendent, which could rightly be considered the most influential position in public education, remains traditionally occupied by men. The U.S. Census Bureau reports that the $\mathrm{K}-12$ public education superintendency is the most masculinized role of any profession in the United States (Brunner \& Kim, 2010). 
As recently as the early 1980s, women occupying superintendent positions dropped nationwide to an all-time low of just less than 1\%. By 2007, 18\% of superintendents nationwide were female. The most recent study by the American Association of School Administrators (Kowalski, McCord, Petersen, Young, \& Ellerson, 2011 ) found that although the data continue to reflect disparity with less than 1 in 4 superintendents in America recorded as women, significant progress has been made. Although the percentage of female superintendents has increased substantially over the last two decades, at the current stubbornly slow rate of change, it will take more than three additional decades before the percentage of female superintendents approaches proportionality with its representation in the ranks of education (Kowalski et al., 2011). Grogan and Shakeshaft's (2011) estimation of a $0.7 \%$ annual growth of female superintendents stretches the disproportionality as far out as 77 years or the turn of the 22 nd century. Furthermore, the representation of women of color in the superintendency is even more problematic as their percentage was estimated at $1 \%$ of all superintendents in 2000 and now only hovers around 7\%. Researchers struggle to find reliable data on women of color as race and gender are rarely surveyed together (Brunner \& Grogan, 2007; Grogan \& Shakeshaft, 2011). With $76 \%$ of teachers and $50 \%$ of students in the classroom being female, nowhere do we see a dissonance that is greater than in the rank of the school district CEO. As the statistics indicate, the female superintendent operates in a paradigm designed around men, and the image the data may conjure up could be one of a passive victim. However, this study finds that women are making remarkable 
contributions with respect to redefining and changing district leadership in an era when reform has become a "moral imperative" (Fullan, 2010).

Coinciding with the statistics showing that a majority of promising educators within schools and districts are locked out of top leadership positions, a double crisis in $\mathrm{K}-12$ leadership impends as aging baby boomers prepare to retire and the traditional role of a school superintendent shifts dramatically (Kowalski et al., 2011). Several researchers forecasted this predicament by 2015, and it is now imminent (Glass \& Franceschini, 2007). Thirty-nine percent of superintendents plan to either leave their position or retire within the next five years (Kowalski et al., 2011). Imaginably the individuals who will fill these vacancies will be representative of our culturally diverse society with equitable gender representation in the field of educational leadership. However, for such transformational changes to occur, a consciousness of gender issues in educational leadership must be raised.

Educational leaders are also under increasing pressure to reform public schools. The accountability and achievement demands from the federal No Child Left Behind (NCLB) Act of 2001 called for a flurry of reform efforts by prescribing a multitude of performance standards for districts and schools over the last decade, shifting the role and focus of educational leaders to meet these demands. This reform frenzy has been compounded more recently by the creation of both national standards, referred to as the Common Core, and new multistate assessment systems. The educational standards in California, the California Common Core State Standards (CACCSS), were adopted in 2010, and the California Assessment of Student Performance and Progress (CAASPP) 
System was established by the California Department of Education (CDE) in 2014

(California Department of Education, 2015). Reform stresses are intensified in California with the 2012 adoption of a groundbreaking new budget formula called the Local Control Funding Formula (LCFF) and corresponding accountability process called the Local Control Accountability Plan (LCAP) (CDE, 2014). Subsequently, the majority of superintendents have acknowledged that their responsibilities in relation to school reform have expanded, requiring them to both design and carry out mandated changes (Kowalski et al., 2011).

A convergence of reform initiatives and the realities of the information-based society have transformed normative, hierarchical communicative behavior for superintendents. Superintendents must now work within a relational model of communication, requiring them to facilitate school improvement by collaborating with school employees, students, parents, and other stakeholders and to maintain positive relationships with a myriad of stakeholder groups (Kowalski et al., 2011). The postmodern superintendent is expected to determine shared beliefs and their influence on school effectiveness in order to be an effective agent of school and district culture change, widely considered "one of the greatest institutional issues facing current superintendents" (Kowalski et al., 2011, p. 6; Lemasters \& Roach, 2012). Change leadership in this new era of performance-based accountability thrusts superintendent relationships, trust, and instructional leadership into a defining spotlight of this increasingly difficult assignment. 
Still, even though the new management techniques show that "intuition, sensitivity, and relationship-building, generally recognized as feminine traits, will be the leadership style of the future," thereby redefining patriarchal power relations as the worst ways to manage, women's representation in traditional male leadership positions, such as CEO and superintendent, remains stubbornly limited and parity with respect to their ranks in the schools elusive (Ardovini, Trautman, Brown, \& Irby, 2010, p. 24; Senge, 2006). Moreover, “feminine-aligned and inclusive practices such as collaborative arrangements, site-based decision making, teacher empowerment and community building" are in place in many schools and espoused as best practices for schools by top scholars. Yet these practices do not parallel the leadership and management practices predominant in district administration and management theory taught in administration courses today (Ardovini et al., 2010; Fullan, 2001, Brunner, 1998). As early as 1992, Sergiovanni stated the old-school model of hierarchical bureaucracy needed to be changed into an idea-based community following his admission that "while women were underrepresented in principalships, they were over-represented in successful principalships" (Brandt, 1992, p. 47). This "admission" strongly implied a need for a feminine style of leadership.

This study further examines how feminine ways of leading are increasingly tied to relational, transformational, instructional leadership and, ultimately, the change leadership shown to have a positive impact on student achievement and staff morale (Leithwood \& Mascall, 2008; Lemasters \& Roach, 2012; Seashore, Dretzke, \& Wahlstrom, 2010; Vinkenburg, van Engen, Eagly, \& Johannesen-Schmidt, 2011). 
A number of studies investigate the barriers to executive leadership advancement for women in the business and educational sectors (Eagly \& Karau, 2002; Ibarra, Ely, \& Kolb, 2013; Vinkenburg et al., 2011; Wickham, 2008). Barriers for women in business and education intersect on lack of mentorship, institutional patterns of preferential sponsoring and promotional practices toward men, and the perception of women as frontline managers. Only in the recent three decades has research on top administrative roles included the "voices of women" (Brunner \& Grogan, 2007, p. 5). Such research examines androcentric bias within the superintendency (Björk, Glass, \& Brunner, 2005; Brunner \& Grogan, 2007; Shakeshaft et al., 2007). Early justification for this trend highlighted gendered career pathways, perceptions of glass ceilings, and personal aspirations. This study centered on the leadership styles of women who chose to pursue and succeeded in achieving an uncommon career goal. The research is valuable because it identifies the factors that influence this choice and the leadership behaviors that lead to successful outcomes. Moreover, the number of studies on women in educational leadership, more specifically the superintendency, published between 1990 and 2000 is significantly larger than the number of studies published following 2000 , revealing an untimely retreat from this area of research (Lemasters \& Roach, 2012).

\section{$\underline{\text { Research Questions and Design }}$}

This study was designed to identify the common experiences and leadership behaviors that contributed to women's success in attaining and effecting positive change while in the position of $\mathrm{K}-12$ public school superintendent. Understanding that women 
also confront numerous obstacles in their path to leadership, this study investigated the following research questions:

1) How do female educational leaders who succeed in attaining the $K-12$ superintendency describe barriers and facilitators to their success?

2) How do female superintendents describe the leadership styles and behaviors that enabled them to attain a superintendent position and to facilitate positive, measurable change in their school systems?

This research was drawn from the perspectives of female superintendents currently serving or who have recently served districts in several Northern California counties .

This study employed a multiple case study research design. A multiple case study approach analyzes or compares a collection of individual cases. A case study is a qualitative, inductive approach using descriptive methods of data collection, which is effective when researchers are more interested in discovery, exploration, and interpretation of data than in hypothesis testing (Yin, 2009). It involves intense description of empirical inquiry of a phenomenon set in its real-life context and is particularly appropriate for a study that seeks to answer how and why questions, for the purpose of making analytic generalizations of a theoretical proposition, rather than statistical generalizations based on expanse of sample size (Yin, 2009).

In this study of female superintendents, the collective case studies are the unit of analysis. Data collection was performed through semistructured, qualitative interviews, document reviews of résumés or curricula vitae, and a brief demographic questionnaire. 
The resulting data will be compared using a cross-case analysis to discover patterns and draw conclusions.

Creswell (2013) indicated that qualitative research is appropriate when the researcher relies on the views of participants to gain understanding on the positions they hold about an educational issue. Moreover, in-depth interviews can be described as a thorough exploration of a group of individuals. In-depth interviews are one of the most common and powerful ways to understand the experiences of participants rather than to predict or to control that experience (Seidman, 2013). Document analysis of the female superintendents' résumés and curricula vitae provides insight into the career pathways and experience garnered by these women in preparation for their position as $\mathrm{K}-12$ superintendent. By implementing this type of case study research, the researcher will give voice to female superintendents and examine how they successfully transcended the socially constructed barriers during their ascension to and successful execution of the superintendency.

\section{Conceptual Framework}

Differences in management styles for women and men were illuminated by the feminist ethical development theory (Gilligan, 1982). Gilligan's (1982) groundbreaking work, In a Different Voice, reconstructed psychology's misperception of a single primary moral imperative, justice, which favored male ethical development. In it she theorized that the problem was not about women's ability to lead, but that their way of leading is different from that of men: 
In the different voice of women lies the truth of an ethic of care, the tie between relationship and responsibility, and the origins of aggression in the failure of connection. The failure to see the different reality of women's lives and to hear the differences in their voices stems in part from the assumption that there is a single mode of social experience and interpretation. (Gilligan, 1982, p. 173)

She theorized that there are two moral imperatives-justice (masculine) and care (feminine). Gilligan's “ethic of care" held that female ethical development placed the "welfare of others," or individual consideration, as a significant factor in considering moral dilemmas. Her study, establishing two gender-based ethical stances of thinking about moral dilemmas and decision making, provides a relevant foundation for this study on female leadership.

Social role theory, a perspective speaking specifically to leadership behaviors of male and female leaders, adds to the theoretical premise for this study, which examines the position of $\mathrm{K}-12$ superintendency and the barriers female aspirants face both in pursuit of this position and in the execution of the role. Social role theory, constructed by Alice Eagly in the 1980s, introduces the influence of social expectations on the behavior of male and female leaders resulting from historical divisions of labor (Eagly \& Karau, 2002). It highlights the influence of both gender roles, as defined by cultural perceptions of male and female behavior (descriptive gender stereotypes about leadership styleshow men and women do behave), and social roles (prescriptive gender stereotypes referring to beliefs regarding how they should behave) as behavior defined by position in 
the hierarchy of an organization. This theory complements previous frameworks applied to studies of women in educational administration, such as feminist poststructuralist and "ethic of care" frameworks, because it places both theoretical concepts onto a platform where the dynamic is played out within an organizational structure (Gilligan, 1982; Grogan, 1996). Moreover, social role theory and its recent progeny by Eagly and Karau (2002), role congruency theory of prejudice toward female leaders, are especially appropriate for a comparison of the differences in behavior of male and female leaders because they begin to consider not only impediments that may still surface for women due to gender beliefs - in their aspirations to senior positions in education-but also the suitability of a female style of leadership in a traditionally male-dominated, hierarchical field.

Within the combined context of organizational expectations of leader roles and societal expectations of gender roles, further studies have begun to feature transformational leadership styles successful women have adopted that appear to be strategic facilitators to both overcoming barriers and leading successful educational reform. This study used the voices of women who have successfully acquired the rarest of positions as female educators to more closely examine the following five most common leadership behaviors among women in educational leadership to date, according to Grogan and Shakeshaft (2011), two of the most prolific researchers of women in educational leadership. Grogan and Shakeshaft's (2011) collection of most common leadership approaches used by female educators includes: a) leadership for learning or instructional leadership; b) leadership for social justice; c) relational leadership; d) 
spiritual leadership; and e) balanced leadership. The collective use of these comportments, referred to as a "diverse collective," appears to be a strategic benefit for women when traversing the "labyrinth" of social role incongruence and allowing them to successfully enact positive, measurable change across a school system (Grogan \& Shakeshaft, 2011, p. 6; Eagly \& Carli, 2009).

Ethical Considerations and Confidentiality

According to Creswell (2013), valuing participants and authority structure of educational institutions by obtaining permission prior to data collection is a critical ethical practice. However, because the position of superintendent holds the highest level of staff operational authority to grant institutional permission (assuming there is no policy at the board of trustees level prohibiting research activities akin to this study), the researcher made the assumption that institutional permission was embedded in participant permission.

In order to assure that this research did not harm participants, the researcher received the necessary approval for conducting research involving human subjects from the Human and Animal Subjects Committee at San Francisco State University (Appendix A). This is a prerequisite that was created by legislation in the 1970 s to supervise campus-based research because of preceding occurrences with the mistreatment of humans in experiments (Creswell, 2013).

Individuals who agreed to participate in the study signed an informed consent form (Appendix B), a declaration that participants sign preceding participation. 
Individual candidates, by signing the informed consent form, agreed to participate in the study and acknowledged that their confidentiality is guaranteed (Creswell, 2013). The researcher respected Seidman's (2013) recommended informed consent adapted for indepth interviews consisting of

1. An invitation to participate; explaining the purpose of the study, how it will be conducted, and for how long,

2. An outline of the potential risks of discomfort that might result from taking part in the study,

3. An explicit statement that participation in the study is voluntary and that refusal to participate would carry no penalty,

4. An outline of the possible benefits of the study in general and for the participant specifically,

5. The steps that will be taken to ensure each participant's identity is confidential,

6. An indication of how the researcher will disseminate the results of the research,

7. A clarification of how to contact the researcher and the local Internal Review Board (IRB) if participants have questions about their rights or anything else about the study.

The researcher completely divulged the intent and intended outcome of the study from the onset and at each juncture in the data-collection process. The researcher also guaranteed exact observance to confidentiality regarding participants. In fact, data were 
kept in both coded electronic files on a nonwork computer and stored in a cabinet in the researcher's home office only, and the names of participants and the K-12 districts were disguised, so as to protect the confidentiality of all participants. By obtaining consent and plainly describing the intention of the study before the data-collection process, the researcher reduced any distraction the research may trigger (Creswell, 2013). Likewise, to further safeguard the privacy of participants, transcribed data will be destroyed within three years of the completion of the study. The researcher assured that all participants were well over the age of 18 .

Justification for the Study

The purpose of this multiple case study of nine female superintendents was to examine the experiences of several women in their successful ascendancy to and execution of the position of $\mathrm{K}-12$ superintendent. Currently, women remain underrepresented in the most powerful position in public education. Research has analyzed perceived barriers to ascendancy and social constructs embedded in our organizational cultures and socialization that inhibit women's progress in the attainment of the position (Eagly \& Karau, 2002; Wickham, 2008). Using social role theory's foundational assertions of gender roles manifesting differences in management styles between males and females, this study sought to further the understanding of women's leadership styles as recently defined by Grogan and Shakeshaft (2011). This study strove for deeper insight into the experiences and perspectives on leadership from the vantage point of successful female superintendents in order to accomplish the following three objectives: 
1) Inform aspiring female superintendents about potential barriers and facilitators, attributed by successful superintendents, to achieve the soughtafter position.

2) Inform the current discourse on leadership by examining the ways women talk about leadership with respect to overcoming barriers, attaining a position as superintendent, and achieving positive, measurable change within their school systems.

3) Decrease the underrepresentation of women in the $\mathrm{K}-12$ superintendency (inclusive of $\mathrm{K}-8$ \& 9-12 union and unified districts) by understanding why women lead the way they do and how the collective use of these leadership approaches might effect positive change across whole school systems.

Previous research in the area of female $\mathrm{K}-12$ superintendents focused primarily on obstacles to attainment of the superintendent's chair. This study, which aimed to explore how successful women have overcome obstacles in their path to executive leadership and what they saw as most advantageous to their success, can help aspiring female educational leaders to navigate the complex road to the $\mathrm{K}-12$ superintendency. Additionally, by also asking how these successful female leaders recognized and internalized important elements of their leadership styles and how they used these approaches to effect positive change, this research project targeted more than an audience of aspiring female superintendents. This study also aimed to add to the current discourse on leadership by asking these superintendents how they think about and use their leadership. Last, by both revealing stubborn barriers for women and highlighting strategic 
ways women lead that effect positive, measurable change, this study adds to the literature denouncing the persistent underrepresentation of women in the $\mathrm{K}-12$ superintendency.

\section{$\underline{\text { Key Terms and Definitions }}$}

Agenic behavior. An independent, masterful, and assertive behavior; associated with a top-down leadership style (Moskowitz, Suh, \& Desaulniers, 1994).

Balanced leadership. A leadership style allowing the leader to successfully juggle work, life, and family responsibilities; leadership that uses caretaker role experience as a skill in the leadership role; one of the five most common ways women lead that move beyond traditional leadership definitions (Grogan \& Shakeshaft, 2011).

Barrier. Any factor or obstacle that hinders career advancement to the next level in administration or management (Shakeshaft et al., 2007).

Cognitive shift. A change in mind-set resulting from the reframing of an issue or situation during transformational change; a generalized outcome of the five most common ways women lead (Foldy, Goldman \& Ospina, 2008; Grogan \& Shakeshaft, 2011).

Command-and-control paradigm. A model of traditional top-down leadership in which power resides in the individual rather than the collective; associated with male approaches that are more transactional and often laissez-faire and contrasted with feminized leadership that focuses on building human capital and using their experiences as mothers and teachers as a leadership asset (Grogan \& Shakeshaft, $2011)$.

Communal. Characterized by friendly, unselfish behavior and concern with others; associated with a collaborative leadership style (Moskowitz et al., 1994). 
Diverse collective. A cooperative grouping of people deliberately chosen for their diverse perspectives, with the goal of disrupting the status quo and creating a new group idea or decision; a generalized outcome of the five most common ways women lead (Grogan \& Shakeshaft, 2011).

Double bind. A conflict that can develop for female leaders when sex-role stereotypes create a mismatch between conventionally feminine qualities and opposing qualities thought necessary for leadership (Ibarra et al., 2013).

Leadership for learning. Leadership focused on the instructional core and pedagogical reform; one of the five most common ways women lead that move beyond traditional leadership definitions (Grogan \& Shakeshaft, 2011).

Leadership for social justice. Leadership that is critical of the status quo and strives for equity and diverse perspectives; one of the five most common ways women lead that move beyond traditional leadership definitions (Grogan \& Shakeshaft, 2011).

Leadership style. A relatively stable pattern of behavior that is manifested by a leader (Eagly \& Johannesen-Schmidt, 2007).

Relational leadership. Leadership that focuses on relationships, individual consideration, and an "ethic of care"; one of the five most common ways women lead that move beyond traditional leadership definitions (Grogan \& Shakeshaft, 2011).

Spiritual leadership. Leadership that is mindful of the interconnectedness of one's actions or that incorporates a faith-based value system; leadership that is equated with service above one's self or as a higher calling; one of the five most common ways women 
lead that move beyond traditional leadership definitions (Grogan \& Shakeshaft, 2011).

Successful ascendancy. As used in this study, the situation of having served in the position of superintendency for one or more years.

Superintendent. The chief executive officer of the school district, hired by the school board to manage the administrative affairs of the district (Kowalski et al., 2011). Systems thinking. One of the five disciplines of a learning organization that emphasizes interconnectedness and follows the principle that structure influences behavior (Senge, 2006).

Transformational leadership. Leadership with a collaborative, relational, inspirational, emotional intelligence, paying attention to individual considerations and reframing for the audience (Vinkenburg et al., 2011).

Transformative leadership. Leadership that considers issues of justice and democracy, critiques inequitable practices, and addresses both individual and public good, using critical race theory as a conceptual framework (Shields, 2010). 


\section{CHAPTER 2. REVIEW OF THE LITERATURE}

\section{$\underline{\text { Introduction }}$}

As leaders and advocates of America's public schools, superintendents play a central role in local, state, and federal policy dialogues and decisions. Because they eventually impact the shape and future of public schools, it is vital that the most qualified candidates be sought. Yet, in this field of education, where women outnumber men by over 4 to 1 , the superintendency has been the slowest of all $\mathrm{K}-12$ administrative roles to integrate women. Understanding not only the factors influencing this gender gap phenomenon, but also the leadership approaches used by women who have overcome the barriers and achieved success as a superintendent is important to women aspiring to the superintendency and essential to someday achieving universal access to this role in public education. This literature review begins with the historical perspective of women in the superintendency, career barriers for female superintendents, and leadership styles of males versus females. The chapter culminates with a survey of the five most common leadership behaviors of females in educational leadership followed by a summary and implications for further research.

\section{Brief History of Women in Educational Leadership}

Since public education was instituted in the United States, the management of schools has been a male-dominated field populated by politicians, lawyers, ministers, farmers, and businessmen, all traditionally masculine roles (Tyack \& Hansot, 1982). In 
the 1800 s, female teachers entered the picture, and by the mid-19th century, female teachers increased while the number of male teachers significantly declined (Brunner \& Grogan, 2007). With the increased feminization of the teaching ranks and the supervisory roles remaining in the hands of males, the education system began to parallel the traditional home. Males, in fatherly or husbandlike roles, directed the females, who then oversaw the children much as mothers do (Miller, Washington, \& Fiene, 2006; Wickham, 2008).

While the numbers have always remained relatively small, there was a period of time where women were represented in the ranks of the superintendency in greater numbers. In the early 1900s, the women's movement and suffrage activism helped women fill nearly $11 \%$ of K-12 superintendencies (Brunner \& Grogan, 2007; Shakeshaft, 2007). Ella Flagg Young, superintendent of Chicago schools from 1909 to 1915 , predicted women would soon dominate school leadership like they did the teaching ranks (Shakeshaft, 1989). Moreover, the years 1900-1930 are remembered as the "golden age" for women in school administration (Tyack \& Hansot, 1982). The notion of it being a golden age is tempered by the fact that women held administrative positions overwhelmingly in less desirable elementary school principalships and in county superintendencies. Elementary positions came with lower salaries and status and were significantly less likely than secondary principalships to be gateway positions to promotion and the superintendency (Brunner \& Grogan, 2007).

Following World War II, many men returning to the workforce from wartime positions pursued teaching and educational administration with support from the GI 
Bill—a law that afforded needed retraining for reentry into postwar communities. During the war, men also entered the classroom as a way of avoiding the draft because these positions were protected (Blount, 1998). In the 1950s and 1960s, school management positions opened up widely for men, but women's access to management declined due to broad phenomena of gender role realignment. The decline of women in educational leadership corresponded with societal expectations, particularly after the war, when "men were encouraged to be leaders and administrators; women were encouraged to remain at home" (Hanson, 2011; Shakeshaft, 1989, p. 45). Postwar propaganda set the social expectation that women should discontinue employment either after marriage or certainly after becoming pregnant, and this expectation continued through the 1970s. This discriminatory practice, "based on sex and favoring the entry of men over women into administrative positions, continued into the 1960s and beyond" caused the female ranks of superintendents to fall to a historic low by 1982 (Brunner \& Grogan, 2007, p. 4; Kowalski et al., 2011).

Consideration given to sex discrimination was inclined to follow discrimination by color during the civil rights movement. The Civil Rights Act of 1964 and Title VII allowed women to file sex-based job discrimination suits, but government agencies were reluctant to enforce compliance of statutes. Title IX of the Civil Rights Act had positive consequences on female employment and in the educational setting. It prohibited gender discrimination in any program or agency receiving federal funds. The passage of Title IX drew public attention to the status of women, initiating a period of observation and debate resulting in the subsequent passage of the Glass Ceiling Act of the Civil Rights Act of 
1991 (Brunner \& Grogan, 2007; Hanson, 2011). Despite breakthroughs in civil rights legislation designed to equalize opportunity and prevent discrimination, women have been unable to gain traction toward reducing their disproportionality in the $\mathrm{K}-12$ superintendency with respect to their numbers in the ranks highlighting the fact that certain gender-based hurdles still mark an uneven playing field for women.

\section{Career Barriers for Female Superintendents}

More women are being lauded for having strong skills for leadership and for presenting leadership styles associated with effectual performance as leaders (Eagly, 2007; Pfaff, Boatwright, Potthoff, Finan, Ulrey, \& Huber, 2013; Vinkenburg et al., 2011). Nonetheless, studies show people preference male bosses over females making it more difficult for women than men to become leaders and to become accomplished in masculinized leadership roles (Eagly, 2007; Ibarra et al., 2013; Pfaff et al., 2013). Ibarra, Ely, and Kolb (2013) discuss the importance of recognizing "second generation gender bias" and attending to the negative impact on women in the workplace (p. 64). Second generation gender bias is described as subtler and often more invisible than traditional definitions of sex discrimination. It includes gendered career paths and gendered work, women's lack of networks and sponsors, "double binds," and a scarcity of role models in mentoring positions (p. 65). Each of these workplace elements can combine to create an organizational culture that has a caustic effect on a woman's ability to develop and internalize a leadership identity (DeRue \& Ashford, 2010; Ibarra et al., 2013).

The research on barriers reviewed in this section followed the categories outlined originally in the Handbook for Achieving Sex Equity through Education (Klein, 1985) 
and subsequently followed up by Shakeshaft et al. (2007) in Increasing Gender Equity in Educational Leadership. The comprehensive list of identified barriers for women entering the educational leadership hierarchy or traversing the ladder includes: 1) career pathways of women; 2) poor self-image or lack of confidence; lack of aspiration or motivation; 3) socialization, sex-role stereotyping, and leadership-identity construction; 4) family responsibilities; lack of support, encouragement, or counseling; 5) preparation programs and curriculum materials; 6) too few role models, sponsors, mentors, and networks. In 1985, the barriers to women were described as either internally imposed or externally imposed. The most recent research finds that more barriers previously identified as internal, such as self-efficacy, motivation, or aspiration, have been overcome in comparison to barriers previously identified as external or socially imposed, which constitutes the culmination of the list.

\section{Barriers in Career Pathways for Women}

Kim \& Brunner (2009) trace career trajectories using the AASA decennial study of the American School Superintendent to analyze the career pathways/trajectories of male and female superintendents. When they looked at entry positions and administrative positions on the path to superintendency, they saw men receiving a more speedy and direct route with more "line positions," such as department chair, vice principal, principal and superintendent and women taking a slower, less direct route by taking more "staff support positions," such as resource teacher, content specialist/coach, coordinator, director, assistant sup positions (p. 101). They also saw a clear slant of male superintendents coming from secondary education, in which they postulated had more 
power and status from "power over money, large facilities and populations, visibility and decision-making power," and females more populated in elementary with possibly fewer politics, a closer connection to teaching and less direct decision making (p. 104).

The follow-up to this national study, The American School Superintendent: 2010 Decennial Study, confirms that these same trends continue. Men still maintain a speedier trajectory to the superintendency enabling them to enter the position younger on average than women with $30 \%$ below the age of 51 to women's $20 \%$. Women stay in the classroom significantly longer, take more less visible "staff" positions than more status heavy "line" positions in their pathway, and on average gain more years of experience before entering the superintendency (Kowalski et al., 2011). Women also still gain more education before entering superintendency with $52 \%$ holding doctorates compared to $42 \%$ of males (Kowalski et al., 2011).

\section{Poor Self-Image Inhibiting Aspiration}

Shakeshaft et al. (2007) claim that women who aspire to become administrators are more likely to report lowered aspiration or lack of confidence than women who become administrators causing the postulation on the presence of this barrier to now be mixed. Earlier studies argued that women's lack of success in obtaining administrative positions was due to lowered self-confidence; yet, several more recent studies show healthy levels of female aspiration and little evidence of poor self-image (Hanson, 2011; Grogan \& Shakeshaft, 2011). This has led researchers to look toward leadership identity theory, which is tied to external socialization and social role theory, over self-efficacy and motivation theories to examine the perpetuation of women feeling that they 
continually need more education and more experience prior to seeking the superintendency causing at minimum a slower, if not impeded, career trajectory (Kim \& Brunner, 2008; Shakeshaft, 2007).

Gender Roles and Leadership Identity Formation for Women

Eagly, Johannesen-Schmidt, and van Engen (2003) described gender roles as "consensual beliefs about the attributes of women and men" and noted "people react to leaders in terms of gendered expectancies" (p. 572). Other recent theorists believe that gender roles are indeed present in organizations and that they set a background for complex social dynamics in the workplace. DeRue and Ashford (2010) propose that a leadership identity is "co-constructed in organizations when individuals claim and grant leader and follower identities in their social interactions" (p. 627). Through this claiminggranting process, individuals internalize an identity as leader or follower, and those identities become relationally recognized through "reciprocal role adoption and collectively endorsed within the organizational context" (p. 633). Leadership identity formation is therefore a dynamic process of strengthening or weakening of leadership capital and cyclical in nature. Depending on how the claiming-granting behaviors are reinforced collectively on an individual in the organization, this process is thought to result in either positive or negative spirals. In other words, recognition and affirmation strengthen one's self-identity as a leader, which in turn motivates one to search for new opportunities for growth. A negative spiral occurs when "failing to receive validation for one's leadership attempts diminishes self-confidence as well as the motivation to seek developmental opportunities" (Ely, Ibarra, \& Kolb, 2011, p. 476). Subsequently, these 
behaviors are less likely to be repeated in the future and the individual participates in fewer, weaker claiming behaviors, ultimately impacting motivation.

Ely, Ibarra, and Kolb (2011) attach gender bias in the culture and in organizations to DeRue and Ashford's (2010) leadership identity construction theory claiming they cause subtle interferences with the identity work of women leaders. Women behave in ways that reflect their lesser power in the organization, according to Kanter (1976) in an early study. Employee behavior, thusly, is determined by the organization's structure rather than the worker's intrinsic character. The organizational dynamics where individuals claim and grant leader identities are shaped by culturally available ideologies about what it means to be a leader. The prevalent ideology in our culture equates leadership to masculinity_decisive, assertive and independent (Ely et al., 2011; Eagly \& Karau, 2002). By contrast, women are thought to be "communal-friendly, unselfish, caretaking - and thus lacking in the qualities required for success in leadership roles" (Ely et al., 2011, p. 477; Eagly \& Karau, 2002). Ely \& Rhode (2010) argue that a "central developmental task for an aspiring leader is to integrate the leader identity into the core self;" consequently, this objective is troubled from the beginning for a female, "who must establish credibility in a culture that is deeply conflicted about her authority" (p. 477).

\section{Barriers in Socialization and Sex-Role Stereotyping}

Because traditional stereotypes cast women and minorities as socially incongruent as leaders, they face greater challenges becoming integrated into the organization. There is evidence that social role theory's premise that socialization of gender roles causing women to present leadership behaviors somewhat differently than men has both 
advantages and disadvantages for female leaders leaving them with the challenge of balancing the two spheres of influence. The advantages, which will be covered later in this chapter, fall in the realm of leadership styles more recently attributed both to desirable leaders and effective organizational outcomes, such as morale and student achievement (Rosette \& Tost, 2010; Louis et al., 2010; Robinson, Lloyd, \& Rowe, 2008; Leithwood \& Mascall, 2008). The female disadvantage is substantiated in such measures as the nationwide Gallup Pole and employee 360 evaluations (Pfaff et. al, 2013). Gallup Poll surveys conducted from 1953 to 2006, showed a consistent preference for male bosses over female, even among other female respondents (Eagly, 2007). The phenomena of females displaying preference for male bosses have been attributed to the "queen bee syndrome." The term "queen bee syndrome" was devised in the 1970s, following a study led by researchers at the University of Michigan (Staines, Tavris, \& Jayaratne, 1974) who examined promotion rates and the impact of the women's movement on the workplace. The study revealed that females who realized success in male-dominated organizations were more likely to combat the ascent of other women. According to Staines et al. (1974) this transpired essentially because the male-controlled environment of work "encouraged the few women who rose to the top to become obsessed with maintaining their authority" (Ibarra et al., 2013, p. 1).

Likewise, The Harvard Business Review in 2013 described the "double binds" and conflicting feedback women receive during 360 evaluations. Women who had been evaluated as "competent managers often fail the likeability test, whereas competence and likeability tended to go hand in hand for similarly accomplished men" (Ibarra et al., 2013, 
p. 65; Ely et al., 2011). Sex-role stereotypes create a mismatch between conventionally feminine qualities and qualities thought necessary for leadership puts female leaders in a "double bind" (Ibarra et al., 2013, p. 65).

Eagly and Karau (2002) explain the two forms of prejudice that arise from this mismatch of social roles in their role congruity theory of prejudice toward female leaders. Role congruity theory is conceptually framed in social role theory's diagnosis of the content of gender roles and their agency in catalyzing sex difference in behavior. According to this theory, the "perceived incongruity between the female gender role and leadership roles leads to a) perceiving women less favorably than men as potential occupants of leadership roles and b) evaluating behavior that fulfills the prescriptions of a leader role less favorably when it is enacted by a woman" (p. 573). Prescriptive gender stereotypes explain values regarding how men or women should behave and descriptive gender stereotypes refer to beliefs regarding how women and men do behave. Prejudice is likely to occur if those who make selection, evaluation, and promotion decisions believe that women's leadership styles are different from men's because of the descriptive belief that they are more communal or that women should not manifest certain leadership styles, which constitutes the prescriptive beliefs that leaders require more agenic qualities that only males possess (Eagly \& Karau, 2002; Vinkenburg et al., 2011).

The double bind of women in leadership is multiplied when ethnicity is added to the equation. Studies show women of color are on the receiving end of a double standard due to sex and race stereotyping. Asian women are often stereotyped as "passive, reserved, and lacking in ambition," and Latinas are frequently seen as too emotional (Ely 
et al., 2011, p. 477; Giscombe \& Mattis, 2002). Moreover, African American women are especially victimized by such stereotypes that portray them as "aggressive and confrontational" (Ely et al., 201 1, p. 477). In multiple studies, women who are viewed as competent are seen as less well liked than males. Behavior by men that appears to be assertive, entrepreneurial, or confident is by contrast interpreted as arrogant, aggressive, and overly ambitious when displayed by a women (Heilman \& Okimoto, 2007; Eagly \& Carli, 2009). Meanwhile, women in positions of authority who enact a conventionally feminine style may be liked but are not respected, ultimately deemed too emotional to make tough decisions (Ibarra et al., 2013).

\section{Barriers Due to Family Responsibilities}

While family dynamics in American homes have progressed somewhat, women still carry the heaviest burden of household and family obligations; therefore, several studies of women in leadership have probed female leaders about how they manage their job and home life (Grogan \& Shakeshaft, 2011). According to Shakeshaft et al. (2007), "family, place-bound circumstances, moves with spouses or misalignment of personal and organizational goals" contributed as barriers to a women's administrative pathway because either the obligations listed above restricted them or those who hired believed women would be distracted by family commitments (p. 107). Mahitivanichcha and Rorrer (2006) reported that women feel the situation in which for men marriage and family is an asset, but professionally for women marriage and family are seen more as a liability is an ongoing reality for them. The also observed the magnitude of the superintendent's job duties interfered with household duties to the extent that women 
who want to advance feel they are not able to do so. Accordingly, significant mention is given to conflict with family responsibilities when relocation would be expected. Only aspiring to job opportunities within the proximity of one's home, considering that large, high status superintendent positions serve districts often spanning multiple cities and expansive unincorporated regional boundaries, severely restricts employment options (Miller et al., 2006; Hansen, 2010). The research clearly shows that the overwhelming responsibility for managing work-family conflicts falls largely on women administrators, thus markedly impacting females' career goals or aspirations related to educational leadership (Mahitivanichcha \& Rorrer, 2006; Sanchez \& Thornton, 2010).

Barriers Due to Preparation Programs and Curriculum Materials

At first glance, barriers due to programs and curriculum seem to have been addressed. According to The American School Superintendent: 2010 Decennial Study (Kowalski et al., 2011), when asked about professional preparation, not only were respondent's opinions about their professional preparation positive, but also female and male superintendents expressed virtually identical opinions. In 2010, $77 \%$ of females and $78 \%$ of males rated their preparation as excellent or good. Males and females also exhibited insignificant differences in their opinions about the nature of academic courses and the credibility of school administrators (Kowalski et al., 2011). However, the implications in California become less clear cut as there is currently no superintendent preparation requirements or corresponding program curriculum requirements. Additionally, administrative credentialing programs, traditionally administered by universities, took a hit when the California Commission on Teacher Credentialing 
(CCTC) began offering an exam for qualified certificated personnel that would fulfill the preliminary requirements (preliminary administrative services credential) for acquiring an administrative position. Therefore, formal professional preparation for superintendency in California would only refer to one of the following: 1) an administrative credentialing program likely taken many years, if not decades earlier in one's career; 2) California Association of School Administrator's (ACSA) Superintendent's Academy, which comprises a handful of sessions on topics important to aspiring superintendents; 3 ) doctoral programs in educational leadership, of which women hold the majority of degrees, over 67\%; and 4) no formal preparation as they come straight from a career outside of education. This equates to an inconsistent preparation and curriculum at best and potential to perpetuate barriers encountered by women who seek the superintendency at worst.

Brown and Irby (2006) argue that current educational leadership curriculum is based upon gender deficit theories and provide insufficient information regarding female relationship with local school boards. Synergistic Leadership Theory (SLT) is the only deliberate, gender-inclusive leadership theory referenced in widely used educational administration texts (Shakeshaft et al., 2007). According to Synergistic Leadership Theory, organizational structure includes promoting nurturing and caring, rewarding professional development, and valuing members of the organization (Irby, Brown, \& Yang, 2009). SLT theorists argue that women in educational administrative programs have particular and unique needs, concerns, and challenges, which should be addressed in leadership preparation programs. Dispersing power within an organization is a 
foundational aspect of the SLT model because it promotes leading through and not over others. The female leaders in this study endowed others by nurturing individual development and ingenuity and acknowledging the growth aptitude of others. The leaders in the study did not exhibit an aspiration to have individual authority but instead a need to promote a more cohesive system by investing in those around them (Irby et al., 2009). A recent study by Ardovini, Trautman, Brown, and Irby (2010) validated, qualitatively, the Synergistic Leadership Theory to be a gender-inclusive leadership theory because of the inclusion of the female as well as the male perspective.

\section{Barriers Due to Few Role Models, Sponsors, Mentors, and Networks}

Future leaders need role models whose styles and behaviors they can experiment with and evaluate according to their own standard and others' reactions. Fewer female leaders means fewer role models and can suggest to young aspiring leaders that being a woman is a liability, hence invalidating senior women as reliable sources of advice and support (Ibarra et al., 2013). The learning of new roles is most often accomplished by imitating those one identifies with in a new role and experimenting with "provisional identities and evaluating experiments against internal standard and external feedback (Ely et al., 2011, p. 477). A scarcity of role models leaves younger women with few models whose styles are viable or consistent with their self-concept. This problem is described as particularly acute for women of color, who frequently cite lack of role models of same race and gender as a major barrier to advancement (Ely et al., 2011; Giscombe \& Mattis, 2002). 
Following the premise that all roles are socially constructed, informal networks stand to act as power facilitators of social capital or insurmountable barriers to career opportunities. Networks "regulate access to jobs, channel flow of information and referrals, establish reputation", provide protection and ultimately facilitate promotion (Copeland \& Calhoun, 2014; Ely et al., 2011). Women continue to cite their lack of access to influential colleagues as a major barrier to advancement. Furthermore, the networks women do have tend to be less effective than men's networks. Men's networks are more likely to have members who help them get promoted, while at the same time, men in positions of power tend to direct developmental opportunities to junior men, whom they view as more likely than woman to succeed (Giscombe \& Mattis, 2002; Ibarra et al., 2013). While Dunbar and Kinnersley (2011) found that there were no differences in the provisions of career or psychosocial mentoring between mentees with female mentors and mentees with male mentors in higher education, others have found that females who had female mentors perceived that the gender was important and would have an impact on the effectiveness of the mentoring relationship. Moreover, black female networks for African American women were perceived as vital (Brunner \& Grogan, 2007). Asian women and African American women appear to perceive the strongest barriers to advancement due to lack of mentoring and sponsorship from a same sex, same ethnicity leader (Jackson, Chiu, Lopez, Simmons, Skrla, \& Warner, 2013; Salleh-Barone, 2004). These preferential sponsoring and promotional practices help to explain the gender disparity in the superintendency. 
Mentoring can exist in both formal and informal contexts. According to Dunbar and Kinnersley (2011), informal mentoring is spontaneous, impromptu, free-flowing, and contains friendship actions, support, and advocacy. Formal mentoring is described as resulting from a structured program, such as coaching, with designated benchmarks for implementation (Dunbar \& Kinnersley, 2011). Copeland and Calhoun's (2014) recent mixed-methods study of female superintendents found that $91 \%$ of surveyed participants and $100 \%$ of interviewed women perceived mentoring as beneficial and the majority of them indicated they secured both formal and informal mentoring within the first year. Copeland and Calhoun's (2014) study also found that although $63 \%$ of participants said they had a male mentor, the interviews unveiled that while these "women appreciated and supported male mentors in the field, they felt that women better understood women, and a female mentor could better assist with the challenges specific to women (p. 40).

\section{Gender and Leadership Styles}

More recently, the conversation about effective leadership styles has become a topic of significance for educational leaders. Traditional measures of success of a superintendent has centered around such orders of business as maintaining order and safety, balancing a budget, and passing bonds and parcel taxes. Our school communities have customarily regarded the model leader for these challenges as one "displaying forceful, masculine qualities associated with the behavior of men in formal positions of authority" (Miller et al., 2006, p. 219). Conversely, scholars of contemporary social science, business management and educational leadership have recorded an evolution in preferred leadership styles to one that is less "command and control," traditionally 
assigned to a masculine style, to one that is more "relational," traditionally assigned to a more feminine style (Kowalski et al., 2011; Senge, 2006). This evolution toward more collaborative, relationship centered leadership approaches is now often referred to as the "female advantage" or the "feminization of leadership" (Eagly \& Johannensen-Schmidt, 2007; Lopez-Zafra \& Garcia-Retamero, 2012; Rosette \& Tost, 2010).

Leadership styles evolved in the 1970 s as a semantic used to describe leaders who encouraged their followers to contribute to the organization as transformational, compared to those who used more directive methods of leadership as transactional or laissez-faire (Burns, 1998). This new work emphasizing that effective leaders inspire their followers and nurture their ability to contribute to the organization originally appeared in Burns's (1998) delineation of a type of leadership he coined "transformational." Transformational leaders, skeptical of the status quo, spur innovation by mentoring and empowering their followers by encouraging them to develop to their full potential, thus contributing more capably to their organization (Eagly et al., 2003). Social justice and equity based reform scholars have taken the foundational elements of transformational leadership, emphasizing this critical thread of disrupting the status quo that maintains social reproduction and relabeled this critical leadership as transformative leadership (Brown, 2004; Shields, 2010). Shields's (2010) case study examines female leaders to illustrate the capacities and outcomes embedded in transformative leadership.

What leadership styles manifest in women because of gender role influence in the workplace has also been documented. Moskowitz et al. (1994) found that women behave more "communally" within organization roles than men. Eagly and Johnson (1990) 
reinforced that styles were gender stereotypic as women used democratic or participative leadership behavior while men were more autocratic. The sway of gender roles on these specific organizational behaviors occur, according to Eagly et al. (2003), also when the demands of the female gender role and the leader roles are incongruent. Gender roles have different implications for female and male leaders because contradictions often endure between the largely "communal qualities that perceivers associate with women (i.e. Friendly, kind, unselfish) and the predominantly agenic qualities that they generally believe are necessary to succeed as a leader (i.e. Assertive, masterful, instrumentally competent)" (Eagly et al., 2003, p. 572).

Generalizing the aforementioned female leadership tendencies, social science and business management research finds that female leaders engage in more transformational behaviors, which has shown positive correlations between leaders' effectiveness (Eagly et al., 2003; Vinkenburg et al., 2011). Transformational leadership, as defined by the Multifactor Leadership Questionnaire, known as MLQ, includes a) attending to individual needs/mentoring b) examining new perspectives c) exhibiting optimism e) communicating values/purpose and f) demonstrating qualities that motivate respect (Avolio, Bass, \& Jung, 1999). Furthermore, when literature specific to women in educational leadership is surveyed, one not only finds elements relating to transformational leadership, but also approaches more closely resembling transformative leadership, which diverges from transformational leadership in its emphasis on leadership for social justice and the type of "cognitive shifts" necessary to produce deep, 
sustainable, second order "change in social conditions" (Brunner \& Grogan, 2007; Grogan \& Shakeshaft, 2011, p. 3; Shields, 2010, p. 563).

In Peter Senge's revision (2006) of his seminal work on organizational management, The Fifth Discipline, he adds insight to the original disciplines of a "learning organization" as well as "frontiers for the future" that specifically identifies "women leading as women" as possessing leadership behaviors well suited to lead successful 21 st century organizations that have the "three core learning capabilities: fostering aspiration, developing reflective conversation, and understanding complexity" of human systems (Senge, 2006, p. xii). Senge (2006) explains that although women in senior leadership position have been steadily increasing over the several decades, the first few generations had to lead "more like men than men" in order to prove leadership prowess by the masculine norms still dominant (p. 368). What came to light since his original publication was that a disproportionate number of people leading the highest impact of sustainability initiatives were women. Upon further inquiry into this phenomenon, he learned that women "gravitate toward longer-term issues that lie at the periphery of most business attention, like sustainability, and approach these from a standpoint of collaboration and discovery rather than solutions and plans" (p. 368). Additionally, these female leaders saw themselves as "developmentally oriented" and "less ambitious about personal advancement" and more ambitious about the vision, the core values and the commitment to the communities in which they did business (pp. 368369). There exists, according to Senge (2006), "untapped potential" and goodwill in 
organizations harvested from these female leaders who avoid the "politics and internal competition in favor of people's hearts" (p. 369).

Women superintendents are increasingly perceived as emergent in this contemporary vein of scholarship surrounding educational leadership (Brunner \& Grogan, 2007; Shakeshaft et al., 2007). These researchers in the field of educational leadership have reconceptualized the superintendency to include a manner of leadership that inserts communal practices, instructional leadership, emotional intelligence and a transformational approach, or leading with and through, as opposed to over, which is more frequently correlated with female leadership traits. This re-envisioning entails swapping the top-down ranked structure with an inclusive, weblike methodology whereby the leader maneuvers from the epicenter of the organization or team. It requires communication, collaborative strengthening of human capital, and empathy (Grogan \& Shakeshaft, 2011; Simmons \& Johnson, 2008).

\section{$\underline{\text { A Collective of Common Female Leadership Behaviors }}$}

According to Grogan and Shakeshaft (2011), women lead schools and districts purposefully and with a larger social context in mind, which allows them to effectively carry out large scale cultural and systematic change required for improving student achievement. This study intends to more closely examine the following five most common approaches among women in educational leadership to date, according to Grogan and Shakeshaft (2011): a) leadership for learning, b) leadership for social justice, c) relational leadership, d) spiritual leadership, and e) balanced leadership. These five categories help refine and sharpen what has previously been more broadly and somewhat 
amorphously termed by research on feminine leadership as "communal," "interactive" or “transformational” (Eagly \& Johannesen-Schmidt, 2003; Moskowitz et al., 1994). The culminating experience of these five principles of feminine leadership, according to Grogan and Shakeshaft (2011) is a phenomenon they call "the diverse collective" (p. 101). The strength of the "diverse collective" is the claim that the ways women lead can be strung together to produce the kind of "collective action" most likely to create a "cognitive shift" (p. 102-105). Cognitive shifts are the result of the reframing and perspective swings that occurs during transformational change (Foldy et al., 2008).

\section{Leadership for Learning}

Grogan and Shakeshaft's (2011) leadership for learning underscores a leadership approach that places the instructional core in the center of a leader's mission. Women leaders are more likely to come to the superintendency after spending more time in the classroom and with a strong curriculum and instructional background from serving positions, like content specialists or curriculum coordinators, making them more likely to push for instructional change that improves learning (Brunner \& Grogan, 2007). Women superintendents are also more likely than men to pursue professional development opportunities, especially in the area of curriculum and instruction (Kowalski et al., 2011; Brunner \& Grogan, 2007). Pedagogical expertise has benefited women since the advent of the No Child Left Behind Act of 2001 and strenuous state accountability measures. Reform pressures have shifted a superintendent's focus to serving as chief academic officer leading instructional improvement and culture change in order to meet the demands of improving student achievement (Brunner \& Grogan, 2007; Kowalski et al., 
2011). For this reason, there is mounting evidence that women's focus on student learning has had immediate impact on being hired as a superintendent (Lemasters \& Roach, 2012; Brunner \& Grogan, 2007). Furthermore, the American School Superintendent: 2010 Decennial Study (Kowalski et al., 2011) reported that both men and women indicated the same top three reasons for being hired to their current position (personal characteristics, potential to be a change agent, and ability to be an instructional leader); however, women reported the most important reason was "to be an instructional leader, whereas among males, it was personal characteristics" (p. xvii).

An important component to the female superintendent's focus on leadership for learning is their personal mastery. On average, female superintendents had more teaching experience than their male counterparts. The American School Superintendent: 2010 Decennial Study reports that women are twice as likely to have taught for 20 years or more before entering administration (Kowalski et al., 2011, p. xvii).

\section{$\underline{\text { Leadership for Social Justice }}$}

The history of women's suffrage and fight for equal civil rights coupled with the social roles they carry provides an overarching insight into why women would be highly likely to report they went into teaching because they wanted to disrupt the status quo. Women more frequently refer to their jobs as teachers in the language of social justice work (Grogan and Shakeshaft, 2011). Social Justice motivators for female educators are revealed in several studies seeking to discern social justice as both a motivator as well as a continued charge (Sanders-Lawson, 2006). These studies document behaviors that fall under parameters of such effective leadership models as moral leadership (Sergiovanni, 
1992), servant leadership (Greenleaf, 1977), synergistic leadership (Brown \& Irby, 2006), and transformative leadership (Shields, 2010).

Transformative leadership, related to critical race and gender theories such as cultural and social reproduction and social justice leadership, takes seriously Freire's (1998) contention that "education is not the ultimate lever for social transformation, but without it transformation cannot occur" (p. 37). Transformative leadership begins with questions of justice and democracy; it critiques inequitable practices and offers the promise not only of greater individual achievement but of a better life lived in common with others. Transformative leadership, therefore, inextricably links education and educational leadership with the wider social context within which it is embedded (Shields, 2010). In other words, while transformative leadership has its roots in transformational leadership theory, it diverges in a key area: Transformational leadership concentrates chiefly on what happens within an organization, whereas transformative leadership recognizes that the injustices and struggles experienced in the broader culture affect one's ability both to achieve and to thrive within an organizational context.

This critical facet is expressed in Paulo Freire's (1970/2000) term "conscientização," or critical consciousness, the ability to perceive social, political, and economic oppression in one's own reality as well as in others and to take action against the oppressive elements of society. In other words, when students begin to understand how they are conditioned to think and feel and perceive by the dominant culture, it is at that point of consciousness that they can actually begin to free themselves from conditioned beliefs and begin to consider a different reality. 
Freire (1970/2000) contends that both the teacher and the student need to come to consciousness together of their collective situation in order to disrupt the oppressive state that maintains the perpetual cycle of low achievement. Freire's view of authentic humanism is one of eternal optimism in the human condition and the consistent belief that the human condition is always "situational and conditional and therefore an obligation and a project" (Freire, 1970/2000, p. 92). Freire (1970/2000) describes the mind-set and heart of both the teacher and the educational leader, who must see the world and humanity in this altruistic, optimistic way in order to have an impact that interrupts the cycle of oppression:

If I do not love the world - if I do not love life-if I do not love people-I cannot enter into dialogue. ... Founding itself upon love, humility, and faith, dialogue becomes a horizontal relationship of which mutual trust between the dialoguers is the logical consequence. ... Hope is rooted in men's incompletion, from which they move out in constant search - a search which can be carried out only in communion with others. (p. 90-91)

True dialogue is not a one-dimensional, one-way channel of ideas from teacher to student, but two-way interchanges of schema and negotiation that requires a more egalitarian and mutually respectful relationship. When this critical bond is formed, affective filters are lowered, free exchange of experience is tapped, and learning springs (Freire, 1970/2000). However, teachers and educational leaders cannot "enter into dialogue" until they raise the consciousness of race-based inequality in the classrooms 
and in the communities in which their students reside (Freire, 1970/2000; DuncanAndrade \& Morrell, 2008).

Sanders-Lawson et al. (2006) argue that the social context of black women leaders in particular have strongly influenced them to concentrate on justice and their responsibility to improve conditions in their community. Instructional leadership overlaps with leadership for social justice as the changes women introduce in their organizations most often relate to the improvement of learning, which most directly impacts social conditions of the students and the community it serves (Grogan \& Shakeshaft, 2011). In this light, being an instructional leader can be a "double-edged sword" for highly ethical women superintendents who are serving in poor urban districts in greater numbers than men and willing to stand up for what is right regardless of the political or career consequences, possibly contributing to their overall shorter tenure than men (Lemasters \& Roach, 2012, p. 8).

Women ascended to the superintendency at the turn of the 20 th century because they were perceived to symbolize an ethical and honest alternative to their corrupt male counterparts (Lemasters \& Roach, 2012). Fueling leadership behaviors with a social justice lens is the female superintendent's ambition for the longer term, idealized vision with an approach based on community collaboration over personal advancement coupled with a disdain for politics and infighting (Senge, 2006). Ardovini, Trautman, Brown, and Irby (2010) expressed this as well in their research validating synergistic leadership behaviors among female administrators. They noted that superintendents relayed a desire for a connection of all concerned stakeholders. "The female superintendent was very 
intent on the need to be in touch with what was going on in the community and described the need to have an inclusive vision" (p. 43).

\section{$\underline{\text { Relational Leadership }}$}

Although closely related to women's desire to community build and seek out diverse voices from the periphery, relational leadership in this context begins with her ambivalence to power. According to Grogan and Shakeshaft (2011), relational leadership suggests that leadership is about being in a relationship with others in a horizontal rather than a hierarchical sense. Women conceptualize power differently than men and are more likely to seek to expand everyone's power. Their working definition of relational leadership is grounded in women's "conceptions of power and the importance they place on relationships," thus defining one of the key ways in which women superintendents differ from men in their approach to power (p. 7). Successful superintendents, it appears, do not attempt to directly control others to accomplish their agenda. In fact, efforts to exert authority directly are often met with hostility echoing Eagly and Karau's (2002) role congruity prejudice against female leaders. The gender-inclusive Synergistic Leadership Theory also speaks of women as less interested in individual power and more inspired to foster a powerful environment by empowering those around them heralding Gilligan's (1982) “ethic of care” (Ardovini, Trautman, Brown, \& Irby, 2010; Irby et al., 2009). Whether by generations of weaker stature or by leader identity construction via social role theory, it is this approach to power that characterizes women as collaborative leaders and makes them successful in districts that necessitate cooperation and the communing of diverse community interests (Lemasters \& Roach, 2012). Therefore, as 
Grogan and Shakeshaft (2011) explain, "power through relationships is more likely to be how women confront change" (p. 7).

\section{Spiritual Leadership}

Grogan and Shakeshaft (2011) state that the "idea of leadership grounded in spirituality" became a strong theme in their research on women superintendents and most profoundly from the reflections of women of color (p. 13). Spirituality within this leadership approach has several meanings from religious contexts to "consciousnessraising" to "on-going peace and self-understanding in a spiritual journey (p. 14). Women superintendents commented that it was their spirituality that gave them hope and made them resilient. For African American female superintendents, spirituality was not just a vehicle for hope, but a source of self-identity as they symbolize the change in the status quo they want to disrupt (Simmons \& Johnson, 2008, cited in Grogan \& Shakeshaft, 2011). Spiritual leadership is defined by leaders who prefer work that is community building, person centered, product oriented, principle driven, religious, mission and/or purpose driven, and interpersonal in nature (Bezy, 2011). Dantley (2005), in his article conceptualizing Cornel West's notions of prophetic pragmatism in urban schools, describes African American spirituality as a "functional phenomenon in schools" that functions distinctly differently than its connection to organized religion (p. 654). Dantley (2005) explains,

Religion emphasizes conformity and adaptive behaviors, whereas spirituality inspires creativity, inquiry and transformative conduct. Our spirit enables us to connect with other human begins; it underpins our 
ability to take steps to dismantle marginalizing conditions while simultaneously creating strategies to bring about radical changes to lessthan-favorable circumstances ... our spirituality connects our lives to meaning and purpose. (p. 654)

For these female superintendents, spirituality is a source of personal strength as well as a way to understand connectedness to others and to the greater world. It gives them the ability to better recognize that they have a responsibility to respond to others and to use their gifts in the greater context of our interconnected life. The principal or the superintendent who can build a culture of critical consciousness and mutual trust between teachers and students can have profound impact on learning, but the instructional leader cannot activate this change without embodying the "call of service" (Deal and Peterson, 2010). Using this "call" the effective school leader should be able to "infuse passion and purpose into an enterprise and build a common spirit and cohesive culture" (p. 252).

According to Deal and Peterson (2010), shaping school culture and reviving the belief and myth of our school system has to be a leaders calling, as they eloquently write, "Culture in successful organizations arises in the yeasty crucible of meaning somewhere between mystery and metrics. It is the glue, the hope, and the faith that holds people together" (p. 5). It is the role of leadership in education to keep the focus of a school on teaching and learning for all students and in this focus a culture equipped to raise rigor, expectations and achievement is born. 
In Leading Good Schools to Greatness, Gray and Streshly (2010) found a correlation between effective principals leading schools to closing the achievement gap and Collin's Level 5 Executive with one difference. They had all of Collin's Level 5 qualities with one additional trait — the ability to build trust in relationships and the understanding that these relationships directly impact culture - a leader's greatest change agent (Gray \& Streshly, 2010; Collins, 2005). Building trust through relationships is the embedded nexus within the student/teacher/content triad as well. Hence, in the school business both inside the classroom and out, one must possess a love in humanity and curiosity for relationships with all stakeholders and all micro and macro cultures on a campus. Deal and Peterson (2010) explain in order to carry out enduring change, the leader must lead with "soul" and a love of community.

\section{Balanced Leadership}

Grogan and Shakeshaft (2011) assert that successful female leaders not only learn to balance the competing roles of mother, wife, partner, and leader, but also use these skills to enhance their management practices. In other words, managing households and caring for family members have brought a "dimension to women's leadership that can enhance their performance" (p. 24). Finding that balance, according to Grogan and Shakeshaft (2011), give women sort of an equilibrium in both spheres allowing them confidence to negotiate even the most stressful and complicated issues.

Several studies cite the importance of family support for women as key their ability to balance work and family during their journey to top leadership positions (Brunner \& Grogan, 2007; Cheung \& Halpern, 2010). Cheung and Halpern describe 
these balanced leaders as having "collective identities that emphasized family loyalty," while relying on family support as an emotional fall back of sorts (p. 186). These collective identities relied on a combination of supportive husbands, extended families, and often hired help to outsource domestic work in an effort to integrate work and family as opposed to managing them as separate spheres that they vacillate between (Cheung \& Halpern, 2010). Female leaders described healthy couple behaviors with these supportive husbands, such as "alignment of goals, mutual encouragement and acceptance, commitment to equality in the relationship, empathic listing and open communication ... and willingness to engage in joint conflict resolution" (p. 187). In other words, as with their highly collaborative, egalitarian leadership preferences, there was a lot of compromise, debate and negotiation in their marriage and mothering roles as well (Cheung \& Halpern, 2010). Balanced leadership means these female leaders "embraced the multifaceted roles involved in being women" (p. 187). Instead of segregating work roles and family roles into distinct domains that could result in conflict, they integrated them in ways to benefit from combining their dual roles (Cheung \& Halpern, 2010).

A study surveying 140 female superintendents and females aspiring to the position of superintendent about the barriers that prevented the female applicant from attaining the superintendent position found that one of the top three barriers included self imposed decisions based on the demands of family and the unwillingness to relocate one's family. The women in the study that did succeed appeared to have "unusually resilient, flexible and accommodating systems of family support" (Derrington \& Sharratt, 2009, p. 11). Aligning with Cheung and Halpern's (2010) assertion that successful female 
executives form more egalitarian households, Derrington and Sharratt (2009) suggest female superintendents 1) choose supportive spouses who share their values and understand their drive, 2) negotiate home and family demands and household duties, and 3) transform gender roles in a marriage.

\section{Chapter Summary}

The $\mathrm{K}-12$ public school superintendent remains a highly masculinized, maledominated role. Even with the highly feminized role of teaching reaching close to $78 \%$ female, less than a quarter of all superintendents in America are women. Social role theory supports the notion that while conflicting expectations of gender roles and leader roles contribute to this glass ceiling for women, both gender and leader roles also influence male and female leadership styles.

Eagly's (2007) role congruity theory finds that female leaders confront challenges when they display agenic behavior expected of a leader, such as assertiveness, because it is incongruent with female social role expectations that call for them to behave more feminine or passive. Leadership styles that are associated with perceptions of gender roles include a more communal or transformational style in women and more agenic or transactional style in men. Common social expectations ask women to be more communal and nurturing while they prefer men to be more directive in a chain of command structure.

The barriers women have historically encountered on their pathway to the superintendency include slower career trajectories within staff positions; sex and social 
role discrimination leading to disrupted leadership identity formation and/or conflicting performance evaluations that damage advancement potential; family responsibilities that highlight the challenge of relocating; a paucity of role models, mentors, sponsors, and effective networks; and lack of leadership programs attending to the specialized needs and concerns of women.

The study of leadership styles of men and women have found that women exhibit more transformational leadership traits, while men present more transactional behaviors. Transformational leadership has been increasingly linked to effective and desirable management. Transformational leadership, along with relational and instructional leadership, has also been recently correlated to increased staff morale and overall student achievement.

Grogan and Shakeshaft (2011) have recently identified more highly delineated effective leadership behaviors most commonly found in female educational executives presenting a possible advantage to women endeavoring to penetrate the glass ceiling to the superintendency. Those ways of leading include relational leadership, leadership for social justice, spiritual leadership, leadership for learning, and balanced leadership. All of these behaviors culminate into a highly collaborative leadership style, one that is highly inclusive of "voices from the margins," which builds a "diverse collective." This approach, they claim, enables these female superintendents to produce the "cognitive shifts" necessary for second order culture change (p. 3). 
Gender in educational leadership is an understudied and underdocumented topic. Grogan and Shakeshaft (2011) quipped that it is easier to find the number of caribou in Alaska than to find the number of female superintendents in any given region. Additionally, the majority of these studies have included surveys canvassing female aspirants of top leadership positions, such as superintendent, leaving a gap in the literature for the counternarratives - those women who were successful in overcoming the barriers. This study chose to bypass the scale of the broad questionnaire in order to delve deeply into understanding how a few female superintendents, who have successfully achieved positive, measureable change in their districts, lead. This multiple case study, which was grounded in the theory that there are discernible differences in male and female management behaviors, presents findings in the proceeding chapters that have implications on the curriculum of administrative credentialing programs, the expectations of the role of the superintendent and the discourse on school reform and change leadership. 


\section{CHAPTER 3. METHODS}

\section{Overview}

This chapter introduces the research methodology used in this study. It begins with a description of case study research, following by the context of the study and the research design, including a description of the participants, role of the researcher, instrumentation and data collection, data analysis and interpretation, and validity. The section culminates with a summary.

\section{Overview of the Study's Procedures}

The purpose of this multiple case study was to examine the experiences of women in their ascendancy to the position of $\mathrm{K}-12$ superintendent and the type of leadership they employ to successfully execute the role. By asking how these successful female leaders recognize and internalize important elements of their leadership styles and how they used these approaches to effect positive change, this study aims to add to the current discourse on leadership by asking how they think about and use their leadership. Case study is a qualitative, inductive approach using descriptive methods of data collection appropriate when researchers are more interested in discovery, exploration, and interpretation of data than in hypothesis testing (Yin, 2009). It involves thorough depiction of the empirical inquiry of a phenomenon set in its real-life context. It is particularly useful when the "boundaries between phenomena and context are not clearly evident" and the researcher has little or no control over the events being explored (Yin, 2009). The case study is 
chiefly suitable when the scholar is inquiring in the context of how or why questions, such as to female superintendents, because "one cannot understand human behavior without understanding the framework within which subjects interpret their thoughts, feelings, and actions" (Yin, 2009; Marshall and Rossman, 2010 p. 49).

\section{Interview Participant Selection}

My intent was to study leadership behaviors and characteristics of successful female superintendents and not the districts themselves. Hence, a criterion to establish "success" was necessary. The measure of "success" used for selection of the participants in this study was student test performance, specifically, the California Academic Performance Index (API). The State of California's API formula gives certain weights to each of the demographics; therefore, even though each district differs in its demographic composition a district cannot meet its API growth targets unless it makes marked improvement in each of its significant subgroup growth targets set annually by the state, which include such underrepresented groups as African American, Latino, English learner (EL), and free or reduced-price meal eligible (low-income status as determined by the National School Lunch Program). Female superintendents must have been serving in the position for a minimum of two years through 2013 during which time the improvement is trended. The final criteria included minimum district size and geographical convenience within seven Northern California counties proximate to the San Francisco Bay area region. Because it is far more common to find a female superintendent in a small elementary district, a minimum size of 4,500 students was 
established to focus on those finding success in the more traditionally male domain - the large districts that include secondary schools.

The state of California has an exceptional number of small districts. Almost three quarters of all California school districts have an average daily attendance (ADA) below 5,000 . However, together these 688 districts contain just 15 percent of total ADA in the state. Moreover, 230 of the state's districts contain only a single school. At the other extreme, 15 very large districts with over 40,000 ADA educate about one quarter of all students in the state, with one district, Los Angeles Unified, representing about $10 \%$ of total state ADA. The participants in this study serve midsize districts with an ADA between 4,500 and 20,000, with multiple school sites, large boundaries, and most serving multiple municipalities.

Table 1

Participant Selection from Four Bay Area Counties

\begin{tabular}{|c|c|c|c|c|c|c|c|c|}
\hline County & $\begin{array}{l}\text { Districts } \\
\text { in } \\
\text { county }\end{array}$ & $\begin{array}{l}\text { Female } \\
\text { supts. in } \\
\text { county }\end{array}$ & $\begin{array}{l}\text { Percent } \\
\text { of supts. } \\
\text { who are } \\
\text { female }\end{array}$ & $\begin{array}{c}2+\text { years } \\
\text { with } \\
\text { ADA } \\
4,500+\end{array}$ & $\begin{array}{c}\text { Improved } \\
\text { student } \\
\text { achicvement }\end{array}$ & Invited & Responded & Participants \\
\hline Santa Clara & 32 & 12 & 37 & 6 & 6 & 6 & 6 & 5 \\
\hline San Mateo & 18 & 7 & 38 & 2 & 2 & 2 & 1 & 1 \\
\hline Alameda & 25 & 12 & 48 & 3 & 3 & 3 & 2 & 2 \\
\hline Contra Costa & 18 & 8 & 44 & 4 & 4 & 4 & 1 & 1 \\
\hline Total & 93 & 39 & 41 & 15 & 15 & 15 & 10 & \\
\hline $\begin{array}{l}\text { Percentage of } \\
\text { female supts. } \\
\text { fitting criteria }\end{array}$ & & & & $15.00 \%$ & & & & \\
\hline $\begin{array}{l}\text { Total } \\
\text { participants }\end{array}$ & & & & & & & & 9 \\
\hline
\end{tabular}


In the summary, the participant selection criteria are as follows:

1. Gender of female,

2. Attained one or more superintendent positions,

3. Served or serving as superintendent in one of the seven surrounding Bay Area counties convenient to the researcher,

4. Met or exceeded target API growth for district during tenure as superintendent,

5. Minimum two years tenure during growth trend, and

6. Minimum district size of 4,500 .

For the purposes of this exploration, 14 female superintendents were identified initially. From those initial 14, nine agreed to participate. The study is composed of nine successful female $\mathrm{K}-12$ public school superintendents from four counties surrounding the San Francisco Bay Area: Alameda, Contra Costa, San Mateo, and Santa Clara. A typical qualitative research can include few individuals in order to gain in-depth information about the given area of study, and having a large number of cases becomes difficult to manage and results in superficial perspectives (Creswell, 2013). Moreover, according to Yin (2009), “case studies are generalizable to theoretical propositions and not to populations or universes" (p. 15). Therefore, one should avoid thinking of case study in terms of "the sample of cases" or the "small sample size of cases," as if a single case study were "like a single respondent in a survey or a single subject in an experiment" 
(Yin, 2003, p. 33). The goal for multiple case study design is "to expand and generalize theories or analytic generalization" (Yin, 2009, p. 15).

\section{$\underline{\text { Participant Recruitment }}$}

According to Creswell (2013), to enable the collection of qualitative data, the researcher must achieve admittance to the local education agency and acquire authorization to study staff or students within the organization. Seidman (2013) further cautions that those who determine eligibility of access to prospective participants can potentially obstruct the investigator from gaining access to said participants; however, because the participant holds authority to grant access, consent to participate doubled as consent to access the local education agency. School district directories publically available on the four county offices of education websites, which include San Mateo, Santa Clara, Alameda, Contra Costa, and the California Department of Education website (Dataquest), were used to identify the female superintendents who fit the criteria and gain access to their contact information. To determine district demographics, size, and student performance for the remaining selection criteria, the education data partnership between the California Department of Education (CDE), EdSource, and FCMAT was used (see Table 2). 
Table 2

District Performance Data

\begin{tabular}{|llcccc|}
\hline Superintendent & School district & $\begin{array}{l}\text { Years tenure/ } \\
\text { Year started }\end{array}$ & $\begin{array}{c}\text { API at starting } \\
\text { date }\end{array}$ & 2013 API & $\begin{array}{c}\text { API } \\
\text { growth }\end{array}$ \\
\hline Patricia Patterns & Cardiff Hills Union & $2(2011)$ & 951 & 962 & 11 \\
\hline Sandy Structure & Solano Bay Unified & $2(2011)$ & 777 & 783 & 6 \\
\hline Mary Mediator & Granite Gulch Unified & $7(2007)$ & 731 & 804 & 73 \\
\hline Constance Culture & El Capitan Union Elementary & $3(2010)$ & 874 & 886 & 12 \\
\hline Terry Teacherfirst & Freedom Valley Union High & $7(2007)$ & 840 & 890 & 40 \\
\hline Elizabeth Engager & Santa Vista Springs & $3(2010)$ & 839 & 843 & 4 \\
\hline Carrie Community & Margarita Meadows Unified & $7(2007)$ & 775 & 837 & 62 \\
\hline Barbara Breakingthemold & Live Oak Unified & $4(2009)$ & 817 & 840 & 23 \\
\hline Susan Systems & Pilgrim Park Unified & $4(2009)$ & 903 & 915 & 12 \\
\hline
\end{tabular}

Note: Names of superintendents and school districts have been fictionalized. Statistics adapted from EdData (2014).

A letter of introduction was sent via e-mail with the informed consent form attached (Appendices B and C). A phone call followed to make a personal introduction, invite the individual to participate, and schedule an interview appointment. As the researcher is an assistant superintendent in one of the seven counties in this study, her involvement in the professional networks that include several of the superintendent candidates aided in gaining access to the busy schedules of these executive women.

\section{$\underline{\text { Study Context }}$}

California has 48 county offices of education, 1,043 school districts, 10,296 schools, and over 6.2 million students. The district configurations and governance vary: 540 districts are elementary $(\mathrm{K}-5$ and $\mathrm{K}-8), 80$ are high school districts (9-12 and 7-12), and the remaining 422 districts are K-12 unified districts. Student achievement and enrollment also vary greatly, with the largest 25 districts accounting for $30 \%$ of the 
student population and the smallest 25 districts making up less than $1 / 10$ of 1 percent and serve elementary grades only (Ed-Data, 2014).

Table 3

District Demographic Data

\begin{tabular}{|lccccccccc|}
\hline & $\begin{array}{c}\text { Cardiff } \\
\text { Hills } \\
\text { Union }\end{array}$ & $\begin{array}{c}\text { Solano } \\
\text { Bay } \\
\text { Unified }\end{array}$ & $\begin{array}{c}\text { Granite } \\
\text { Gulch } \\
\text { Unified }\end{array}$ & $\begin{array}{c}\text { El Capitan } \\
\text { Union } \\
\text { Elementary }\end{array}$ & $\begin{array}{c}\text { Freedom } \\
\text { Valley } \\
\text { Union } \\
\text { High }\end{array}$ & $\begin{array}{c}\text { Santa } \\
\text { Vista } \\
\text { Springs }\end{array}$ & $\begin{array}{c}\text { Margarita } \\
\text { Meadows } \\
\text { Unified }\end{array}$ & $\begin{array}{c}\text { Live } \\
\text { Oak } \\
\text { Unified }\end{array}$ & $\begin{array}{c}\text { Pilgrim } \\
\text { Park } \\
\text { Unified }\end{array}$ \\
\hline Grade span & $\mathrm{K}-8$ & $\mathrm{~K}-12$ & $\mathrm{~K}-12$ & $\mathrm{~K}-8$ & $9-12$ & $\mathrm{~K}-8$ & $\mathrm{~K}-12$ & $\mathrm{~K}-12$ & $\mathrm{~K}-12$ \\
\hline Enrollment & 18,650 & 14,600 & 11,290 & 13,347 & 10,535 & 11,456 & 4,807 & 12,629 & 14,932 \\
\hline No. of schools & 25 & 25 & 17 & 18 & 6 & 20 & 9 & 18 & 15 \\
\hline $\begin{array}{l}\text { Ethnic composition } \\
\text { White }\end{array}$ & $18 \%$ & $22 \%$ & $19 \%$ & $7 \%$ & $21 \%$ & $28 \%$ & $51 \%$ & $52 \%$ & $50 \%$ \\
\hline $\begin{array}{l}\text { Hispanic } \\
\text { African }\end{array}$ & $5 \%$ & $36 \%$ & $72 \%$ & $28 \%$ & $16 \%$ & $35 \%$ & $29 \%$ & $29 \%$ & $10 \%$ \\
$\begin{array}{l}\text { American } \\
\text { Asian }\end{array}$ & $1 \%$ & $4 \%$ & $1 \%$ & $2 \%$ & $1 \%$ & $2 \%$ & $3 \%$ & $2 \%$ & $2 \%$ \\
$\begin{array}{l}\text { Other } \\
\text { English learners }\end{array}$ & $12 \%$ & $28 \%$ & $28 \%$ & $24 \%$ & $9 \%$ & $27 \%$ & $3 \%$ & $14 \%$ & $7 \%$ \\
\hline $\begin{array}{l}\text { Free or } \\
\text { reduced-price } \\
\text { meal eligible }\end{array}$ & $5 \%$ & $46 \%$ & $52 \%$ & $32 \%$ & $15 \%$ & $31 \%$ & $26 \%$ & $23 \%$ & $6 \%$ \\
\hline
\end{tabular}

Note: Names of superintendents and school districts have been fictionalized. Statistics adapted from EdData (2014).

The four Bay Area counties selected, San Mateo, Santa Clara, Alameda, and Contra Costa, together comprise 758,411 students, or approximately $12 \%$ of California students. In these four counties, 163,074 students are English learners, which is $12 \%$ of California's English learner population. Two of the counties have higher than state average English learner populations, while all the counties fall below state averages for free or reduced-price meal services (those who are eligible for federal meal programs indicate families in poverty or low-income families), with an average of $33 \%$ free or reduced-price meal eligibility. The highest of the group has $44 \%$ low income students. 
Additionally, the collective Latino population is below the statewide average at $35.4 \%$, and the African American student population is equal to the statewide average at $6 \%$. Each of the four counties also scores higher than the state average in several measurable areas, including cohort graduation rate, $\mathrm{UC} / \mathrm{CSU}$ a-g completion rates, and average total SAT score. Nationwide, just fewer than 1 in 4 (24\%) superintendents are female.

In summary, the context of this study encompasses four counties in Northern California with higher-than-average performance levels, higher-than-average English learner populations, higher-than-average socioeconomic levels (Ed-Data, 2014), and higher-than-average percentage of female superintendents with $41 \%$. It must be noted, however, that only $15 \%$ of the females fit the study criterion of tenure of two years or longer in a district larger than 4,500 students.

Instrumentation

Three sets of data were generated for this study; data-collection tools include interview, curriculum vitae documentation, and a brief demographic questionnaire (Appendices C and D). A qualitative approach was used to gather extensive descriptions of the personal journeys as told by each superintendent as they relate to leadership behaviors and experiences during their ascendancy and tenure. The researcher recorded the superintendent's own words as she reflected about her experiences, leadership style, and her perceived barriers and facilitators to success for both her personal career trajectories and the school reform each endeavored to undertake. Each interview occurred in an authentic setting of the participant's choice that not only was convenient to the participant, but also provided for the ability of the researcher to clearly record the entire 
interview. Seven of the participants chose to be interviewed in their offices, one participant chose to be interviewed in a café in the morning before work, and one participant, recently retired, chose to be interviewed in the evening at her home.

The researcher anticipated multiple contacts prior to the interview to obtain agreement and set up appointments. Initial contact was made by e-mail (with document attachments and scanned signatures) and follow-up contact, mainly with executive secretaries, was by both phone and e-mail. The semistructured interview format involved a person-to-person conversation. Each interview was initiated with casual conversation to build rapport and lower affective filters. The participating superintendents seemed to want to know who they were talking to, so an introductory biographical sketch of the researcher often precipitated the interview session. This was followed by the demographic questionnaire, a review of the informed consent, and a reminder that the interview was being recorded and that the interview should last between 60 and 90 minutes. Nearly all of the interviews greatly exceeded the 90 timeframe. Two hours was the average time span, with 3 interviews lasting $2 \frac{1}{2}$ to 3 hours. Each interview concluded with the researcher expressing gratitude and requesting future contact for follow-up questions. All participants expressed a willingness to be contacted for follow-up and data verification. Participants also expressed appreciation for the open, casual format of the semistructured interview, and all pointed out that they often receive requests to fill out surveys, but that they more often than not turn down these requests because the limiting question format felt less accurate to them. Assurances were also given that, upon request, 
copies of transcriptions, recordings, or drafts of the analysis would be provided to each participant.

The interview, according to Bogdan and Biklen (2007), is a "purposeful conversation, usually between two people but sometimes involving more, that is directed by one in order to get information from the other" (p. 103). Bogdan and Biklen (2007) go on to describe the interview as a tool used to gather descriptive data in the individual's own words so that the investigator can form perceptions into how human beings construe their world. The interview is a tool that allows the researcher to uncover the participant's insight by giving her the space to "frame and structure" the responses. This would ideally take the form of a conversation with a purpose (Marshall \& Rossman, 2010, p. 82). Moreover, primary to the qualitative researcher is the assumption that the interviewee's perspective of the phenomenon of interest be allowed to evolve as the participant understands it, not as the researcher perceives it (Marshall \& Rossman, 2010).

\section{$\underline{\text { Role of the Researcher }}$}

The researcher's role in this study was primarily that of interviewer, recorder, and interpreter of data. Although as my current career position of assistant superintendent situates me within the realm of operationalizing and coconstructing a superintendent's vision and responsibilities on a daily basis, the researcher's character also was of scholarpractitioner. The role of interviewer, participatory in nature because of the personal interaction and authentic setting involved, is a comfortable and natural interaction for a scholar-practitioner. The use of a semistructured interview, guided by a list of questions, permitted the scholar to address explicit evidence from all participants (Appendix C). The 
questions were intended to focus conversation on specific features of the topic, several of which were grounded in the foundational literature of Grogan \& Shakeshaft (2011). To best address the research questions, the study ensured that all participants were led to articulate the same areas of the topic. Furthermore, these open-ended, topic-focused questions were used to stimulate the women to expand upon their responses so as to elicit deep reflection when conveying their experiences that culminated in a successful career as superintendent.

The researcher came to this study with the view that certain barriers exist for aspiring female superintendents. Moreover, she perceived a focus on instruction as being more prevalent among female administrators than among males. However, she had neither a perspective on nor a solid understanding of the leadership preferences or personal motivations that inspire those women who overcome the barriers to become superintendents. To circumvent the effect of researcher bias during data collection and analysis, the researcher referred often to the literature to reframe and ground the findings. Procedures were also carefully documented to ensure that the findings of the study replicate the viewpoint of the participants and not those of the researcher. The documentation was performed through data memos, in-text notation, color coding, and data tables to categorize the findings under themes and to conduct cross-case analysis. The data memos included researcher thoughts during interviews, descriptions of the interview setting, the participants' visual cues, tentative hypotheses, emerging patterns, associated questions, and thoughts or feelings the researcher had about her assumptions. 
$\underline{\text { Internal Validity }}$

In order to increase internal validity and ensure the accuracy of the data, the researcher utilized several methods. Initially, the participant inclusion/exclusion criteria precisely regulated who participates in the study (Creswell, 2013). Construct validity, which involves forming the precise operational measures for the idea being studied, was met by selecting exact perceptions to be examined and by establishing that the selected measures of these perceptions provide applicable and adequate data (Yin, 2003). This probing study concentrated on the female superintendent's perceptions of her own experiences in reaching and achieving success in the position of superintendent.

Additionally, interview questions were vetted with Margaret Grogan and Charol Shakeshaft, the authors of Women and Educational Leadership (2011), the foundational book outlining the five most prominent leadership attributes of women in educational leadership, in order to assure alignment with their leadership behavior claims. Then, during the spring/summer sessions of 2014 , the interview questions were "piloted" with a female superintendent who did not participate in the survey. Piloting the questions provided the researcher with information on which questions are unclear or unnecessary and led to revisions to improve the questions.

Lastly, validity is stronger when more than one data source is used, and such is used in this multiple case study. Interview, document review, and demographic questionnaire were the methods of data review in this study. According to Yin (2003), a critical benefit of multiple sources of data is the use of converging line of inquiry "in a triangulating fashion" as a result of multiple forms of data coming together within the 
same set of findings (p. 14). Confidence in the results was validated through member checking and follow-up correspondence with participants. Lincoln \& Guba (1985) called "member checking" a process through which participants verify data resulting in interpretation. This process was necessary to ensure validity and establish credibility. All participants were sent their transcriptions via e-mail. Seven responded, thanking the researcher for the opportunity to read the transcription; four of the seven sent back edits and additional comments on the transcriptions (three via mail, one via e-mail "track changes" on a attached Microsoft Word document), and three scheduled follow-up phone calls with the researcher as a continuation to member checking.

A second technique used to ensure validity of the coding system was peer review. The researcher asked a doctoral-level peer to review large sections of the transcripts using the coding system developed by the researcher. There was early understanding on many of the codes. After independent coding was completed, the results were then shared and discussed, resulting in some explanations of the codes and greater parity between coders.

\section{External Validity}

In case study research, the goal is not to compare the sample to larger populations via statistical generalization. Rather, the aim is to examine the particulars of a case in detail, compare the case to other similar cases, and derive patterns that may be transferred to similar situations. Therefore, to accomplish external validity, the study was grounded on theory that will find strong support through replication logic rather than through replication of statistical findings (Yin, 2003). This research project used social role theory 
combined with structured data collection, interpretation, and analysis methods that allow for analytical generalization. Replication and reliability was insured by documenting the specific procedures that were utilized. For example, the use of a coding matrix for crosscase analysis will help a later investigator to replicate this study and find comparable results.

$\underline{\text { Data Analysis and Procedures }}$

Interview data were audio recorded so that the researcher was able to focus completely on communicating with the participants, and so that no information was missed through note-taking. Through audio recording, the researcher preserved the words of participants and possesses the original data to check for accuracy (Seidman, 2013). After each interview, verbatim transcriptions of the audio-recorded data were typed using Microsoft Word. Transcription is the process of converting audio-recorded information into word-for-word text data, which allows for data analysis (Creswell, 2013). By performing a full verbatim transcript herself, the researcher was able to fully reflect on the interview themes during transcription and multiple times thereafter (Seidman, 2013).

Upon transcribing the data, the researcher performed an initial reading of the data using an initial probing analysis (Creswell, 2013), which involved reading the data to obtain a general sense of the transcripts and to begin thinking about the ways in which the data will be organized. Second, the researcher reread the transcripts and highlighted key words and phrases that align with Grogan and Shakeshaft's (2011) five themes and wrote short memos consisting of phrases, terms, and thoughts in the margin of the transcripts (Bogdan \& Biklen, 2007). Categories for the first round of coding were based on an 
analysis of the responses in relation to Grogan and Shakeshaft's (2011) characteristics and behaviors in their "five ways women lead." The second round of coding was expanded to include additional leadership focuses and behaviors generated by the interviewee (e.g., human systems dynamics, systems thinking, re-creating the superintendent role).

Third, the researcher scrutinized the transcript line by line in the third reading and coded the data, organizing the material into code families within Grogan and Shakeshaft's (2011) leadership categories. Families of codes, described by Bogdan and Biklen (2007), were used to establish criteria under Grogan and Shakeshaft's (2011) defined leadership themes. These families of codes include relationship and social structure codes, which refer to regular patterns of behavior of interaction among participants; strategy codes, which refer to conscious ways people accomplish various things; activity codes, referring to documentation of regularly occurring kinds of behavior; event codes, which are related to specific activities that occur in the setting; process codes, which include words and phrases that assist in categorizing sequences of events or changes over time and come from a group or phenomena over time; perspectives held by subjects codes, which include subjects' orientation toward particular aspects of a setting; and situation codes, which describe how participants define the setting in which they are experiencing. The researcher referred to the literature for assistance in determining appropriate relationship of coding categories to both Grogan and Shakeshaft's female leadership themes and additional emergent themes. During the coding process, additional ideas generated from the questions asked, or by ideas 
volunteered from the interviewee, materialized, and coding was refined further to explore patterns among the superintendents interviewed relevant to the study. Related codes were grouped together in code families (Creswell, 2013). Table 4 presents the code families applied in this analysis. The constant comparison approach was used throughout to compare new elements of data with previously coded data, which refined emerging themes (Bogdan \& Biklen, 2007). Finally, charts and matrices were created to organize and cluster themes and supporting direct quotations in a clear and logical manner (Creswell, 2013). 
Table 4

\section{Code Families}

\begin{tabular}{|c|c|}
\hline Code family & Related codes \\
\hline $\begin{array}{l}\text { Leadership } \\
\text { for learning }\end{array}$ & $\begin{array}{l}\text { 1. Focuses on curriculum } \\
\text { 2. Focuses on teaching } \\
\text { 3. Focuses on classroom } \\
\text { 4. Focuses on student } \\
\text { 5. Focuses on performance data } \\
\text { 6. Values staff development } \\
\text { 7. Values personal lifelong learning; personal mastery } \\
\text { 8. Spends much time in the classroom } \\
\text { 9. Believes supt. must learn all organizational functions, but prioritize instructional leadership }\end{array}$ \\
\hline $\begin{array}{l}\text { Leadership } \\
\text { for social } \\
\text { justice }\end{array}$ & $\begin{array}{l}\text { 1. Focuses on underrepresented populations (both students and community members) } \\
\text { 2. Expresses need to change an injustice in the schools with respect to special populations } \\
\text { 3. Stands up against or protested injustice } \\
\text { 4. Expresses strong emotions regarding negative perceptions of minorities } \\
\text { 5. Repeatedly mentions equity } \\
\text { 6. Uses examples of racism or discrimination to emphasize commitment to education } \\
\text { 7. Expresses pride in improving disparate conditions of students of color in her district }\end{array}$ \\
\hline $\begin{array}{l}\text { Relational } \\
\text { leadership }\end{array}$ & $\begin{array}{l}\text { 1. Minimizes or disdains positional power or authority } \\
\text { 2. Expresses no need or desire for power or authority } \\
\text { 3. Gives credit to others } \\
\text { 4. Prefers consensus building } \\
\text { 5. Makes unilateral decisions only when forced or compelled } \\
\text { 6. Is highly collaborative } \\
\text { 7. Describes community building } \\
\text { 8. Encourages diverse perspectives }\end{array}$ \\
\hline $\begin{array}{l}\text { Spiritual } \\
\text { leadership }\end{array}$ & $\begin{array}{l}\text { 1. Expresses passion for "the work" } \\
\text { 2. Sees the job as service } \\
\text { 3. Reflects upon work as a higher calling } \\
\text { 4. Expresses commitment above self } \\
\text { 5. Values emotional or mental self-work } \\
\text { 6. Sees work as a mission } \\
\text { 7. Calls on inner strength and core beliefs to withstand difficulties of the job } \\
\text { 8. Calls on religious foundation to clarify vision and mission }\end{array}$ \\
\hline $\begin{array}{l}\text { Balanced } \\
\text { leadership }\end{array}$ & $\begin{array}{l}\text { 1. Mentions balance as an asset, not a struggle } \\
\text { 2. Sees and uses family as source of strength and support } \\
\text { 3. Views family as not in conflict with job } \\
\text { 4. Has exerted effort to maintain emotional or physical well-being } \\
\text { 5. Describes healthy personal or family relationships } \\
\text { 6. Uses healthy family relationships to enhance work relationships } \\
\text { 7. Mentions ethic of care for both work and family relationships }\end{array}$ \\
\hline $\begin{array}{l}\text { Systems- } \\
\text { thinking } \\
\text { leadership }\end{array}$ & $\begin{array}{l}\text { 1. Focuses on human systems within the organization } \\
\text { 2. Focuses on organizational psychology } \\
\text { 3. Believes structure impacts function } \\
\text { 4. Recommends training for collaboration and shared decision making } \\
\text { 5. Mentions training for management on interpersonal relationships and on including diverse perspectives } \\
\text { 6. Encourages principles of a learning organization } \\
\text { 7. Uses outside consultants familiar with business organizational management or team building for training }\end{array}$ \\
\hline $\begin{array}{l}\text { Change } \\
\text { leadership }\end{array}$ & $\begin{array}{l}\text { 1. Did not aspire to supt. role because of negative perception of the role } \\
\text { 2. Believed the supt. role was more political than focused on teaching, learning, and effecting change } \\
\text { 3. Discussed functional differences with predecessor; disagreed with traditional concept of the role } \\
\text { 4. Wanted more contact with students, teachers, and families } \\
\text { 5. Wants more direct impact on classrooms and instruction } \\
\text { 6. Desires to disrupt status quo } \\
\text { 7. Sees role as agent of change, not merely manager of facilities and budget } \\
\text { 8. Reverses traditional priorities of politics, money, and facilities to kids, classrooms, teachers, and community }\end{array}$ \\
\hline
\end{tabular}


As noted in Table 4, code family headings were the leadership priorities and behaviors that Grogan and Shakeshaft identified in their "five ways women lead." In addition to their five categories, two additional code family headings were added: "systems-thinking leadership" and "change leadership," or changing the superintendent's role as a leader for positive change. As the superintendent responses were coded, notes were made to clarify reasons for the coding. The refined coding of the responses served to organize the data, interpretations, and connections to existing literature, analysis, and conclusions of the study.

Case study is strengthened by establishing "converging line of inquiry" as a result of multiple forms of data coming together within the same set of findings. The researcher placed the results of the demographic questionnaire into a table for analysis and to enable patterns pertaining to personal characteristics to emerge. 
Table 5

Participant Demographic Results Chart

\begin{tabular}{|c|c|c|c|c|c|c|c|c|c|}
\hline \multirow[b]{2}{*}{ Superintendent } & \multirow[b]{2}{*}{ Race } & \multirow{2}{*}{$\begin{array}{l}\text { Relationship } \\
\text { status }\end{array}$} & \multirow{2}{*}{$\begin{array}{c}\text { Current } \\
\text { age } \\
\end{array}$} & \multirow{2}{*}{$\begin{array}{c}\text { Age } \\
\text { became } \\
\text { supt. }\end{array}$} & \multirow{2}{*}{$\begin{array}{l}\text { Years supt. } \\
\text { in current } \\
\text { district }\end{array}$} & \multicolumn{3}{|c|}{ District } & \multirow[b]{2}{*}{ Doctorate } \\
\hline & & & & & & Name & Type & Size & \\
\hline Patricia Patterns & Caucasian & Married & 49 & 47 & 2 & Cardiff Hills Union & $\mathrm{K}-8$ & $10,000-20,000$ & yes \\
\hline Sandy Structure & Caucasian & Married & 60 & 53 & 2 & Solano Bay Unified & $\mathrm{K}-12$ & $10,000-20,000$ & yes \\
\hline Mary Mediator & Caucasian & Married & 61 & 46 & 7 & Granite Gulch Unified & $\mathrm{K}-12$ & $10,000-20,000$ & yes \\
\hline Constance Culture & Caucasian & Married & 53 & 50 & 3 & $\begin{array}{l}\text { El Capitan Union } \\
\text { Elementary }\end{array}$ & $\mathrm{K}-8$ & $10,000-20,000$ & no \\
\hline Terry Teacherfirst & Caucasian & Married & 65 & 57 & 7 & $\begin{array}{c}\text { Freedom Valley Union } \\
\text { High }\end{array}$ & $9-12$ & $10,000-20,000$ & no \\
\hline Elizabeth Engager & Caucasian & $\begin{array}{l}\text { Single, } \\
\text { divorced }\end{array}$ & 64 & 38 & 3 & Santa Vista Springs & $\mathrm{K}-8$ & $10,000-20,000$ & yes \\
\hline Carrie Community & Caucasian & Married & 63 & 55 & 7.5 & $\begin{array}{c}\text { Margarita Meadows } \\
\text { Unified }\end{array}$ & $K-12$ & $4,000-5,000$ & no \\
\hline $\begin{array}{l}\text { Barbara } \\
\text { Breakingthemold }\end{array}$ & Caucasian & Married & 48 & 44 & 4 & Live Oak Unified & $\mathrm{K}-12$ & $10,000-20,000$ & yes \\
\hline Susan Systems & $\begin{array}{l}\text { Middle } \\
\text { Eastern }\end{array}$ & Married & 56 & 52 & 4 & Pilgrim Park Unified & $K-12$ & $10,000-20,000$ & no \\
\hline
\end{tabular}

Note: Names of superintendents and school districts have been fictionalized. All participants identified themselves as heterosexual, and all have children. 
The third source of data was the document review of the superintendents' curricula vitae and/or résumés. Both the demographic questionnaire and the document review of participant résumés were used to evaluate barriers and facilitators embedded in personal characteristics, career pathways, personal mastery, and public distinction and/or fame. The researcher performed cross-case analysis of document data and used the resulting patterns to provide a richer context by which to portray possible factors contributing to the successful ascendancy and successful execution of the superintendency. 
Table 6

Career Pathway Chart: Curricula Vitae/Résumés

\begin{tabular}{|c|c|c|c|c|c|c|c|c|c|c|c|c|c|c|c|c|}
\hline \multirow[b]{2}{*}{ Superintendent } & \multicolumn{5}{|c|}{ Site responsibilities (years in position; school type) } & \multicolumn{4}{|c|}{$\begin{array}{l}\text { District office responsibilities (years in } \\
\text { position; school type) }\end{array}$} & \multicolumn{3}{|c|}{$\begin{array}{c}\text { Outside K-12 } \\
\text { responsibilities (years) }\end{array}$} & \multicolumn{4}{|c|}{ Personal mastery } \\
\hline & Teacher & $\begin{array}{l}\text { Guidance } \\
\text { counselor }\end{array}$ & $\begin{array}{c}\text { Vice } \\
\text { principal }\end{array}$ & Principal & $\begin{array}{l}\text { Dept. } \\
\text { chair; } \\
\text { athletics }\end{array}$ & Coordinator & $\begin{array}{l}\text { Dir. } \\
\text { curr. and } \\
\text { inst. }\end{array}$ & $\begin{array}{l}\text { Asst. } \\
\text { supt. }\end{array}$ & Supt. & $\begin{array}{l}\text { Adj. } \\
\text { prof. }\end{array}$ & Prof. & Consultant & $\begin{array}{l}\text { Contínaing } \\
\text { professional } \\
\text { development }\end{array}$ & Awards & $\begin{array}{l}\text { Professional } \\
\text { networks }\end{array}$ & $\begin{array}{l}\text { M.A.; } \\
\text { E.d.D. }\end{array}$ \\
\hline Patricia Panterns & $\begin{array}{l}5 ; \text { middle, } \\
\text { high }\end{array}$ & & 4; high & 5 ; high & & & 1 year & $\begin{array}{c}6 ; \\
K-12\end{array}$ & $\underset{K-8}{2 ;}$ & 7 & & 6 & $\begin{array}{l}22 \text { sig. } \\
\text { trainings }\end{array}$ & $\begin{array}{c}\text { ACSA prin. of } \\
\text { year; ACSA admin. } \\
\text { of year }\end{array}$ & $\begin{array}{l}\text { ACSA; ASCD; } \\
\text { NASSP }\end{array}$ & Both \\
\hline Sandy Structure & $\begin{array}{l}\text { 14; middle, } \\
\text { high }\end{array}$ & & $\begin{array}{l}2 \text { years: } \\
\text { middle }\end{array}$ & $\begin{array}{l}\text { 11; } \\
\text { elementary, } \\
\text { high }\end{array}$ & & 1 & & $\begin{array}{c}3 ; \\
k-12\end{array}$ & $\begin{array}{c}6 ; \\
K-12\end{array}$ & 1 & 2 & & $\begin{array}{l}15 \text { sig. } \\
\text { trainings }\end{array}$ & $\begin{array}{l}\text { ACSA admin. of } \\
\text { year; Phi Kappa } \\
\text { Phi; PTA vol. of } \\
\text { year }\end{array}$ & $\begin{array}{c}\text { ACSA; } \\
\text { Kiwanis; } \\
\text { Lions; Rotary }\end{array}$ & Both \\
\hline Mary Mediator & $\begin{array}{c}6 ; \\
\text { elementary }\end{array}$ & & & & & $\begin{array}{c}5 ; \\
K-12\end{array}$ & $\begin{array}{c}6 ; \\
k-12\end{array}$ & $\begin{array}{c}6 ; \\
K-12\end{array}$ & $\begin{array}{c}14 ; \\
K-12\end{array}$ & & & & $\begin{array}{l}15 \text { sig. } \\
\text { trainings }\end{array}$ & $\begin{array}{c}\text { ACSA admin. } \\
\text { of year; Teacher } \\
\text { of Merit; fellow } \\
\text { UCSB }\end{array}$ & AASA; $\mathrm{ACSA}$ & Both \\
\hline $\begin{array}{l}\text { Constance } \\
\text { Culture }\end{array}$ & $\begin{array}{l}10: \\
\text { elementary }\end{array}$ & & $\begin{array}{c}3 ; \\
\text { dementary }\end{array}$ & $\begin{array}{c}4 ; \\
\text { elementary }\end{array}$ & & & $\begin{array}{c}4 ; \\
K-8\end{array}$ & $\begin{array}{l}3 ; \\
K-8\end{array}$ & $\begin{array}{c}3 ; \\
K-8\end{array}$ & & & & $\begin{array}{l}10 \text { sig. } \\
\text { trainings }\end{array}$ & & $\begin{array}{l}\text { ACSA; ALAS; } \\
\text { ASCD; } \\
\text { FCMAT board }\end{array}$ & M.A. \\
\hline Terry Teacherfirst & $7 ;$ high & 6; high & 4: high & & & $4 ; 9-12$ & $4 ; 9-12$ & 4 & 7 & & & & & & $\begin{array}{l}\text { Chamber; } \\
\text { Rotary }\end{array}$ & M.A. \\
\hline $\begin{array}{l}\text { Carrie } \\
\text { Community }\end{array}$ & $\begin{array}{c}10 ; \\
\text { clementary }\end{array}$ & & 3 & & & $\begin{array}{c}7 ; \\
k-12\end{array}$ & $\begin{array}{c}3 ; \\
k-12\end{array}$ & & $\begin{array}{c}7 ; \\
k-12\end{array}$ & & & 4 & & $\begin{array}{l}\text { County, Rotary } \\
\text { teacher of year }\end{array}$ & Rotary & M.A. \\
\hline $\begin{array}{l}\text { Barbara } \\
\text { Breakingthemold }\end{array}$ & $\begin{array}{l}12 ; \\
\text { elementary, } \\
\text { middle, high }\end{array}$ & & & $\stackrel{2 ;}{2 ;}$ & $\begin{array}{c}\text { 6; } \\
\text { middle }\end{array}$ & $\begin{array}{l}2 ; \\
\text { middle }\end{array}$ & $\begin{array}{c}3 ; \\
k-12\end{array}$ & $\begin{array}{c}3 ; \\
k-12\end{array}$ & $\underset{K-12}{4 ;}$ & & & & $\begin{array}{l}49 \text { sig. } \\
\text { trainings }\end{array}$ & $\begin{array}{l}\text { ACSA admin. of } \\
\text { year, teacher of } \\
\text { year; summa cum } \\
\text { laude, magna cum } \\
\text { laude UCB }\end{array}$ & $\begin{array}{c}\text { ACSA: } \\
\text { AERA; } \\
\text { ASCD; } \\
\text { Rotary; com. } \\
\text { advisory } \\
\text { board }\end{array}$ & $\begin{array}{l}\text { Both; } \\
\text { Ed.D., } \\
2015\end{array}$ \\
\hline Susan Systems & $\begin{array}{c}12 ; \\
\text { elementary }\end{array}$ & & $\begin{array}{c}1 ; \\
\text { elementary }\end{array}$ & $\begin{array}{c}5 ; \\
\text { elementary }\end{array}$ & & & $k^{3 ;} ;$ & $\begin{array}{c}3 ; \\
K-12\end{array}$ & $\underset{k-12}{4 !}$ & & & & & & $\begin{array}{l}\text { ACSA; ASCD; } \\
\text { Soc. for } \\
\text { Organiza- } \\
\text { tional } \\
\text { Learning; } \\
\text { Chamber; } \\
\text { com, hoard } \\
\text { member }\end{array}$ & M.A. \\
\hline
\end{tabular}

Note: Names of superintendents have been fictionalized. 


\section{Chapter Summary}

This chapter presented the research design, which used a multiple case study methodology. The unit of analysis was the experiences of the female superintendents working within four counties in Northern California. The setting for performing data collection was authentic, familiar, and convenient for all participants. In all but two cases, this location was the superintendent's office. The participants were informed of the research process at multiple points of the study, starting with the letter of introduction, face-to-face prior to the commencement of the interview session, and during the member checking process. All participants were warm, gracious, and open. Informal member checks were performed during the interview, providing the researcher with confidence in the reliability of the data. Validity was strengthened by peer review and multiple data sources.

Data inquiry and analysis were achieved through thematic coding of transcribed text. During data reduction, thematic codes and families were prescribed to Grogan and Shakeshaft's (2011) “five ways women lead," and thematic codes and families were identified as additional themes emerged. Furthermore, a cross-case examination aided the researcher in distinguishing patterns in the career pathway experiences of the participants. The documentation of both emergent leadership themes and leadership themes aligned with the "five ways women lead" led to findings presented in Chapter 4 and the conclusions presented in Chapter 5. These findings should deepen the understanding of the leadership behaviors leading to the successful ascendancy and the successful execution of the position of superintendent for female educational leaders. These findings 
should also add to the discourse on change leadership for both men and women that would contribute to positively impacting student achievement and equity in $\mathrm{K}-12$ education. 


\section{CHAPTER 4. PROFILES OF THE NINE FEMALE SUPERINTENDENTS}

Introduction

This chapter presents a narrative of each of the superintendents and their districts, as perceived by them and shared with the researcher during the interviews. Elements of each superintendent's leadership styles and behaviors and several relative elements will be evident. The successful female superintendents were identified by the success of their districts in the California Academic Performance Index (API) growth for a minimum of two years during their tenure up to 2013. Selection criteria also included minimum size of district and inclusion of secondary schools within each district narrowed the eligible participant pool to only $15 \%$ of the superintendents in four Bay Area counties. The use of codes for the female superintendents and fictitious names for their districts maintains confidentiality. In this study, superintendents initially identified as superintendents " 1 through 9," and their true districts, have been given the following pseudonyms:

1. Patricia Patterns, Cardiff Hills Union

2. Sandy Structure, Solano Bay Unified

3. Mary Mediator, Granite Gulch Unified

4. Constance Culture, El Capitan Union Elementary

5. Terry Teacherfirst, Freedom Valley Union High

6. Elizabeth Engager, Santa Vista Springs

7. Carrie Community, Margarita Meadows Unified 
8. Barbara Breakingthemold, Live Oak Unified

9. Susan Systems, Pilgrim Park Unified.

\section{$\underline{\text { Successful Female Superintendents }}$}

Patricia Patterns, Cardiff Hills Union School District

Patricia Patterns was selected for participation in the study because of her district's API growth and the large size of her district, as shown in Table 7.

Table 7

Demographics and Academic Performance, Cardiff Hills Union School District

\begin{tabular}{|ll|}
\hline Grade span & $\mathrm{K}-8$ \\
\hline Enrollment & 19,194 \\
\hline Number of schools & 15 \\
\hline Ethnicity & \\
White & $18 \%$ \\
Hispanic & $5 \%$ \\
African American & $1 \%$ \\
Asian & $73 \%$ \\
Other & $3 \%$ \\
\hline English learners & $12 \%$ \\
\hline Free/reduced-price meal program & $5 \%$ \\
\hline Superintendent tenure & 2 years; started 2011 \\
\hline API at start of tenure & 951 \\
\hline 2013 API & 962 \\
\hline API growth & 11 \\
\hline
\end{tabular}

Cardiff Hills Union School District is a K-8 district comprising 25 elementary and middle schools crossing multiple, mostly suburban communities in the Bay Area. It has earned a reputation for providing students with a solid educational foundation. It serves a population of 19,194 students: 18\% White, 73\% Asian (including East Indian, Japanese, Chinese, and South East Asian), 5\% Hispanic, and 1\% African American. 
Their school community is a diverse representation of some lower, but predominantly upwardly mobile middle and upper socioeconomic levels, residing in primarily singlefamily dwellings with a spattering of condominiums and apartments. The majority of parents work in professional and semiprofessional occupations.

The schools within the district are described by the superintendent, Patricia Patterns, as "high flying" and "off the charts" compared to districts in which she previously served. Most of the schools are California Distinguished Schools, and a few have been recognized nationally as National Blue Ribbon Schools because of their high performance on mandated California state standardized tests. Patricia expresses pride in the work she has done to "open the district" and bring the voices of the staff and community together to be part of an "open system" and points to the mission of the district, which claims "to provide a child-centered environment that cultivates character, fosters academic excellence, and embraces diversity. District families, community and staff join as partners to develop creative, exemplary learners with the skills and enthusiasm to contribute to a constantly changing global society."

Patricia Patterns is a self-proclaimed morning person, so at her convenience, our interview took place very early in her central office suite before any other employee arrived. The first impression of delicacy and insubstantiality from her bespectacled small stature and demure comportment during introductions was quickly betrayed when she began to field questions she seemed born to answer. With each follow-up question, her escalating tone of conviction and animated display of assuredness, tempered by warmth and humor, belied her age or any self-limiting, gender-prescribed proclivities. Regardless 
of her confidence and charisma, she still encounters gender discrimination in the form of being talked over, dismissed, or "mistaken" for the assistant superintendent. These situations most often arise when she is traveling with male members of her cabinet and meets new male superintendents, or in discussions with other male superintendents, or when gendered topics prevail, such as facility issues, construction bonds, parcels tax campaigns, or other budget-related issues or topics. Although she still expresses incredulity that the gendered role expectations still exist, she has learned to use humor and her love of sports, especially of golf and of the Giants baseball team, to "enter the ring" with male peers.

Patricia says that others, including her board members, would describe her as calm and "centered," and she acknowledges that being a cancer survivor has strengthened her belief that things will usually work out in the end and to differentiate between the "little problems" and the "big problems." With both the large and the small issues, people can expect she will respond with:

“Okay, we'll take care of it. It's going to be all right." .. . Even my board members know I don't let negative energy into the space ... people spend lots of time worrying or predicting negative [consequences]. . . Let's talk about what is actually happening; let's not talk about what isn't happening. We call it "the stories we tell ourselves." We tell ourselves lots of stories, but they're stories! They're not grounded in evidence. I try to approach it from evidence. Questions about her leadership approach took her back to her steadfast focus on "the work" and the importance she puts on the ability to see patterns in relationships, 
especially in an organization. She defines "the work" in a manner that evokes a mission or a calling when she goes on to say, "I think people who either work with me or have interacted with me know that, and 'the work' means the kids, not all of us as adults."

At 49, Patricia is the second youngest sitting superintendent in this study's participant pool, and Cardiff Hills Union School District is her first superintendency. She has been serving in this district for two and a half years. She came to this district having previously served as chief academic officer and area superintendent (network executive officer) in large $\mathrm{K}-12$ districts in an adjacent county for six years. She also served as high school principal in two large, comprehensive high schools giving her critical "line" experience for a female in leading large staffs, student populations, and facilities, and she taught for five years, providing her with key classroom experience. Less typical of a female superintendent's career path was her significant stint outside of K-12 public education in the roles of principal coach, senior research associate, and senior consultant and professional development specialist in both for-profit and nonprofit educational agencies. Patricia describes the difficult and painful decision to move outside of $\mathrm{K}-12$ education as not so much a choice, but as being "thrown out" of the system. She related a story pivotal to her career surrounding her first principalship.

Patricia Patterns became a high school principal at the young age of 32 and ambitiously went about enacting many reforms centering on improving access to college preparatory coursework for Latinos and English learners in a semirural, agricultural community. When multiple upper-class white parents began to protest this detracking effort, her superintendent visited her moments before a board meeting and informed her 
that the board was going to vote to remove the Latino students from the honors and AP classes they were taking. Horrified at the thought of "looking the students in the eyes" and telling them "you can't go in that room because of who you are," she told him, "I'm not going do it. I won't do it. That's not going to be me," and she quit in protest.

This incident, according to Patricia, caused her to be blacklisted as she tried numerous times to interview for new principal positions. She described:

making it all the way through the interviews, and when I'd hit the super, they'd say, “Okay, okay, you now are going have an interview with the superintendent." I'd say, "great." And--three times in a row?-I'd get called up after the interview was set up and get told it was cancelled. They'd set them up and then they would cancel. So, I realized, “Okay, I can't. I can't go on in a school district right now."

Being shut out of the system proved to be decisive to her career pathway, and she also associated this episode, and the direction it took her career, to key foundations of her leadership style. When she secured consulting and coaching jobs, they took her to multiple districts throughout the state. The opportunity to look from the outside in, in her various experiences in different districts, gave her the ability to see the bigger picture and to see the commonalities and "patterns" that emerged. When she was forced into "seeing a broader system," she stated emphatically,

That's when I started to be able to make the link to systems. I really started to look at it and say, "Okay, this is a systems issue. It's not me. It's not them. It's not a union. It's not any of that. It's the systems," and part of 
dealing with that are the structures that are in place for us, and structures force our function.

She realized this is when she started looking at things differently and started questioning how one approaches leadership and reform from more of a systems perspective. She described the revelation that organizational problems are not simply intrinsic to certain personalities and politics within faculties or communities, but instead usually exist because "It was set up that way! If you set up a structure, oftentimes you're going to get what the structure is going to yield." Consequently, coming in from the periphery, according to Patricia, actually helped her in the end, because being "thrown out" enhanced her ability to see:

I don't think that ever would have happened to that degree had I not [been outside the system], and I tell a lot of people now, ... "Sometimes you need to step away from it or at least move districts." Sometimes people stay in the same spot all the time, and they can't see anymore. They stop seeing.

When Patricia Patterns came to Cardiff Hills Union School District after this enlightening experience of consulting and helping to operationalize change within many school systems, she instantly saw some of the same patterns in her new district. Even though her district was "high flying," with scores "off the charts, it didn't mean our instruction was." When she saw a "system of rows and silence," she was shocked and sick about it for two months. Her instinct, as she realized it meant "our kids get a lot of stuff outside of our schools . . from their parents," was to keep her new insight to herself 
while she learned about the organization that institutionalized this type of learning. Luckily for her, she reflected, she brought with her the ability to see the larger system critical to fostering the kind of collective leadership needed to enact large-scale, sustainable change.

She believes educational improvement doesn't start with the classroom, but with the management. Patricia explained,

We had to start with management because if the managers are not going to make that shift and didn't understand ... and I go in a meeting and don't know how to head towards a decision of an area and identify a problem for adaptive action, then we're all in trouble, right? Then, we are all going spin.

Management needs to lead the change, and this means, according to Patricia, they are taught about keeping the focus of the work about kids and how the relational aspect is going to help move her organization in the right direction. Patricia emphasizes that it's about "empowering the people you're with-building strong teams and empowering them."

Once the managers at all levels - cabinet, principals, directors, and maintenance and operations - know how to facilitate discourse and problem solving that "builds on assets of self and others and engages in joyful practice," Patricia expanded her scope. Gathering the teachers and staff together to share problems of practice, she commenced with the same mind-set when developing professional learning communities among her teaching staff. As Patricia continued to reflect on her most powerful impact on student 
achievement, she described how she brought teachers together monthly for learning over a three-year period:

Starting with "how do we learn together; who are you as a team?" and "what do we need to do?" and "what happens when you go back?" But, every morning for that whole day we were learning together, and then every afternoon they were tasked with the "now what?" "So you learned this, is now the right time to bring it back?" "So how are you going to do that?" "If not, then what are you working on, and how do you move towards this learning; how do you integrate it into what you're doing?" ... and then you would share out, so you were always accountable.

Patricia Patterns explained that the key to the effectiveness to the aforementioned professional learning community (PLC) session was what happened preceding that day. Once a month she would take three to four members from each team, including the principal, and she would converge upon a school and visit every classroom in the school. Each of the teams would go to about five classrooms. Before they headed out to the rooms, that school's leadership team would tell the visiting team what they were currently working on and what they wanted them to look for. Then they were asked to look for evidence, being careful not to talk about any particular teacher, so there would be no judgment. It was purely evidence. The observing team, Patricia explained, was trained to "either see it or . . hear it, and if you don't see it or hear it, it didn't happen." The individuals in each team would be assigned a particular role when they went into the room-one person would observe only the teacher, another would observe only the 
students, another would observe the room environment, and another would observe equity. In tandem, they had an equity coach working with those teams during that full day of learning. During the debrief, the team would create charts of all the evidence for their five rooms. This became a way of seeing what was happening and understanding the patterns in the whole school. The leadership team would then take its information and decide how to share it with staff and use it with subsequent professional development. This process was performed every single month for three years and, according to Patricia, it is still happening.

This example of sustainable reform that deeply impacted student achievement in her district was an example of a systems approach, and tending to the systems takes paying attention. According to Patricia Patterns, “you're paying attention to patterns. That's our job as leaders: to see, understand, and influence patterns because everything is a pattern. Trust is a pattern. It's not a thing out there; it's a pattern." A final pattern Patricia described, with a note of pride, was her weekly staff recognition. She began publically recognizing teachers, staff, and administrators for inspiring acts that she had witnessed or heard about; her weekly kudos led to the amazing phenomenon of employees around the district recognizing each other and anticipating the accolades of good works across the organization. It all goes back to seeing that everything people do at work is a function of the greater system and therefore one must learn to see all patterns that emerge as symptomatic of the organizational structure, which is composed of many interdependent and nested human systems with their own histories, agendas, and norms. 
Sandy Structure, Solano Bay Unified School District

Sandy Structure was selected for participation in this study because of the API growth of Solano Bay Unified School District during her tenure as superintendent and the qualifying size and type of her district, as shown in Table 8.

Table 8

Demographics and Academic Performance, Solano Bay Unified School District

\begin{tabular}{|ll|}
\hline Grade span & $\mathrm{K}-12$ \\
\hline Enrollment & 14,600 \\
\hline Number of schools & 25 \\
\hline Ethnicity & \\
White & $22 \%$ \\
Hispanic & $37 \%$ \\
African American & $4 \%$ \\
Asian & $24 \%$ \\
Other & $15 \%$ \\
\hline English learners & $28 \%$ \\
\hline Free/reduced-price meal program & $46 \%$ \\
\hline Superintendent tenure & 2 years; started 2011 \\
\hline API at start of tenure & 777 \\
\hline 2013 API & 783 \\
\hline API growth & 6 \\
\hline
\end{tabular}

Solano Bay Unified School District is a midsize district comprising 25

elementary, middle, high, and alternative schools serving approximately 15,450 students in the Bay Area. The district provides schools for a mostly suburban city south of San Francisco. Remnants of the city's roots in agriculture and missions are barely evident. Visitors would see mostly urban sprawl from many successful industries claiming the city as their home. The district receives a healthy amount of parcel tax revenue typical of local business success and rising home prices. The variety of businesses more recently occupying this city has brought increased diversity. Approximately $37 \%$ of the students 
are Hispanic, 22\% White, 24\% Asian, and 4\% African American, and 15\% identify as other or multirace. Twenty-eight percent of the students are classified as English learners, and $46 \%$ receive federally funded free or reduced-price meals for socioeconomic status.

Sandy Structure served this district for two years and recently retired from $\mathrm{K}-12$ public education at age 60 to work in higher education. She acted as superintendent for a total of seven and a half years, and Solano Bay Unified was her third and final superintendency. Sandy's career pathway included significant time in the secondary classroom (13 years in middle and high school) and a long, winding path of both line and staff positions, which include secondary vice principal, alternative high school principal, and assistant superintendent of educational services and human resources. According to Sandy, her path to superintendent was somewhat meandering in part because she purposely waited until her children were grown and in part because she never intended to become a superintendent. An outgoing superintendent eventually convinced her to seek the job, but she insisted that the position didn't initially appeal to her, as she truly preferred to stay closer to the classroom, the teachers, and the kids. In reflection, she felt that for her, seeing the "juxtaposition from a bad administrator to a good administrator was really pivotal. It's really what made me go into administration. And then, as an assistant superintendent, having a horrible superintendent.”

When asked about her leadership, she began with her moral purpose and then circled back to her own need for structure and clarity and modeling of expectations. She passionately described a deep belief in public education and "always being grounded in the belief that public education is one of the most important things we can do for a 
democracy and for our nation ... and I really believe that." She goes on to describe herself as a

very linear, anal person. I like things to be very laid out and very structured, and I think people appreciate when they know what the expectations are, and I think you can hold people accountable. ... It's not fair to hold them accountable if you don't lay out expectations.

Understanding that there's a comfort and a confidence in structure, she also admitted, cautiously, following my probing questions, that she couldn't have earned the kind of loyalty and respect from her employees and the community to make impactful change by accountability and moral imperative alone. They needed to sense something even more important in her leadership: her commitment to them, and her caring for them. She stated circumspectly,

I cared about what we did. I cared about the people that I worked with. . . Maybe this was part of it, too; as a superintendent I felt a huge responsibility to care for and protect ... the students and the employees of our district. I felt that was my job.

In the same breath, Sandy was quick to qualify her caring. It was important for her to be clear about her "caring" and to distinguish her ethic of care from being a "softy" or "nice all the time." In fact, her care could easily take the form of fierce protection or fearlessly standing up for people: 
I certainly wasn't the touchy-feely 'huggy-huggy, kissin', 'Oh my God, their cat died, so let's buy 'em roses ..."' That's not me, but I will be the first one to protect you from a board member who screamed at you. You know I will be the first one to say, "No, no, no, we're not going to ask our teachers to work an extra five hours this week, because they already put in twenty hours last week; let's all think about this differently."

An additional example of her qualified form of caring and commitment was her role in her district's first successful parcel tax campaign, which she relayed jubilantly as her proudest accomplishment. She believed it was critical that the superintendent was "hands-on" working in the trenches. She stated emphatically, "you have to be in the trenches with people. You have to be there to get those stakeholders involved." So, for example, with the parcel tax campaign, "I lived there for four months. I was there every night."

For Sandy, improving academic achievement at the superintendent level meant more than being visible and setting a vision from above. She described not only needing to believe in "those kids," but also having the curriculum and instruction background to know how it was going to get done and what resources would be needed. Sandy seemed to say that the superintendent couldn't simply be the figurehead and politician, but also needed to genuinely take part in and understand the work that needed to be done:

It was a social justice thing on the one hand, because it meant supporting those kids to meet those expectations and believing they could do it, and then it was the 
technical piece of "This is how it works. This is how you do it." So in order for the principals to be giving the message, they had to hear it from me, too. Everybody needed to know that we were all on the same page.

To Sandy, leadership for learning and social justice goes hand in hand. She believed that you can't help the neediest kids by caring and empathy alone; in fact, empathy was implied to be the enemy of equity in her experience. As an example, she described a distraught teacher in her office, pleading with her in tears:

"You don't love these kids if you give them all these formative assessments." It was a huge endeavor to get past mental attitude about the kids and the families, and it was a huge leap for that district. It was huge. Major changes to how teachers taught English learners and the assessments and data they had to inform instruction. It was the big curricular stuff that changed the direction of the district and me being in the fray right there with them.

During initial stages of the interview, Sandy did not offer up evidence of barriers and facilitators to her success. However, when pressed, she offered up, almost reluctantly, that she had been told by her lawyer, after a successful series of negotiations, that she was very "engaging," and this, as she reflected upon it, had probably made it easier for her to traverse some political scenarios, especially in a male-dominated role. Sandy also referenced as "capital" her knowing when to "shut up." Other personal skills she mentioned included learning to navigate a political scene and climb an administrative career ladder; also, her not being a "whiner," and not being "a shrinking violet or 
obnoxious," yet also not being afraid to "speak up." She felt like she "read [situations] pretty well and that was an advantage for her." It appeared that she was keenly aware of gender perceptions, both the positive and negative attributions that can be ascribed to women, and "capital" for her was guarding herself against falling into the prescribed traps of female stereotypes.

She also credited her family with a great role in her success. She and her husband, she said, have a "great partnership," and she reflects on her son's influence with "thanks," for he helped her to more easily be "one of the boys." He is a college coach, and he invited her to participate in more "male conversations" than she could begin to relate. Because she can "talk sports" and has lived in "that world of athletics and kind of maleness," she feels it has served her very well. "I can play with the boys, and that is important."

Sandy concluded her reflections upon her leadership with an illustration of what "community" meant to her. She related the exhilarating experience of a "true community effort," how it had empowered her ability to make positive measureable change, and how it had enabled her to make the difficult decisions that correspond with sustainable change efforts when she knew the "community was behind me." It was a

very awesome thing to watch the teachers, the union, the classified staff, kids, parents, and local retirees totally work their asses off . . because we were really concerned about our financial state and what we would be able to provide kids as far as their education, and I think that's why it [the parcel tax] passed. 
She did a lot of work out in the community, talking to groups, forging partnerships, and gathering resources, so when there was a difficult situation with the board or something she needed to get passed with the board, "I knew I had the community behind me."

Mary Mediator, Granite Gulch Unified School District

Mary Mediator was selected for participation in the study because of the API growth during her tenure and the size, type, and location of her district, shown in Table 9.

Table 9

Demographics and Academic Performance, Granite Gulch Unified School District

\begin{tabular}{|ll|}
\hline Grade span & $\mathrm{K}-12$ \\
\hline Enrollment & 11,290 \\
\hline Number of schools & 17 \\
\hline Ethnicity & \\
White & $19 \%$ \\
Hispanic & $72 \%$ \\
African American & $1 \%$ \\
Asian & $3 \%$ \\
Other & $5 \%$ \\
\hline English learners & $28 \%$ \\
\hline Free/reduced-price meal program & $52 \%$ \\
\hline Superintendent tenure & 7 years; 2007-2013 \\
\hline API at start of tenure & 731 \\
\hline 2013 API & 804 \\
\hline API growth & 73 \\
\hline
\end{tabular}

Granite Gulch Unified School District is a midsize K-12 school district

comprising 17 elementary, middle, high school, and alternative education schools and located in a more rural area outside of the Bay Area. The community is known for its thriving agriculture industry; its peaceful residential environment; its award-winning parks, golf course, and recreation programs; and its "urban forest," for which the city has 
won Tree City USA awards annually since 1979 . Approximately $72 \%$ of the students are Hispanic or Latino, $19 \%$ are White, $3 \%$ are Asian, and 1\% are African American; $5 \%$ identify as multiple race or other. Twenty-eight percent are English learners, with most speaking Spanish. Fifty-two percent of the students qualify for free or reduced-price meals. The district has a history of politically active parent organizations and of strife arising from the community's significant socioeconomic and racial divides. However, recently, according to Mary, the community has been positively and proactively involved in volunteering at many school campuses.

Mary has served as superintendent in this district for the past seven years and at age 61 hopes to retire from this district, now that much of her hard work has paid off: There have been significant gains in student achievement, and "coming election pending," there has been peace and accord among board members and the community. Also, her cabinet and administrators, mostly of whom were hired by her, are increasingly competent and "on the same page." Granite Gulch is Mary's third superintendency, and 2015 will usher in her 15 th year as a superintendent. Each of her previous districts, in Southern California, had been midsize (15,000 and 11,000 respectively) and unified (inclusive of high schools), which is traditionally more predominantly the domain of male superintendents. As she prepares to enter her eighth year at Granite Gulch, she will surpass her longest tenure as a superintendent by four years. Her perception is that there is a strong correlation between her length of tenure and her ability to enact sustainable improvement measures. The data support her assertion as she has the highest growth increase of the participant pool, with a whopping 72-point API growth, and one of the 
longest tenures as superintendent. The two other superintendents in this study who have served for seven years made the second and third highest API increases, with 62 and 40 points respectively.

Mary attributed athletics and sportsmanship for part of her successful career ascendancy, as a way to transcend gender barriers and a key foundation on which many leadership behaviors lie. She even referenced her own dissertation research on female educational leaders by espousing "a lot of the women that were successful had also been athletes and members of a team all their lives, which is certainly my case." When she reflected upon her career, she remarked that one technique that had served her well was to think of the work dynamic as like being on a team. Team members each have a critical role in reaching a common goal. This concept allowed her to switch comfortably between participant and coach roles, and it always seemed to keep her from taking on an autocratic dictatorial role, which she has seen many leaders slip into. Another consistent aspect of being an athlete, Mary explains, is,

If you're a good one, you set goals, and you set them higher and higher, and that's what I've done throughout my management. Every year sitting down with staff and talking about our goals, our visions, and always bringing it back to the students: How does this benefit the students, not us, but the students?

Mary describes herself as very honest, open, up-front, and transparent and believes those attributes are characteristic of her leadership. She believes that people would perceive her as goal centered because her eye is always on instruction, and she 
made it clear from day one that she was there to close the achievement gap. Her goalcenteredness can also be attributed for her setting her sights on the role of superintendent early in her career, back when there were only two or three female superintendents in the entire state of Massachusetts; she met and admired each one of them. But, as is common with most female professionals, both her career and her doctorate were interrupted for family. She had to relocate to California to take care of an ailing mother-in-law and chose to start her doctoral program over again. She and her husband tried, but didn't conceive children until late in her career, but she chose not to stop her career again; rather, she adeptly balanced work and motherhood as an assistant superintendent and superintendent.

She didn't have to pause when asked to name her proudest achievement; she immediately stated: "Academic achievement here would be my number one. I'm absolutely proud of what we've done in that area." She described her current district's academic performance when she arrived:

[It was] very weak, and you know our API was not good. So we talked about it as a management team, and we all agreed that our goal would be an API of 800 in five years, and we just mapped out how we were going to get there because we had a long way to go, and we did it.

Every superintendent knows that in order to tackle an achievement gap and increase your API, you needed to look deeply at the performance of your subgroups; in California, that most often means the English learner population, and this is exactly where Mary went when she began talking passionately about her career and her leadership. She shared that 
her teaching experience in special education and her administrative experience in child development and student services in Massachusetts brought her in contact with mostly poor, disadvantaged kids, so it became what she most cared about. She also related:

A lot of it has to do with my own upbringing with being a poor, disadvantaged kid myself, and my husband was a poor Latino kid, so from a very young age I've just really believed in public school for breaking that cycle. If we can give kids a great education, have them go to college ... so that's a huge initiative in our high schools.

Mary credits her success to her sharp focus on instruction and her commitment to an intense array of professional development initiatives and accountability structures. These include five monthly educational services curriculum meetings, monthly principals meetings, and weekly elementary principals meetings, which she is invited to often, so they are all "speaking the same language" and so she can accurately convey their concerns to the board. Additionally, she visits all 15 sites three times a year for a 3-4hour walk-through with the principal. One of these visits includes a structured protocol walk with a representative from the her district's educational services department, who looks for evidence of specific instructional practices. Following this visit a short report is written and shared with the staff.

Mary was raised in a Baptist minister's household, and she credits this background for giving her "Christian principles" and for forming her "in ways" she "can't get away from"; she admits that some people would attribute her religious 
background for her bringing the Character Counts program into her district. She clarifies that while it is not a religious program, religious leaders were involved when the six pillars of Character Counts were formed, and she believes in them very strongly. She goes on to explain that she has brought them to all three districts, and she believes "it's made a difference in the way our staff and our kids behave. . . It's about values and belief systems, and that drives your behavior on a daily basis."

Although Mary's focus and goals are always on instruction, she has reflected that her main role, recently, is in helping people "see each other's perspectives." For this, she credits her development of "mediator" skills because she's "been at the table" her "entire career in negotiations." The ability to effectively negotiate, both at the table and among relationships in an organization, is a terrific, invaluable talent, according to Mary. She uses it in all facets of her day, including managing board member interests, crossfunctioning departments, union interests, and intersecting community factions. We negotiate, according to Mary, in all of our relationships, at work and at home, and the better one is at facilitating win-win outcomes for all parties, the less often one is forced into compromising political positions. Such positions are most common in transactional leaders, who typically behave as daily deal brokers, brokering deals that often detract from the goals of the organization in order to keep peace. A transformational leader, on the other hand, is one who proactively attends to individual needs and interests in order to bring them into a larger vision for student achievement. 
Constance Culture, El Capitan Union Elementary School District

Constance Culture was selected for participation in the study because of the API growth, size, type, and location of El Capitan Union Elementary School District, as shown in Table 10.

Table 10

Demographics and Academic Performance, El Capitan Union Elementary School District

\begin{tabular}{|ll|}
\hline Grade span & $\mathrm{K}-8$ \\
\hline Enrollment & 13,347 \\
\hline Number of schools & 18 \\
\hline Ethnicity & \\
White & $7 \%$ \\
Hispanic & $28 \%$ \\
African American & $2 \%$ \\
Asian & $52 \%$ \\
Other & $11 \%$ \\
\hline English learners & $24 \%$ \\
\hline Free/reduced-price meal program & $32 \%$ \\
\hline Superintendent tenure & 3 years; started 2010 \\
\hline API at start of tenure & 874 \\
\hline 2013 API & 886 \\
\hline API growth & 12 \\
\hline
\end{tabular}

El Capitan Union Elementary School District is a midsize district comprising 18 elementary and middle schools that serve a community that is considered firmly middleclass, but which has been expanding in recent years with new, elegant housing developments popping up toward the eastern fringe of the neighborhood. Constance Culture describes El Capitan's community atmosphere as hard to define, given the various, diverse microneighborhoods it incorporates. Some blocks have attractive, treeshaded streets, while others are bare of any communal foliage. Some residents take great 
pride in their lots being freshly manicured, while others leave lots unattended. El Capitan's schools service a student population that is $28 \%$ Hispanic/Latino, $7.2 \%$ White, $52 \%$ Asian and 7.2\% Filipino, and 2\% African American/Black; 3\% identify as multiple race. Twenty-four percent of the students are English learners, and 32\% of the students qualify for free or reduced-price meals. A consistently high performing district in the last decade since California schools received their first APIs in 2003, the district continued to raise its academic performance during Constance's tenure as high as 19 points in 2012 and settling at a 12 point growth in 2013, the last year of the API formula.

Constance has spent her whole career in El Capitan School District, and she is the only participant in this study to remain entirely in one district throughout her career. She taught for 10 years before entering into administration, following a strong suggestion from her principal at the time that she consider preparing to be an administrator. Constance highlights her record of increasing student achievement during each assignment in El Capitan School District, especially at Title 1 sites (Title 1 sites receive funding based on high populations of socioeconomically disadvantaged students receiving free or reduced-price meal services). She speaks proudly of being principal of the first Title 1 school in the district to exceed an 800 API score and subsequently receiving the California Distinguished School Award in 2004. Moreover, while she was in charge of curriculum and instruction in El Capitan as director and assistant superintendent of educational services, the district's API grew by a whopping 62 points. During this time, she supervised 15 elementary sites and evaluated 18 principals, 10 of which earned California Distinguished School Awards between 2005 and 2011. 
Constance described how her mentors encouraged her to pursue leadership, both her principal, when she was a teacher, and her superintendent, when she worked in the central office under him. Although she was thankful for "a lot of good things I learned from" the superintendent, she was quick to clarify that "he and I had very different leadership styles." Pursuing leadership for Constance was initiated by encouragement from mentors, then catalyzed with the apprehension that she had "strong opinions," the realization that she often thought to herself "if I was in charge, I would change X," and the recognition that it was very difficult "carrying out someone else's vision," which, referring to her male superintendent mentor again, was very different from her own.

When asked to define her leadership, Constance rarely referred to her own personal characteristics but rather provided examples of how others had influenced her success or the success of projects she helped her principals and teachers to execute. When pressed to think about her own leadership behaviors, she explained that these type of questions are complex; she commented that this complexity is one reason why she rarely agrees to participate in surveys that force multiple-choice labeling with little context to illustrate a descriptor. Given a moment to reflect, while sitting in a corner seat at a busy coffee shop, with her back to the wall, allowing her to see the comings and goings of all the coffee patrons, she finally responded:

It's just being solid, common sense, dependable, loyal. If I'm going to hire a principal, I want all those traits, right? I don't want somebody who is high maintenance or very needy. I want somebody who can come in that is very capable, who is able to do the job and do it well. 
When asked to describe herself, Constance shifted instead to what her expectations would be of others, specifically a person she would hire to be principal. As opposed to naming one specific personal trait, she positions her leadership with respect to what people needed of a leader by contrasting it with stereotypical female traits of being "high maintenance" and "needy." She is acutely aware that her success was based on genderneutral or nonfeminine attributes, such as competence, emotional stability, and rationality.

Interestingly, despite the fact that the emotional drama and insecurity wrapped up in "needy" and the constant instability and need for praise embedded in "high maintenance" are usually considered negative female stereotypes, Constance later positioned them as possibly more commonly as male traits in her field. She suggested that female leaders have "less ego" than male leaders and explained that, in dealing with politics, "when I look at my female colleagues, I would say women have less ego involved in such things than men do. A little more logical, a little more balanced." She delved into the subtle and complex differences between male and female superintendents, describing how she has dealt with the "crazy amount of politics" in her job as superintendent. She conceptualized these dynamics in a conversation with her husband:

I went home and told my husband [that] I feel like every day I fight somebody; I go up against them, you know; somebody's not happy; and I had to come to terms with that. I think women probably feel that more than men do. I'm going to stereotype: I think men block some of that, and I think women perhaps internalize it a little more and are more sensitive to people not being happy. 
Constance implies that men's acumen for the political nature of the job has to do with their ability to not internalize a "fight" or to not personally bear the issues surrounding the job. Women's internalization challenges them to balance their passion with a logical, commonsense approach, which is different, Constance clarifies, than letting one's ego chart the course. She implies that ego, more often than not, causes a stasis in leaders when they care more about being a hero and pleasing people in the short term than about solving real problems in the long term. She explained,

We had a sup for like 25 years. We were solid, right? Very top-down management structure. ... He passed it on to his successor, and then it got passed on to my predecessor, and he didn't do anything about it. They didn't do anything! They did all these things on the fringes they could ... eliminating classified positions, raising class sizes to 24 -but to take on the union and tackle healthcare costs . . we just kept giving money ... so now it's on my shoulders to say, "It's gotta change." So we went through 18 months of very ugly, ugly negotiations.

This story, filled with pain and frustration at what she'd been handed by her predecessors and "mentor," revealed her conviction about how she has proven herself as a leader. She seemed to be juxtaposing her leadership style to her male predecessors when she stated:

I would say my style tends to be more, uhhhh ... brutal is the word that comes to mind, but it's like, "We're doing it!" Putting it out there, just rip the Band-Aid off and just deal with it, right? Rather than slowly putting off the inevitable or kicking it down the road to someone else. 
Constance is not afraid to face challenges head-on. She's not afraid of change. She's not afraid of challenging the status quo. She circles back and distinguishes her leadership as a commitment to "fight" her male predecessors and their careful maintenance of a traditional, top-down management system:

You know the old model was working because our schools got high scores, so I ask myself, "[Is] that right?" If the students are going to score well on tests, what do I care about the culture of the school or how happy the teachers are or how happy the principals are? .. . I have a very strong belief that a school's culture should be very warm and welcoming to students. ... So when I look at the kind of culture [El Capitan] had in terms of a top-down kind of fear-based, "you get good scores or you're gone" [culture], that's not conducive to that.

To Constance, the need for change represented the need for culture change, and culture change signified the need for the whole leadership paradigm and management structure to change; so her leadership style epitomized this change as a decision to fight the status quo or maintain it. She describes her job as change leader as a "fight" and therefore explains:

You can take two paths as a sup. You can just go, “Okay, this isn't my fight. Why make my life hard? Let's just manage day-to-day operations." Or, you can look long-term and say, "There are some things that need to be fixed, and here are the changes that are worth fighting for, and this is what we're going to do." Because honestly, that's the work. That's why I want to do this, right? 
Constance believes that changing the culture of the district goes beyond her own vision; it is also what the community wants and needs. At this place and time, Constance rationalizes, the people demand it. People are asking questions, seeking access to information, and expecting the opportunity to provide input; it is the new culture in the community. Therefore, the district needed a new culture that was open, transparent, and collaborative. There's "this need for the stakeholders to know how decisions get made and for principals to have some defined autonomy." This was an enormous endeavor that she realized would take significant ongoing training. In order to move from a "paternalistic, very top-down" culture, the principals and management team needed to learn how to have input in collaboration, but to also accept responsibility. She explained, "For me, human systems dynamics (HSD) training was a way to help that happen." She defined HSD, referred to her by a female superintendent colleague in the area, as an organization of consultants trained in systems thinking and organizational learning based on the work of Peter Senge's "learning organization" in the Fifth Discipline (2006). Admittedly, she said her cabinet had the most difficult time with "giving the principals some voice and getting them more active in the conversations and decision making ... because they, too," rose through the ranks in "this system that is very top down," and they expected to give orders and have them followed.

Her proudest accomplishment as superintendent thus far relates to how her efforts to change culture have positively impacted her highest poverty school. She brought in project-based learning and allowed $75 \%$ of the best teaching staff to choose to move to this school to change culture and improve academic achievement. So, she exclaims, they 
went in and "they've brought the parents in and engaged the community, and the kids are so much happier." Initially, the school was only bout remediation, which gravely concerned Constance. She expounded:

Remediate, remediate; it was toxic. The culture of a school is a byproduct of the culture of the district. I think that's where my focus and desire to change things stems from.... The biggest changes that we've made that I feel really, really good about have to do with the work we're doing around project-based learning and creating culture at schools that empower students.

Constance believes her change leadership stems from the impact that toxic culture can have at the site and student level, especially at the sites where the high-poverty population is the most vulnerable. Toxic culture, as illustrated by Constance, is one where unhappiness of staff and students is "blocked out." It is where hard decisions that could benefit students and staff morale in the long term are stalled in order to avoid unhappiness in the present. It is where, in order to maintain political stability, decisions are made top down, from a safe distance, without input from a community of stakeholders. In other words, top-down management maintains the status quo by ensuring decisions are made without engaging with the diverse perspectives the school community. 
Terry Teacherfirst, Freedom Valley Union High School District

Terry Teacherfirst was selected for participation in the study because of the API growth, size, type, and location of Freedom Valley Union High School District, as shown in Table 11.

Table 11

Demographics and Academic Performance, Freedom Valley Union High School District

\begin{tabular}{|ll|}
\hline Grade span & $9-12$ \\
\hline Enrollment & 10,535 \\
\hline Number of schools & 6 \\
\hline Ethnicity & \\
White & $21 \%$ \\
Hispanic & $16 \%$ \\
African American & $1 \%$ \\
Asian & $55 \%$ \\
Other & $7 \%$ \\
\hline English learners & $9 \%$ \\
\hline Free/reduced-price meal program & $15 \%$ \\
\hline Superintendent tenure & 7 years; started 2007 \\
\hline API at start of tenure & 840 \\
\hline 2013 API & 890 \\
\hline API growth & 40 \\
\hline
\end{tabular}

Freedom Valley Union High School District comprises four comprehensive high schools, one alternative high school, and one adult and community education site serving approximately 10,710 students in grades $9-12$ and adults with no age restrictions. Like most high school districts, Freedom Valley's attendance boundaries cross multiple cities, embracing the majority of two cities with boundary overlaps in four other municipalities; this creates additional political complications as issues cross multiple city councils and voting constituencies. Because of the clean suburban setting, low crime rate, and quality schools that residents enjoy, this district must vigilantly investigate fraudulent residency 
claims by families wishing to enroll in their schools. Approximately $21 \%$ of the student population is White, 16\% Hispanic/Latino, 55\% Asian, 3\% Filipino, 3\% two or more races, and 1\% African American. Nine percent of the students are English learners. Fifteen percent of the students qualify for free/reduced price meals. As with many districts in this economically booming region, the enrollment is increasing, but like many districts serving predominantly mid- to higher-income single-family homes, Freedom Valley is not funded by Average Daily Attendance (ADA) from the state, but rather is locally funded according to parcels. Therefore, funding does not increase by enrollment increase; it is determined by increase in property value or additional construction of single-family homes and condominiums.

At 65, Terry Teacherfirst is the oldest sitting superintendent in this study's participant pool and has been serving as superintendent of Freedom Valley for over seven years. Seven years is the longest term served within this pool. Of note is the fact that of the female superintendents who saw the largest API growth within this pool, each had served the longest terms -7 years. During Terry's tenure, her district saw an API growth of 40 points, the third highest in this participant pool of districts. She has been an educator and administrator for over four decades as a math teacher, guidance counselor, and central office administrator, which involved almost every aspect of public education. Her 25-year career in this district started as a high school assistant principal and since then has included a wide variety of roles, including district coordinator of student services, executive director of educational services, and deputy superintendent of human resources. 
Among her personal achievements as superintendent, Terry highlighted the development of alternative education programs that serve students with special needs, the development of an open and collaborative approach to negotiations with collective bargaining units, and spearheading the district's recovery from its financial distress of 2002-2005. She also described in detail her activeness in the communities in which her students reside, including Rotary, Chamber of Commerce, and the Board of Directors for Schools for Sound Finance.

Terry never set out to be a superintendent and revealed that her initial lack of confidence and ambition could have arisen from her traumatic childhood. She was adopted, and her adoptive mother was an extremely violent, abusive woman with paranoid schizophrenia. She explained,

If you are an abused child, you tend not to have a lot of willingness to take risks and stand up to people that might be pretty aggressive because that's the way you survive, right? You just acquiesced. So probably as a consequence of that I've not had highly successful marriages and would also acquiesce to believing others were more qualified for positions.

The first of three forces that ultimately propelled her to the superintendency was raising her son as a single mother. Raising her son became a driving factor because she was a single mother for a long time, and she was determined for her son not to be "labeled disadvantaged because he had a single mother." She wanted him to know that he could have a middle-class life. The most ambitious she got, she explained, 
Was I wanted to make enough money so he could have friends over to a house that, you know, seemed like a normal house, and feel like if he didn't have a dad to be proud of for his job, he could be proud of his mother's job.

The second factor that propelled her was a mentor--her principal when she was a high school counselor, who gave her a "swift kick in the pants and said, 'You know you can do this." Since she was always assuming others could probably do things better than her, she felt that it really took someone else seeing it in her to set things in motion. The third factor was the realization that being a leader could in fact be a lot like being a teacher.

Being a superintendent was never part of her intention because she loved teaching. She still often says "teaching was the best job I ever had." She describes watching her superintendent struggle midway through her deputy superintendent tenure and wishing she could coach him to do certain things. She remembers being frustrated at his

Reluctance to do it or [when] his ego got in the way. I just kept thinking to myself, "This is really hurting the place I love." So, I don't know if I ever set out to be a sup. I set out to not lose the great things about this place. . . . If I'd understood the job better, I might have wanted to be it sooner.

Terry implied that if she understood that she could change the role to fit her interests and style, or if the role of superintendent was better understood by teachers and appeared to closely impact teachers, she may have been influenced to pursue the role sooner. Instead, she viewed both her predecessor and her male colleagues working alongside her as 
pursuing the job of superintendent for reasons and intentions to which she did not relate, causing her to view the position as not well suited to her:

The sup right before me, his example was, "I want to be sup cause I want to carry the ball." I want to be "quarterback"? I don't care about carrying the ball . . that sounds very unappealing to me. And someone else actually applied to be sup by bringing newspaper clippings of who they were. You want to because you're in the newspaper front and center? None of that mattered to me. I think I didn't understand the job under those people. ... If I believed that I could influence the culture of a place sooner than I knew, than that would have appealed to me.

The masculine sports imagery epitomized the undesirability and possibly the unattainability of the role of superintendent for Terry and for other women. Women didn't play football. Women weren't quarterbacks. Only one person can carry the ball, which equated with making the decisions and somehow standing apart from one's colleagues in status and rank, as opposed to working side by side. Carrying the ball meant getting the credit and being a star or the figurehead, like the man who carried the newspaper clippings as evidence of his front-man credentials. She explained her disconnect from the role of superintendent:

You don't think "Who's the sup?" And "how are they affecting me, and what does their leadership mean?" The sense of "Could that role have an impact," or “is that role a figurehead?" I didn't get it. And maybe part of it was because some 
of the people, as I moved up the ladder that I got close to, I didn't see that part of their desire.

This female educator did not find the image of the role of superintendent to be appealing because of how the traditional masculine occupiers have played out the role before her. Terry's career trajectory, and that of many other female educators, might have played out differently if she had known that, as superintendent, she could somehow retain her role as a teacher and an educator and influence not only the classroom, but also the culture of the whole district. To date, Terry feels that she has been able to play these roles successfully. She described the epiphany as being like a "light switch" when she realized she could maintain the role of educator and teacher and not feel like she had to defect into a nebulous world of political speeches and charismatic spin-doctoring in order to serve as superintendent:

I could not do a political speech if my life depended on it. But if you ask me to teach somebody about something, I know how to do that. ... So when I finally learned that instead of speaking, I was teaching, it was like turning on a light switch. I could do it anywhere, any time any day, on any subject. It was easy, and that's exactly how I see my role with the board. We continue to teach them until they feel like they understand and can make a good decision. That's our job.

As opposed to lobbying, scheming, and managing board members like they are only politicians and outsiders to school expertise and therefore to be kept at bay and outside of decision making, Terry suggests that they should be treated like students, parents, and 
potential advocates who need to be consistently informed and educated about issues facing their schools, the ramifications of their decisions, and the impact on students on an ongoing basis. Being able to articulate issues so that people feel adequately informed to make decisions, according to Terry, is a job not dissimilar to that of a teacher.

Terry rationalized that if being a teacher means also being knowledgeable about your subject, and if her "subject" involved meeting the educational needs of a diverse set of microcultures within her community, then she needed to learn about them. She emphasized the importance of being seriously involved in the different ethnic groups in her community, of winning their trust and convincing them of her genuine interest in understanding what's going on in their culture and genuinely wanting the success of their kids. She explained that this involved "a real open-minded discussion . . . about their definition of success and helping them understand the Western definition of success and seeing what we can learn from them, seeing what they can learn from us." She further explained that she needed not only to create spaces to have deep, ongoing dialogues with the community, but also to diversify her leadership team to make sure her community's needs are heard and understood:

I think we shy away from those conversations in inappropriate ways. I mean there's nothing racially inappropriate about my saying Chinese kids deserve to see a Chinese face as a leader. ... Over time I think we broke down a lot of barriers. I think we have enormous support from our Chinese community here, and the leadership, both political and local, needed to have their insight into how to help us get parents involved in the schools. 
Terry uses the new Local Control Accountability Plan (LCAP) process as an example of a better, more authentic way to engage the community that supports her leadership style. The LCAP is perfect for collaboration because it engages all the different groups as the district devises ways to serve special education kids, English learners, and low-income and foster youth. Traditionally, she explains, "The more topdown way might be that you already kind of have the ideas in mind, you go out and still engage people, but it's more about convincing them that this is what needs to be done." She advocates shifting the leader paradigm from "collaboration to convince" to "collaboration to include diverse perspectives from stakeholders." In other words, she would use her role as superintendent to empower others to influence by including their perspective as opposed to using her power to influence the opinions of others to fall in line with hers. Terry recalled a situation where she became acutely aware of the subtleties of how one can consciously or unconsciously express positional authority and how that impacts people's perceptions of how you will use this power. A unique situation arose wherein the board had been fighting "like cats and dogs" and voted suddenly at 2:00 in the morning to fire her superintendent; they called her in to the very room where our interview was taking place and asked her to be the superintendent. Telling her story, she stood up, pointed, and said:

That chair was open, and this chair was open, and I consciously chose to sit in this chair. I consciously chose not to sit at the head of the table. I wasn't going to assume any position. I was either going to be part of this team of people, or I knew I couldn't do it. And later on, which I didn't know, that's a very Asian 
thing, to assume the head of the table. The two Asian board members--they both told me-they were waiting to see where I sat, and that was going to make their decision. If I sat at the front of the table, they knew I was going to assume that I was in charge, and I wasn't going to be making an effort to work with all of them.

To those board members, her not assuming positional power by sitting at the head of the table symbolized her desire to share power. Although Terry is not Asian and admittedly did not know this act would be meaningful for them, it was nonetheless intentional and meaningful to her in that it signified the communal, nontraditional way she intended to work with them. She did not want to be their "quarterback" and "carry the ball" for them. She wanted to be their teacher and collaborator to lead this district together.

Culturally symbolic or not, many nonverbal actions can reveal positional authority that can disrupt one's intention to be communal or display the type of power that limits the trust necessary to build solid collaborative relationships. Terry asserts that building trusting relationships is vital to the health and positive culture of a district because it directly impacts collective bargaining outcomes. In negotiations, she explains, we all have to decide what the system needs to be to be good for kids. And, then "we agree to pull it off the top" before salary and benefits and operational costs. Lists or categories don't work; rather, she promoted the use of guidelines jointly written for what criteria that must be met "off the top." However, this collaborative effort does not work if the bargaining units distrust management and think there is money hidden somewhere or if there is disrespect between the units. Terry related that initially, her 
teachers really believed that we were hiding money. I had a business guy who absolutely would sit at the end of the table while we were doing negotiations with his laptop. They'd ask him a question about money, and we'd all have to sit there while he looked it up, and then he would give a number and he would slam his laptop shut. It wasn't like "Well, see here it is." It was a "bam!" They were just $100 \%$ convinced there was money hidden somewhere, and why wouldn't they be?

Terry believes that it takes true transparency, trusting relationships, and teachers really knowing the workings of the district in order to pull them from being entirely focused on their own compensation. To make that work, staff and teachers have to learn that it ultimately enhances their compensation because “compensation isn't just about benefits and salary." Compensation, according to Terry, is "about professional development," and "compensation is about an atmosphere where they see kids in programs that are supported" and where they see and feel support working with struggling students as well. This process takes a lot of open discussions, and it requires the superintendent to personally interact with the staff as a teacher to enable them to fully visualize the impact on them personally. She depicted an example of this process as talking to teachers during “5-7 prep periods for each of the 5 sites" in order to address concerns and provide full details about a professional development leadership structure for teachers that would go far beyond department chair. This included having some compensation for team leadership and professional learning communities. These leaders would be providing leadership in various curricular areas. This dialogue followed a negotiation to add a 185 th day to the schedule; this was proposed because teachers were not always coming to the 
optional professional development day at the beginning of the year. So she committed to “eking out the money for a full day's pay, but I want people there. All means all for teachers, too," she exclaimed, then proudly claimed they got $86 \%$ of the votes.

Although proud to discuss her collaborative nature and how it has transformed the culture of the district during her tenure, she is quick to qualify her style:

I'm not telling you I can't make a decision. I can make a decision ... I have to, and I can make a hard one. I have to hold everybody to the same standard. You can't hold teachers to a high standard and not hold administrators to a high standard. So that may be counter to the collaborative approach, but you can be collaborative and you can hold a high standard and create a culture where excellence is expected.

Terry reveals an acute awareness of gender stereotypes surrounding female leaders and their communal nature when she acknowledges that being communal may be counterintuitive to being agenic. She insists you can have both, but it highlights the timeintensive balancing act female superintendents perform. They need to cultivate high expectations without fear and intimidation within a chain of command, while nurturing individual values and contributions within a collective that functions in an open, shareddecision-making system.

Terry stresses that the successful superintendent must truly be the kind of person who works best in this kind of relationship-based environment. At the core of it, she states, 
You have to be a people person. You have to be somebody that genuinely and sincerely cares about the adults and kids in the system and really listens a lot and really can read the system as a whole-you have to put your finger on the pulse.

Moreover, she professes that in addition to being a genuine "people person" the leader of a district with a healthy culture of successful collaboration must intrinsically be a learning leader. A "learning leader," she asserts, must believe deep down that "it never does any good to be rigidly sure you are right." She illustrates this by asking rhetorically,

Do you want to be right, or do you want to be successful? I think it's very important to leave your ego at the door. You have as much to learn from everybody in the room as you have to offer to everybody in the room. Maybe more to learn. You just got to think about that all the time because once people believe you genuinely want to hear their opinion, you have their respect.

This adeptly aligns with the theories of seminal writers on organizational management Peter Drucker (2008) and Peter Senge (2006), who assert that managers have to change how they lead because, like most organizations in the 21 st century, they no longer lead uneducated, unskilled workers who need to be led and need to have things broken down for them in a highly structured environment; rather, they lead highly skilled, highly educated employees who are often underutilized (Wiseman, 2014). 
Elizabeth Engager, Santa Vista Springs School District

Elizabeth Engager was selected for participation in the study because of the API growth, size, type, and location of Santa Vista Springs School District, as shown in Table 12.

Table 12

Demographics and Academic Performance, Santa Vista Springs School District

\begin{tabular}{|ll|}
\hline Grade span & $\mathrm{K}-8$ \\
\hline Enrollment & 11,456 \\
\hline Number of schools & 20 \\
\hline Ethnicity & \\
White & $28 \%$ \\
Hispanic & $35 \%$ \\
African American & $2 \%$ \\
Asian & $23 \%$ \\
Other & $13 \%$ \\
\hline English learners & $27 \%$ \\
\hline Free/reduced-price meal program & $31 \%$ \\
\hline Superintendent tenure & 3 years; started 2010 \\
\hline API at start of tenure & 839 \\
\hline 2013 API & 843 \\
\hline API growth & 4 \\
\hline
\end{tabular}

Santa Vista Springs School District is a midsize district comprising 20 elementary and middle schools. These 20 schools successfully educate approximately 12,000 students in preschool through eighth grades in two cities harboring the San Francisco Bay, one of which considers itself a master-planned community. Santa Vista Springs School District offers parents a choice of schools for their children. Parents can choose from their school of assignment or one of 12 magnet school programs. The magnet programs range in focus from Mandarin immersion, STEAM (science, technology, engineering, arts, and mathematics), and Montessori to International Baccalaureate, 
Spanish two-way immersion, and a STEM (science, technology, engineering, and mathematics) gifted and talented program. The 20 schools vary widely due to the demographic makeup and socioeconomic status of the neighborhoods they serve. Fewer than 3,200 families speak a language other than English at home, and Spanish is the household language for about 2,200 of these families. Other languages reported by 100 or more families include Mandarin, Cantonese, Japanese, and Arabic. Approximately $28 \%$ of the students are White, 35\% are Hispanic/Latino, 23\% are Asian, and 2\% are African American; $12 \%$ identify with two or more races or other. Twenty-seven percent of the students are English learners, and 31\% of the students qualify for free or reduced-price meals. The number of low-income families has been steadily rising in this area, but this district has stubbornly continued to improve its overall API. Although it was the lowest of the participant pool, Elizabeth Engager saw a 4-point growth in API during her threeyear tenure.

At 64, Elizabeth Engager is the second oldest participant and has served the most districts, with Santa Vista Springs capping her career as her fifth district—her sixth if one counts the interim superintendency she served immediately before taking this position. With several districts under her belt, Elizabeth was able to reflect both on great successes in wildly different regions of the country and on difficult life lessons, including a board voting to buy out her contract in order to terminate her contract. The interview was at her office in the evening, after her staff had departed. She offered hot tea, probed the researcher about her career path, and instantly launched into advice for a young, aspiring female superintendent. She immediately recommended attending the Women's 
Leadership Conference in Sonoma, sponsored by the American Association of School Administrators (AASA) and the Association of California School Administrators (ACSA) and suggested participating in their mock interviews. She referenced a similar experience that helped her be recommended for her first superintendency, in the Northern California foothills.

From the start, Elizabeth spoke intimately about the experiences that formed her leadership identity. She repeatedly used a striking metaphor to illuminate how profoundly difficult the responsibilities of leadership can be, likening the superintendent to a boat at sea:

Every time you make a decision, you're like a boat in the water, and you pick up a barnacle. It might be a little barnacle, if it was a little decision or most people liked it, or it might be a big barnacle, where a lot of people didn't like it. There comes a time where the boat has to be taken out of the water and the barnacles have to be scraped off the hull, and the boat has to be placed back in the water in a new place.

Having been the superintendent for six districts, she came to understand the heavy emotional burden of a leader trying to implement sustainable change. No matter how popular the initial initiatives or decisions, at some point the leader him- or herself can be the drag or the detractor, having "taken too many bullets and attracting too much political heat" to be an effective change agent. And, even with popular or morally right decisions, a leader will acquire enemies that almost certainly multiply over time, especially when 
the leader is more academically oriented and is not a savvy politician. Referencing the superintendency that tested her the most, she spoke about needing to know oneself and finding one's “line," asking rhetorically,

Where is your line? Where will you be flexible, and where can you not be flexible? When you have that clash, by that time you are saying to yourself, “That's not who I am. It's not how I lead." So, then you have to decide, and that was the hardest thing, to be true to yourself.

That "clash" referred to a difficult superintendency when she was hired by a board that "thought they were looking for a collaborative superintendent," but the majority of them really were not used to a collaborative superintendent. They were used to "someone who set the course and said this is the way you're going to do it." What made this experience so difficult was that the board wanted her to make directives to district employees without asking for input from them and letting them be part of the process. The board members from the business community, accustomed to her male predecessor, considered this weak and attributed her resistance to command-and-control leadership to her gender; they continued to pressure her to be more aggressive with her employees to go along with their goals. She maintained that this was not the best way to gain buy-in, until they came to an impasse.

This experience highlighted for her why it's important to have training on collaboration. People may approve of the general concept, but the process of gathering input and sustaining dialogue with various groups with diverse interests is very time- 
consuming and messy, with risks involved if people lose interest, focus, and the bigpicture objectives of the process. She uses a current problem of capacity challenges at some of her schools as an example of needing training and facilitation on collaboration and consensus building:

It's always the right people are at the table and you have to create the circumstances for them to be able to engage. We have a group right now called the Next Steps group, which is working on a solution for our equity challenges that are being created by our school capacity challenges.... I think collaboration, for me, means that you engage the people who will be affected by the decisions. ... Then, once you get a plan in place, there is the follow-up pieces. There's time and structure for collaboration, brainstorming, and the thinking up the idea, and then there's the making it happen.

This example emphasizes that successful superintendents reinforce their open, communal approach with targeted, ongoing training, well-systematized structures, and clear expectations and accountability measures. She is clear that engaging stakeholders does not mean parameters or systems are loosened, but rather that successful collaborations involve a high degree of structure. Transparency and trust is built by how clearly the process is defined, for example: When do people get to be heard? How will the decision be made? And how will the plan be developed that will support the implementation? Elizabeth extended her leadership approach to successful collective bargaining in her district, as well. She trained people in her district in collaborative bargaining and consensus building: 
We learned protocols for how to listen, and we were trained in the Harmony School protocols, which came out of Brown University. You need structure of collaboration and consensus building in order to make it effective. You can't just have a tacit agreement that everybody agrees to be collaborative. You have to have all the processes in place so they allow collaboration.

Elizabeth describes her leadership as collaborative and action oriented. She is very careful to accentuate that a person who does not ultimately take action and make a decision is not an effective leader. The conscious blend of male and female leadership styles, communal and agenic, is accentuated and situated, in Elizabeth's context, in a symbiotic relationship. In other words, the two orientations are a necessary marriage, are interdependent, rather than styles sitting in contrast with each other. The deliberate blending of the male and female leadership "tendencies" is a theme seen throughout this participant pool of successful female superintendents.

Elizabeth's career path and spirituality also defined her leadership. Divorced twice and having to raise a daughter as a single parent impacted her path. Her husband's job transfer caused her to leave her job as principal and start a doctoral program. In this program, she studied superintendents and how they dealt with budget crises and decreasing revenues. Gaining access to these individuals increased her desire to serve in this role. A divorce also provided her the liberty to pursue superintendency and relocate a great distance. She also relates her epiphany of how having a child gave her a better insight into working with parents, understanding their needs, and, she admitted, giving them different advice than before she had children. She even went so far as to say that 
educators really needed to have children in order to understand and advise parents with respect to schooling.

Her spirituality has guided her moral responsibility within her role as superintendent. She sees her role as that of a coach responsible for creating professional development experiences so that teachers and principals "can grow, embrace, and activate what they've learned, so can you be sure that kids are going to learn." She connects this role with her Presbyterian beliefs and her responsibility as a superintendent by elucidating her belief in predestination as

figuring out what you're supposed to do with your life and helping other people figure that out as well. Just because all of us have a purpose - and I really believe that-somebody might not really be meant to be a principal. They have some other purpose. They clearly want to make a difference in the lives of kids, but maybe not as a principal, so it's my job to coach them into the right role. . . So I think from a spiritual standpoint it's about trusting that you're on the right path, and if you feel like you're not on the right path, check it out-you're probably not on the right path.

Her spirituality about being on the right path feeds her conviction about whom she hires as leaders in her district leading the charge. One's principals and assistant superintendents, according to Elizabeth, must be the right people to make transformational, high-impact change at the school sites. She feels strongly that if a person is not an instructional leader, they should be coached. And, if the person is not the 
right person for the job, the superintendent has the moral imperative to counsel that individual to another opportunity inside or outside of the district. She defends this strong statement with a social justice and instructionally focused lens:

I say that so affirmatively because we have several schools in our district who have high percentages of socioeconomically disadvantaged kids, and some of the schools are doing well, and in some of those schools, the kids are not. Now, the populations are similar. What's different? The principal, the teachers, and the instruction, that's what's different.

This justification also propelled her push for desegregation of the schools in her district by busing the kids around the district and out of their neighborhoods. Although controversial, she used the data to prove her argument. Even with vastly increased resources and an influx of specialized programs into the neighborhood schools with $90 \%$ low income, she questioned which kids did better academically. Would it be the kids in the schools with more resources, but homogenously low income? Or would it be the kids who were bused to schools with fewer resources and $50 \%$ or lower socioeconomically disadvantaged? The answer, she stated emphatically, is the latter. Thus her formula for great education is fundamentally centered on leadership for learning and social justice, which is, according Elizabeth,

A combination of really very solid instruction, a principal who knows instruction, and leadership —assistant superintendents and a superintendent who know instruction coupled with mixing up the kids. That's what I believe. 
Carrie Community, Margarita Meadows Unified School District

Carrie Community was selected for participation in the study because of the API growth, size, type, and location of Margarita Meadows Unified School District, as shown in Table 13.

Table 13

Demographics and Academic Performance, Margarita Meadows Unified School District

\begin{tabular}{|ll|}
\hline Grade span & K-12 \\
\hline Enrollment & 4,807 \\
\hline Number of schools & 9 \\
\hline Ethnicity & \\
White & $51 \%$ \\
Hispanic & $29 \%$ \\
African American & $3 \%$ \\
Asian & $3 \%$ \\
Other & $14 \%$ \\
\hline English learners & $3 \%$ \\
\hline Free/reduced-price meal program & $26 \%$ \\
\hline Superintendent tenure & 7 years; started 2007 \\
\hline API at start of tenure & 775 \\
\hline 2013 API & 837 \\
\hline API growth & 62 \\
\hline
\end{tabular}

Margarita Meadows is a small city of 36,663 residents, covering 12.47 square miles on the outskirts of the Bay Area region, where "salt of the earth," mostly white union workers raise their children, where antique stores fill the downtown, and where Amtrak stops daily. It is the home of a marina and large port for industries such as fishing and oil. Margarita Meadows Unified School District comprises 9 elementary, middle, and high schools and has a student enrollment of just fewer than 4,800, the smallest district in the participant pool. Ethnicity of the student population is $51 \%$ White, $29 \%$

Hispanic/Latino, 3\% African American, and 3\% Asian; 14\% indicated two or more races, 
or "other." Only $3 \%$ of the student population are English learners, and $26 \%$ of the students qualify for free or reduced-priced meals. This is a community that gives its schools a lot of support and is steeped in tradition, so one must be always mindful of the history before initiating any change efforts. The mind-set of "no growth" in order to keep the tiny town feel is causing the downtown to languish somewhat due to lack of modern development. The superintendent sits on all the community group boards, such as the chamber of commerce and the Rotary, to keep in touch with the community spirit, local interests, and the small community's few major employers. Recently, due to some local industry infrastructure, environmental issues have arisen for the community and district, as well.

Carrie Community has served Margarita Meadows Unified School District for about seven and a half years. At age 63, Carrie is the third oldest female superintendent in this study and has presided over tremendous API growth, with a whopping 62 points from her start date through 2013, the last year of the current API formula. This is her first and only superintendency, and she expects to retire from this district. As a director of curriculum in Margarita Meadows Unified School District (MMUSD) for only two years, she was encouraged by the outgoing superintendent to apply. Previous to her nine-year tenure in MMUSD, she worked in two nearby districts as an elementary and middle school teacher for 26 years, an assistant principal and principal for three years, and a coordinator of beginning teacher supervision and assessment (BTSA), 7-12 literacy, and gifted and talented education (GATE) for four years. She has also served as adjunct 
faculty at California State University Hayward and National University, and she has been recognized as teacher of the year both at the county level and within two districts.

At the onset of our interview, Carrie was quick to clarify that she "never actually intended to become a superintendent." She explained that she had the position of director of curriculum and instruction for her district, and she felt that was "where my gifts lie in terms of curriculum ... building capacity in our schools to support teachers and learning is where my passion was in education, and I was always really a teacher-principal. It didn't matter what my role was; I was always drawn there." The "serendipity" of her becoming superintendent followed the previous superintendent's sudden resignation after two years, when he examined the district's dismal budget forecast and decided he wasn't the one to lead the district through it. Carrie said that the "sup came to me, and he said, 'I really believe, I really believe you can do this, and I think you should ... put your hat in the ring, no harm, no foul."' She felt truly surprised, but went on to explain that her career

has been much like that, other people have seen in me something I didn't necessarily see in myself. I've never been one to aspire to titles. I've always been one to find a position that fit my heart and soul. I will honestly say that being a superintendent has done that.

Serendipity, as opposed to intentionality or aspiration, allowed Carrie to realize that being a superintendent could fit her heart and soul. To this female educator, heartfelt work and passion resided in the classroom and in the realm of teaching and learning. 
Titles, she imagined, were soulless and only created an intractable distance from the true work of an educator. She illustrated how the superintendent role embodied this image and how she dealt with this:

I envisioned sort of a political role of somebody who was always out in meetings and being the public face, but I have not defined my superintendency in that way. That was one of the things I learned. There is no distinct role. There are many responsibilities, clearly, but how you define what that looks like is individual, and that's what I've chosen to do.

Although she described changing the role to fit her strengths, she feels the role of superintendent is "evolving for every administrator." Common Core, she believes, is a "game changer," because educators are on the cusp of tremendous educational reform. It's causing everybody in this field to stop and examine:

What does it mean to be a teacher? What does it mean to be an administrator? What does it mean to be a superintendent? It is essential the superintendent is an instructional leader . . . that they lead not in a tacit way, but in a very active way.

Carrie reinforced the notion that females need mentors and networks. Not only was her career pathway strewn with advocates giving her the confidence and encouragement that she did not innately possess, but also she reflected on the discomfort when she first attended the superintendent council meetings and she was only one of three females in a room of 18 . Only one spoke to her, and the other was cold, she remembers; the male superintendents mostly ignored her and carried on business without 
acknowledging or welcoming her as a new superintendent. Because of this experience of feeling suddenly alone and isolated as a new superintendent, she is very proactive about reaching out to new female superintendents and offering to meet or provide advice or a friendly, confidential ear. She calls it "pay[ing] it forward" and also created an aspiring leaders academy within her own district and region in order to build capacity and to permit "people to grow in their way, not my way."

Being a true "teacher at heart," as she says her kids call her, is a lens she carries with her, and it has become more of an advantage as a superintendent than a disadvantage because it has given her the ability to engage authentically with teachers and parents about what it would "look like" to build the capacity in their schools to improve academic achievement. She went on to explain that it is even more powerful that her chief business officer (CBO) and human resources (HR) director can see the "big picture of where we are going," and that state accountability measures such as the Local Control Accountability Plan (LCAP) and the Local Control Funding Formula (LCFF) process have helped all of them with this. Most superintendents in the area, she says, have been discussing the arduous new state formula and process with dread and skepticism, but she sees it with a different lens and therefore as an opportunity. Carrie emphasized:

I will say honestly, I think the LCAP, as painful as that process has been, . . has tremendous potential to shift the dialogue in the right way for the right things. We've been able to authentically engage our stakeholders, our parents, our students, our teachers in this process, so it's not something we handed to them. It's something we jointly created. Is it beautiful? No, it's messy and it's changed 
... but it's truly reflective of the goals and the vision that we've established, and I think that's been very powerful.

Carrie realized that it 'isn't about shifting the work, but it's about communicating the work," and she learned that this is a critical difference. One must be able to communicate by being succinct, forceful, and patient enough to repeat one's needs so that people will understand. Carrie said that will often tell herself, "I can't possibly say this again," but then she recalls that she is not necessarily saying it again to the same person. This also now includes different forms of media, from digital videos to town hall meetings to blogs. Last year, she reflected, "we had 11 community meetings." Relational leadership, according to Carrie, is acutely tied to communication and the willingness to learn how to listen and communicate differently to different stakeholders both inside and outside the organization.

Carrie's leadership style stood repeatedly in contrast to that of her male predecessors, even though she was cautious not to point to gender. In her former district, she found her superintendent to be very "oppressive," and "you could just see that his whole methodology or style was really, I felt, anti-women." It was the first time she had ever been in such an oppressive position, and she knew there was going to be no place for her to grow. For the first time, she felt that she needed to leave a job. With emotion in her voice, she stated:

I mean, talk about top down. He was very autocratic obviously in his style. And it's one thing to be autocratic, and it's another thing to be a noneducator. He was 
one of these folks who really wanted you to be the spokesperson. . . "[Carrie] will make that report," and I'm thinking, "Whoa!" . . And I was really reporting on things, ... that he wanted me to say, that didn't feel authentic.

She was the expert, so she was made to be the spokesperson for her autocratic leader, but what she was communicating was his ill-advised or misguided vision that denied her or anyone else's input, which cut to the heart of her passion as an educator, so she had to leave. Her predecessor, who was also her "shoulder tapper" and mentor, was a distinctly different leader as well. She depicts the differences in pathway, focus, and unilateral decision-making style. Two weeks after her superintendent left, she went into his office to find it "utterly bare, with not even a piece of paper in it." When she asked him later during a consultation where all the work had gone, his answer was, "[the] curriculum work's in your office, and the CBO has his." She realized then that he truly was only a figurehead who left all the paperwork to his cabinet. He loved it, she went on, that she was there because she "had a deep knowledge of curriculum and he had none." He'd been a coach and a counselor previously, and he had no interest at all in curriculum and instruction. His superintendency "was about getting us . . he was about facilities." As a leader, he also lacked the willingness to adjust and change. She explained,

My predecessor was very clear, even when I'd go, “Well you know, here's what we've learned." He didn't care. We said we were going to do X, Y, and Z, and "Well, we're going to do X, Y, and Z because we said so." I'm not that way. I think that life gives you information, and you're foolish to ignore it. 
Defining her leadership style as distinctly different than her male predecessor, she depicted his agenic style as clearly neither inclusive of differing perspectives nor open to new information that might cause one to change a decision. Changing one's decision was possibly considered indecisive, and acknowledging one's incorrect decision and adjusting accordingly was viewed as a sign of poor leadership. Disputing this type of egocentric, "saving face" leadership, she related an example of publically admitting an error in judgment as superintendent and declaring that she made a call to pull back on a decision to go 1-1 mobile devices with students:

I went back to the staff and said, "What you see is a person who has egg on her face." . . Some were disappointed, but I honestly got almost no pushback from them or the parents because they realized that we were willing to own it. Was it a mistake? I don't know if you'd call it a mistake or whether you recognize that you may be fraught with way more problems, so I'd rather not go there.

Carrie describes her leadership as collaborative and kid focused. This combination has helped her work with her board in a way that "honors what they bring and helps them work as a team." For a long time she did not feel like they had collaborative mentality. She was constantly struggling to refocus the "lens of the camera" on what is importantthe needs of kids - and she felt for a long time that it was about them. Each individual member of the governing board, she believed, felt passionately about his or her issues, but "it became about single issues, not global, not about the community, but about small groups." So she organized retreats, brought in outside consultants, and kept "whittling 
away at one person at a time." One by one, she refocused the lens of the board to be about the kids rather than the adults. She summarized:

If we think about overall instructionally what we're trying to do for the kids, I have found that very rarely we go wrong. It's when you try to worry about the adults in the building: What do they like? What do they want? A lot of times people want to drive the decision making about their comfort. I don't want to ignore their comfort, but it's not my driving force. I'm not here to make you comfortable. I'm here to try to create the most powerful educational program that I can for students.

Carrie's successful career path was fortified by the support of her family. She declared emphatically that her family had contributed greatly to her success, being her unwavering supporters. She always knew she would have to make sacrifices as she took on the responsibility of school leadership, but her "family was never going to be the sacrificial lamb." She had worked part-time earlier in her career in order to raise her children, and made sure she consulted her family when took on a principalship and the superintendency. She contends that balance is important; one way she maintains balance is by bringing her husband to many events and by rising early and using the quiet of the morning to meditate and "center herself" for the day. This leaves the evenings without email and business whenever possible. These practices made her mindful of others around her and the importance of their balance as well. While they do not always achieve balance with the ebb and flow of 12-hour days, she tries to support a sense of balance as much as she can and repeats the mantra "family comes first." 
Carrie's proudest accomplishment as superintendent of Margarita Meadows Unified School District has been her success at shifting the culture and conversation in the district to that of a "community of we instead of $u s$." It's critical, she emphasized, to have a "common vision of where we're going." Her advice to aspiring female leaders is not to be afraid to step forward in the unknown. If one only moves in areas where the answer is known, then one will never move forward. Regardless of gender, you have to be courageous. One needs the passion and a vision of where it is you believe you could lead others to go and to not be afraid to do it. It's the fear of the unknown that creates the inertia that keeps you where you are. And finally, reach out to others.

Barbara Breakingthemold, Live Oak Unified School District

Barbara Breakingthemold was selected for participation in the study because of the API growth, size, type, and location of Live Oak Unified School District, as shown in Table 14. 
Table 14

Demographics and Academic Performance, Live Oak Unified School District

\begin{tabular}{|ll|}
\hline Grade span & $\mathrm{K}-12$ \\
\hline Enrollment & 13,634 \\
\hline Number of schools & 18 \\
\hline Ethnicity & \\
White & $52 \%$ \\
Hispanic & $29 \%$ \\
African American & $2 \%$ \\
Asian & $7 \%$ \\
Other & $10 \%$ \\
\hline English learners & $14 \%$ \\
\hline Free/reduced-price meal program & $23 \%$ \\
\hline Superintendent temure & 4 years; started 2009 \\
\hline API at start of tenure & 817 \\
\hline 2013 API & 840 \\
\hline API growth & 23 \\
\hline
\end{tabular}

Live Oak Unified School District serves a suburban city surrounded by vineyards, farmland, and cattle ranches that give the area a western image and feel. The city of Live Oak has a population of about 84,000 and encompasses 26.44 square miles east of the bay. Many families move to Live Oak, a middle- to upper-middle-class bedroom community to the high-tech industry, in pursuit of slightly more affordable single-family homes and a more relaxed, less congested lifestyle. Live Oak Unified School District is a midsize district comprising 18 schools: nine elementary schools, two K-8 schools, three middle schools, two comprehensive high schools, and three alternative schools, with a total enrollment of roughly 13,634 students. Approximately $52 \%$ of the student population is White, 29\% Hispanic/Latino, 2\% African American, and 7\% Asian, and $10 \%$ identify as two or more races, or "other." Fourteen percent of the student population are English learners, and 23\% of the students qualify for free or reduced-price meals. The 
percentage of Latino students and English learners has been slowly but steadily rising in the last decade, and the socioeconomically disadvantaged population has dropped slightly since Barbara Breakingthemold began her tenure.

Barbara Breakingthemold has served in the position of superintendent for Live Oak Unified School District for about four and a half years. During her tenure, her district's API growth has risen a very respectable 23 points. At age 48 , she is the youngest sitting superintendent of the study's participant pool, and when she took the reins at age 44, she was likely one of the youngest female superintendents in California in a district this size. Barbara spent most of her still burgeoning career in the Live Oak USD following 10 years as a special education paraprofessional and a teacher and activities director at the middle and elementary school level in a neighboring district. In her current district, she served as a teacher on special assignment for curriculum and special projects $\mathrm{K}-12$, principal of a middle school, director of curriculum, and then assistant superintendent of educational services for an 11-year period before stepping into the position of superintendent. Her academic and professional honors underscore her steep and rapid career trajectory. She was Region VI ACSA Administrator of the Year, Disney Teacher of the Year, Phi Beta Kappa at UC Berkeley, summa cum laude, English at UC Berkeley, magna cum laude, with a general scholarship at UC Berkeley and membership in National Golden Key Honors Society.

Barbara not only did not aspire to be a school superintendent, but also never intended to work in $\mathrm{K}-12$ public education. Her goal was to become a professor of English literature. With her academic accolades, she was set to accept a full fellowship to 
Brown University and turned it down to attend a doctoral program at UC Davis to stay near her new fiancé. Then, one year into her marriage, she became pregnant, which also corresponded with the devastating discovery that her husband had a girlfriend. She dropped out of her UC Davis Ph.D. program and moved back in with her parents to regroup and plan how she would raise a son by herself. While she entertained, in her words, "a pity party for herself," her father helped her to stop wallowing in her grief and focus on her son, who needed a mom. This motivated her to begin searching the want ads for a job to support her son and found an ad for a special education aide. She loved those Sped kids, she recalled, and she never looked back.

Even as a teacher and activities director, Barbara remembers having a negative image of the superintendent and his "entourage of district office people" until he came to her classroom and made a connection with her kids. She remembered

assuming that superintendents were these people that were unapproachable and nobody knew who they were, so I realized you can be both. I did not have a great opinion of the superintendent, but I saw you could still be connected with kids, and that was always my concern. I've always been a natural leader, but I always thought that people who went to work at a district were avoiding kids.

The image of a superintendent in the eyes of this classroom teacher was negative because it appeared so disconnected to the job of an educator. Even teachers who were natural leaders, like Barbara, could not comprehend what leading a school district would look 
like. At minimum, it appeared to her that whatever it was, it definitely did not involve kids.

Barbara's motivation to become a superintendent was also mitigated early in her career because her professional aspirations were heavily influenced by remarrying a man who had young children. Therefore, her career meandered around her path of raising children. Career decisions followed the milestones of her children because that's where "the female thing comes in. I was not going to be a 'less than parent." She explained:

Once my kids got out of elementary school, I became a teacher on special assignment. Then, once they were in middle school, I went to the middle school as principal. Once they went to high school, I went back to the district. Once they were in college, I moved higher in the district. Once they were all in college, I started my doctorate program and became superintendent. I kind of layered it.

Not surprisingly, this young, attractive female administrator did face genderbased obstacles in her career path. For example, she acknowledges her enthusiasm and Italian mannerisms that caused her to wave her arms (once, even knocking over the boardroom microphones) may have caused her to be seen as "ditsy" and thus triggering the labels "cheerleader" or "sorority girl." She recounted a clear case of sexual harassment with a male supervisor when she became director of curriculum. She was aghast when she heard him launch into:

Now I wanna talk about your tits. ... When you don't wear a jacket or cover your tits, all of us, especially if it's a cold [day], we're all looking at your nipples. . . . 
And sometimes you're touchy.... If you touch me here, that's like a direct line to my groin.

However, surprisingly to her, she encountered more unsettling problems being a young, attractive female in the position of superintendent. She described a painful recollection of sexual advances by a prominent businessman in the community who used his donations to the school district to gain access and privilege to her company. She recalls being deeply conflicted about accepting his money for the schools. She ultimately took it, but she retrieved the confidence to tell his associates about his behavior and her discomfort. However, the most conspicuous and repeated gender biases came from female members of her school board and from the women in the search firms. She would receive comments about how she dressed and wore her hair. In a waiting room, a search-firm female looked at her directly and told her that she mistook her for a stewardess. She recalled that she was wearing a navy blue suit. Additionally, a female board member told her she looked like a "cheerleader" and recommended she should wear nylons, close-toed shoes, and cut her hair short. Barbara remarked that she also feels the board members, in general, have more relaxed boundaries with her because she is a woman. On one hand, she senses relaxed boundaries with the female board members, who seemingly prefer to be friends more than professional colleagues. On the other hand, their visiting her house and calling her on weekends would seemingly be less likely if she were a man; she feels that they would respect a man's family and privacy more than they do hers.

When reflecting on topic of gender, Barbara concluded that her most profound professional betrayal came from the female superintendent she served in this district. She 
recited several indicators of how she actively blocked both access to the board and thwarted the board's consideration of her candidacy for superintendent. Board members later told her that the sitting superintendent told them lies about her planning to leave and not wanting to work in their district. Other cabinet members also told her that she secretly convinced the board to appoint the $\mathrm{CBO}$, and they acquiesced to interim, as he was near retirement. It pains her to think that she thought of her as a mentor and as a friend, but in retrospect, Barbara now realizes that her superintendent felt threatened by the thought that people would discover who was really behind all the innovation and major initiatives the board applauded, should her successor be her assistant superintendent of curriculum. The retiring superintendent purposely isolated from the board and reprimanded her if she spoke directly to them, saying, "You are not the voice of the district!"

She also acknowledged that she has observed many female colleagues "who have made choices," and she feels strongly against women having to do this. By "choice," she referred to a mutually exclusive decision between career, and children and family. Her female predecessor didn't have children, a partner, or even pets. Barbara implied that this negatively impacted her predecessor's leadership because she didn't treat her team like family, and she did not respect a decision to put family first when the need arose. She couldn't put her finger on it, but she definitely felt that "making the choice" and giving one's full identity to the job, somehow took the humanity out of the person. She has always been committed to balancing both family and career because it made her a welladjusted, compassionate leader. She also is committed to mentoring her management team to value family and to make accommodations when necessary. 
Her main objective in education before and after taking on the role of superintendent has been to "raise the consciousness" toward disenfranchised youth. When she was a drama teacher, she would get comments such as "oh, you teach delinquent drama," or when she taught student government, her colleagues called her class “opportunity leadership.” Yet, she proudly defended marginalized students:

Everyone has something to offer and contribute and make an impact. You don't have to be popular or have the most votes or have the most money, you just have to have a service-oriented mind-set. Everyone can be a leader. So we had these amazing students who were basically running the school.

Barbara referred to her favorite speech, Martin Luther King Jr.'s Drum Major, to illustrate her point about what she tried to teach her students about leadership. She summarized the key idea:

Everybody wants to be first. Everyone wants to lead a parade. Everyone wants to know they've done a good job and receive praise, and it starts with a baby's first cry for attention. You want to be heard. You want to be noticed. Everyone can be noticed because everyone can be great in service. He [King] says you can be great, because you've done good things. It doesn't have to be for profit. It's what I have modeled.

Her family grit and her disadvantaged early years heavily influence the perspective of Barbara's social justice lens. She proclaims that she has "intense passion for the 
underdog" because she has always related personally to their situation. Reflecting on her childhood, she recounted:

We were going through dumpsters when we were little. Some people wouldn't let us play at their house because they thought we were "those people." My father was an alcoholic and very abusive. My brothers and sisters and I were smart, but it was lost because we were not glossy.

She believes that there are a lot of kids who are, like she and her brothers and sisters had been, "not prepackaged for success." Many kids need to be given the chance to show what they have to offer, but they haven't been given the opportunity. However, she points out that her empathy does not get in the way of her high standards for all students. In fact, it fuels her commitment to open access to college preparatory courses for even her most at-risk students because she believes sympathy can be the enemy of "those people," since it can greatly lower expectations, and low expectations are self-fulfilling prophecies for the poor.

She describes one of her most difficult tasks when she worked to convince her English language development and special education teachers to increase rigor in their classrooms. Following her exacerbating exchange with the kindergarten and first grade teachers, she recounted:

They had high care and low demand, I learned as we interviewed them. The students never had preschool, and the teachers felt they [the special education and English learner students] needed to socialize and learn to share. "We can't stress 
them out with academics," the teachers explained. "Well, no," I thought, "instead you're going to stress them out when they can't get a job." So, kindergarten and first grade was socializing and playing house!

These teachers taught in her highest poverty, lowest performing school, and as she put it, they "cared for them to death. All they did was care, but they completely had no expectations. They coddled and babied them, and they got nothing." At this point in the interview, she got up and drew a chart on the white board in her office to explain the concept she uses with her staff. Her "expectation chart" is shown in Table 15.

Table 15

Expectation Chart Provided by Barbara Breakingthemold

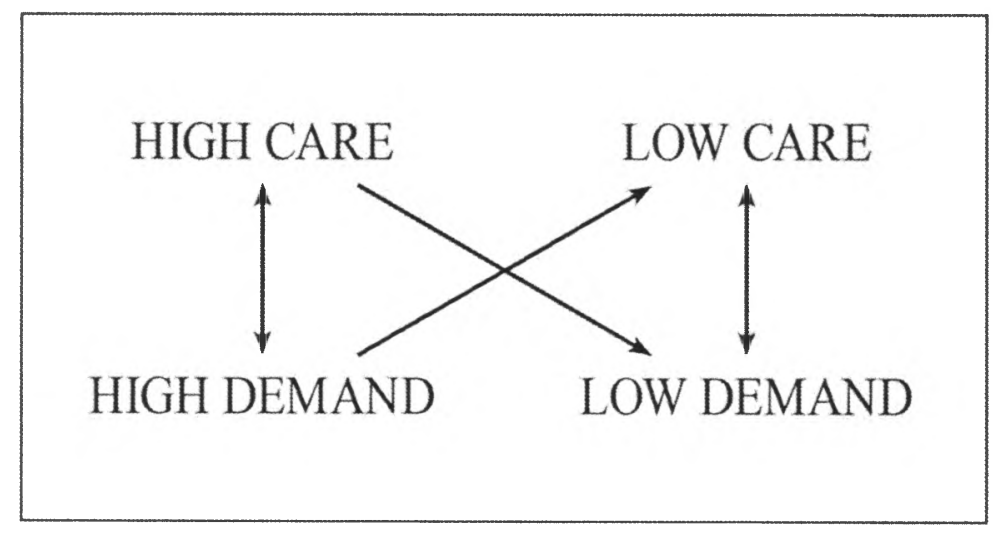

Barbara describes her leadership behaviors as centering around a "high care, high demand" mentality. She explains that she cares about the students and their rough circumstances, but that their circumstances cannot be used as an excuse for low achievement. One cannot care and then never expect anything from them. She wants them to be successful in this competitive world, so she insists that educators have "high 
care, high demand." Her anecdote about the ELD and special education teachers was an example of "high care, low demand," which is fairly common for educators whose strong sense of compassion can inadvertently impede student achievement. The last example she gave was "high demand, low care." This, she said, is a common blind spot created when accountability-centered or content-centered educators put high expectations and pride above their caring about the kids. She believes this only achieves short-term gains because "you don't get commitment, you only get compliance."

She also confronted her third grade teachers about their $15 \%$ proficiency in math. She explained that students could literally guess on such tests and show a $15 \%$ proficiency. She also confronted the reality that many of the teachers there would not put their kids in their own school. She opened up this dialogue in a motivational way, but she challenged them to step out of their bubbles and stop believing that their instructional strategies were actually working for all children. They were, she believed, actually teaching to what she called "kids who are packaged for success." They were focusing their efforts on kids who taught themselves, and if they didn't learn, their parents were going to make it happen. Also, the teachers had not made any adjustments for the new student population that needed their support and expertise. Recently, Barbara wrote an essay about this concept called "Buried in the Burbs." In it, she points out that her community's struggling migrant students are invisible and that the changing demographics are being carefully disregarded or overlooked. She stated incredulously, "there was a Confederate flag flying, and no one is questioning that?" She urgently wanted to raise the consciousness in her community. 
Barbara's proudest achievements, at the superintendent level, reside in a bigger picture. Well before she began these types of deeper conversations about expectations for all kids, she insisted on repairing and strengthening the relationships among the people and the organization. Stepping into her first superintendency, she immediately became aware that she "inherited" arbitration: "I inherited a huge lack of trust; dysfunctional board meetings where people were joking, and hiring people who had not been vetted." According to Barbara, the students suffered for years because of this organizational dysfunction, and it was her first priority to create a culture within her organization that would be receptive to the tremendous amount of work that needed to be done to improve the education they were providing the students in Live Oak USD.

This experience of endeavoring to change culture caused Barbara to have an epiphany concerning her career path. She spent a great deal of time and resources helping struggling teachers develop lessons and curriculum, constantly supporting professional growth, and trying to teach teachers and district managers to have the mind-set necessary to positively impact academic achievement. Yet she could have saved time and resources if she had pursued a position in human resources (HR) and been the one to hire the best people for the job in the first place. She used a saying to illustrate her epiphany,

If your company's mission is to climb a tree, do you hire a squirrel or train a horse? I've been training too many horses; we have not hired the best people in the first place ... so if I ever get a "do over," I would be in HR. 
Barbara's leadership blends communal and agenic in a high care, high demand conceptual model. She explains it as caring so much that she does not want her people to be in a position where they are not competent or successful: "I'm going to hammer them every day if they're not up to par. And that's not good." At the end of her second year as superintendent, she made seven principal and cabinet changes because her leadership team, she insisted, needed to perform at the highest level and set the bar in order to lead their teachers and schools to greatness.

\section{Susan Systems, Pilgrim Park Unified School District}

Susan Systems was selected for participation in the study because of the API growth, size, type, and location of Pilgrim Park Unified School District, as shown in

Table 16.

Table 16

Demographics and Academic Performance, Pilgrim Park Unified School District

\begin{tabular}{|ll|}
\hline Grade span & $\mathrm{K}-12$ \\
\hline Enrollment & 14,923 \\
\hline Number of schools & 15 \\
\hline Ethnicity & \\
White & $50 \%$ \\
Hispanic & $10 \%$ \\
African American & $2 \%$ \\
Asian & $32 \%$ \\
Other & $6 \%$ \\
\hline English learners & $7 \%$ \\
\hline Free/reduced-price meal program & $6 \%$ \\
\hline Superintendent tenure & 4 years; started 2009 \\
\hline API at start of tenure & 903 \\
\hline 2013 API & 815 \\
\hline API growth & 12 \\
\hline
\end{tabular}


Pilgrim Park is located in a major suburb identified by the U.S. Census as one of the wealthiest middle-sized cities in the nation and was included on Money magazine's 2014 list of the "50 Best Cities to Live." Pilgrim Park’s highly educated population and workforce reflect a community that values education and actively supports a preeminent school system, which ranks among the top ten in California. Pilgrim Park Unified School District is the second largest district in the study, with an average daily enrollment of just under 15,000 students attending 15 elementary, middle, and high school sites. Approximately $50 \%$ of the student population is White, $10 \%$ Hispanic/Latino, $2 \%$ African American, and 32\% Asian, and 6\% identify as two or more races. Seven percent of the students are English learners. Six percent of the students are eligible for free or reduced-price meals, the lowest percentage of low-income families in the study's participating districts.

At age 56, Susan Systems is four and a half years into her first superintendency. She spent 23 years working her way through two neighboring districts before reaching the superintendent's seat in Pilgrim Park Unified. She spent 12 years in the elementary and middle school classrooms, six years in site administration at the elementary level, and five years at the central office of a large $\mathrm{K}-12$ district (ADA 31,000) overseeing curriculum and instruction.

Susan's career path, which was focused heavily on instruction, did not point toward superintendency, even when participants of an interview panel were certain she would be a superintendent sooner than she anticipated. She recounted that when she first 
got her principalship, a couple of the people who had been on the interview team repeatedly told her:

"You know, when you interviewed, we just knew, 'She's not going to be here very long. She's going to be a superintendent."' And I just kept laughing, because honestly, that was the farthest thing from my mind. . . I loved students. I loved schools. I've always loved education, and "I'm good where I am."

Somehow loving schools and education did not seem to equate to a superintendent's track. Susan's statement implied that aspiring to be a superintendent, is possibly too far from the classroom or too ambitious for an educator, for it meant betraying one's love of students and love of schools and education. Susan felt that the superintendency "fell into her lap" because of the work she was doing. She was always excited about learning, which meant going to school and going to workshops and getting more information. She pursued staff development and district-wide events, and before she knew it she was asked to come to the district. Because she had been there for 13 years and had come up through the ranks of teacher, principal, and director, she believes her retiring superintendent saw her qualifications and began asking her to fill in for him at many superintendent-level events and activities. This is when she felt she was ready to be a superintendent. Even though she was aware that her male counterpart in human resources was expecting to be next in line to the superintendency, she was given even more confidence when the leader of the superintendent's academy sponsored by the Association of California School Administrators (ACSA) encouraged her to apply. 
Susan recognized that she received a lot of encouragement and support in her career. First, from her family, and then from the superintendents she served. She strongly emphasized the support of a very strong, "incredible" female superintendent who continually told her she would be a superintendent when she was a teacher and a principal. She always looked up to her. Her male influences include her father and brothers, but are most prominently her husband and sons. The irony does not escape her as she acknowledges that her husband is Iranian and comes from a culture that most Americans see as a very sexist, male-dominated society. She describes her husband as the one who does more household chores and is happy to support her career even with his own demanding high-tech job. Although she admits that her sisters, who are much older, had little of the opportunities she had, she gives the credit to her brothers, who now live in Iran and Canada, for "treating her like a boy" and "paving the way" for her.

Because she is the only superintendent in the study who marked a category other than "Caucasian," our interview was sparked instantly by a conversation about equity and her perception of the "narrow-minded" and "ethnocentric" education in America. She bluntly describes the racism and sexism in America as

subtle, yet very real. We share with the entire world that we are the best. We are the most fabulous system, and there is no such thing as racism and no sexism. Then when people [like my relatives] come, they see that it's not that different.

Referring to conditions in her district and community, she candidly remarks, 
In [Pilgrim Park], it's hard to be poor. It is so hard to be poor here because it's in your face. It is a very small town, and everyone knows everyone. For example, a capable kid wanted out of an AP class because he had to sit next to kids who lived in houses his mom cleaned.

Exacerbating this acute example of a clash in race and class is what she calls the "ostrich effect." Both the educators and the community have their heads in the sand about the conditions of the poor in their schools and in their neighborhoods. On the surface, according to Susan, the district is a very high achieving district as indicated by its high API rank, but once she "started unpeeling the onion," she saw the "biggest achievement gap." She believes her unique perspective as both the outsider and the oppressed allows her to see the "forest through the trees," to really see the harm being done when, for example, teachers give projects to cooperative groups to work on only at home, though some of the kids "can't get inside the gates." She recounted passionately, I remember suffering through high school because I came here not speaking . . . English. I honestly went through a very, very difficult time. . . . I remember being bullied on a daily basis at high school. I remember not being supported by some of my teachers, and then I remember the teachers who supported me and helped me get through. So I know exactly what it's like to be a non-English speaker . . . and to encounter racism.

The drive to help the underserved, invisible students in her affluent city and to help her community become conscious of what it means to achieve equity has been Susan's 
proudest, but most difficult achievement. She explains how the governing board initially acknowledged the need to close the abnormally large achievement gap, and that they wrote the goal of closing it into their strategic plan, but when "we got into the actual work and [were] talking about equity, [that] is when it was like, .. 'Ohhh, I get it, however, don't go too far!"' She said she would need to remind the board repeatedly of their goal to close the achievement gap, and that it meant there was going to be opposition and tough decisions. However, in the end, she said most of the backlash was from the teachers and not the board.

Susan keeps pushing forward with the conviction that being a superintendent is a "life, not a job," even though, considering all the bullying she faced as a child, she is adamant that she has faced more sexism and racism as an assistant superintendent and superintendent. When she was an assistant superintendent, she was the only woman in the executive team. She often felt not only as if she was going into battle and "ganged up" on every time she went into cabinet, but also that her ideas were easily dismissed or, at best, used, but attributed to other members of the cabinet. As a superintendent, "being a woman and being Iranian. . . . And being Muslim. I mean they name it. . . . [It is] a double whammy." She laments that it often feels that if she were not a woman,

I would not get all the push back I got. I feel that as women, we work a lot harder than men to do the same thing, to prove ourselves. ... I hear some of the male counterparts leave at 5 p.m.; [they] don't check e-mail, and the men either don't show up to many of the events, or they leave early. . . I'm working 18 hours a 
day and sending e-mails out at midnight because I don't have time during the day. I go to every event, and it's still not good enough.

Susan has been keenly aware, in the last two years in her very affluent, very conservative community, that being Iranian and a woman has been a disadvantage. She has been called a "Muslim terrorist" in blogs, and she has confronted the newspaper about printing racist commentary demanding that "lazy Mexicans" be sent back and other for publishing opinion articles that pointedly argue, "Don't you think people move to this town because there's only 1\% African American?" Instead of toning down her charge for equity, she has stood firm and vowed to "never negotiate and never compromise" when it comes to the students. She holds the same standards for those who work with her. If she finds people in her organization who do not have the passion she has, then she "has no qualms about asking them to leave or helping them find another passion."

Susan was not the only one who felt oppressed in this glossy community. When she undertook a large interview and survey initiative with the students, she found that the students who looked “different, with purple hair, [or were] gay, [or] lesbian," didn't feel comfortable at school. And when the "Hispanic parents were interviewed in Spanish, they said they do not feel welcome in town or at the schools." Her response to this information was to hire three parent liaisons and to bring in an organization called "Loving Solutions" to take on conflict mediation with the students.

Susan manages the principals and the organization differently than her predecessors by creating an open system that is more inclusive of their voices and input 
in planning and execution. She moved her system from a vertical hierarchy to a more horizontal structure. An example of how she instigated a major shift from the traditional top-down hierarchy are a series of exercises she used with her cabinet and principals. She put her cabinet in a fishbowl arrangement (chairs arranged in an inner circle with additional chairs arranged in concentric circles for others to listen and observe) to discuss what they had accomplished and had the principals sit outside to observe and critique. A traditional structure would not put their executive team in a vulnerable position for open criticism from the lower ranks. She explained that these types of exercises are part of the training in organizational development and systems thinking that originated from organizational management gurus Peter Senge and Peter Drucker. Peter Senge, she went further, "talks about the concept of lateral inference" in The Fifth Discipline (2006). She had her whole management team trained in Senge's concepts that underlie how to be a learning organization; they learned how to make a decision as a system, rather than making decisions as individuals in individual departments. She explains,

It's a system ... we are mistaken if we think we change things a little like "one piece here, one piece there." We now look at everything as a system and how everything we do is connected. When I make a decision over here, it is going to impact everybody else in our system, so we need to get everybody on board to see what we need to do to support them.

Susan emphasizes that as a leader, it is important to "start from the end" and establish "desired outcomes as a group" in the form of "agreements" about big-picture beliefs and values. This is important because, according to Susan, if one does not start with the 
outcomes articulated, with a clear vision and measurable indicators of what it looks like to have reached the goal, then "you spend all your time convincing people" on the team the reasons behind decisions and why they should be making certain decisions. She states unequivocally,

I believe that as a leader, when you are about to make a decision, you really need to always look at your entire system and ask yourself, "Who is involved? Who needs to know? Who do we need to get feedback from? Who's going to get upset by this, and why? How do we provide information and an opportunity to have their voice heard so that it's successful?" Because when you don't do all of those things, you are going to have to spend more time and energy to convince people afterwards.

When faced with an issue or decision, her leadership behavior always focuses on the people in the context of the system, the people affected in the system, as opposed to thinking of issues as individual problems to solve in reaction to isolated events or concerns. The system breaks down when individuals negotiate and barter a desired outcome in order to "put out fires" without looking at the impact on the stakeholders in the whole system. How the system reacts to the small issues that arise daily are indicators of the health and overall capacity of the system to reach its goals and positively impact student achievement. 


\section{CHAPTER 5. FINDINGS AND ANALYSIS}

Introduction

This study explored a paradigm for effective superintendent leadership grounded in the research on common leadership behaviors of women in educational leadership conducted by Grogan and Shakeshaft (2011). The research questions investigated are:

1) How do female educational leaders who succeed in attaining the $\mathrm{K}-12$ superintendency describe barriers and facilitators to their success?

2) How do female superintendents describe leadership styles and behaviors that have enabled them to attain a superintendent position and to facilitate positive, measurable change in their school systems?

This chapter presents the findings of data collected through a short demographic questionnaire, document analysis of résumés/curricula vitae, and interviews of nine highly successful female superintendents; it then presents an analysis of the data. First, the information collected through the questionnaire will be analyzed. Second, career pathway data from the résumé review will be presented and analyzed. Third, data from coding of the interview responses will be presented, and the analysis of interview responses in relation to Grogan and Shakeshaft's common female leader characteristics and behaviors will be described. Next, two behaviors noted among highly successful female superintendents that are not included in Grogan and Shakeshaft's "five ways women lead" will be discussed. 
Demographic Questionnaire

Table 5 ("Participant Demographic Results Chart," Chapter 3) and Table 17 summarize female superintendent data collected in the questionnaire. 
Table 17

Summary of Highly Successful Female Superintendent Data Collected in the Questionnaire

\begin{tabular}{|c|c|c|}
\hline Questionaire Results & Tally & $\%$ \\
\hline \multicolumn{3}{|l|}{ Race } \\
\hline Caucasian & 8 & $89 \%$ \\
\hline Other & 1 & $11 \%$ \\
\hline \multicolumn{3}{|l|}{ Relationship status } \\
\hline Married & 8 & $89 \%$ \\
\hline Single/never married & 0 & $0 \%$ \\
\hline Single/divorced & 1 & $11 \%$ \\
\hline \multicolumn{3}{|l|}{ Family } \\
\hline Children & 9 & $100 \%$ \\
\hline No children & 0 & $0 \%$ \\
\hline \multicolumn{3}{|l|}{ Sexual orientation } \\
\hline Heterosexual & 9 & $100 \%$ \\
\hline Gay/lesbian/trans & 0 & $0 \%$ \\
\hline \multicolumn{3}{|l|}{ Age at interview } \\
\hline $40-48$ & 1 & $11 \%$ \\
\hline $49-57$ & 3 & $33 \%$ \\
\hline $58-67$ & 5 & $56 \%$ \\
\hline \multicolumn{3}{|l|}{ Age at first superintendency } \\
\hline $38-45$ & 2 & $22 \%$ \\
\hline $46-53$ & 5 & $56 \%$ \\
\hline $54-61$ & 2 & $22 \%$ \\
\hline \multicolumn{3}{|l|}{ Years supt. in current district } \\
\hline 4 years or less & 6 & $67 \%$ \\
\hline 5 years or more & 3 & $33 \%$ \\
\hline \multicolumn{3}{|l|}{ District type } \\
\hline K-5 (elementary) & 0 & $0 \%$ \\
\hline K-8 (elementary + middle) & 3 & $33 \%$ \\
\hline $\mathrm{K}-12$ & 5 & $56 \%$ \\
\hline $9-12$ (high school) & 1 & $11 \%$ \\
\hline \multicolumn{3}{|l|}{ District size (no. of students) } \\
\hline $4,500-9,000$ & 1 & $11 \%$ \\
\hline $10,000-20,000$ & 8 & $89 \%$ \\
\hline
\end{tabular}

Demographic Questionnaire Findings and Discussion

The successful female superintendents in this study largely had more similarities demographically than they had differences, generally falling within the national average 
profile of white, heterosexual, married with children, and between 50 and 65 years of age. The American School Superintendent: 2010 Decennial Study (Kowalski et al., 2011) reported demographic data respective of size of the districts. The districts falling within roughly the size parameters of this study $(3,000$ to 24,000$)$ reported that $91 \%$ of superintendents were white, $91 \%$ were married, and the modal age range is $56-60$, irrespective of gender. The 2010 Decennial Study (Kowalski et al., 2011) did not collect data on children or sexual orientation. In this study, correlating closely with the national average, 8 of the 9 superintendents were Caucasian, and 8 of the 9 superintendents were married. Six of the 9 had never divorced and were maintaining long-term marriages. All women in the study have been married. All 9 participants had at least one child. All 9 participants described their sexual orientation as heterosexual. The length of tenure of all the women is relatively short, with 6 out of the 9 falling between 2 and 4 years as superintendent. This is short of the national modal range of tenure, which is 5-8 years. Nationally, $74 \%$ of women reported tenure of less than 8 years as superintendent compared to only $56 \%$ of men. Nationally, female superintendents' tenures remain shorter than men's (Kowalski et al., 2011). Brunner and Grogan (2007) report that nearly three fifths $(58 \%)$ of men have been in the superintendency more than 7 years, as opposed to only $31 \%$ of female superintendents. Shorter tenure has been attributed to women's relatively older age upon entering the superintendency and to their focus on the classroom, rather than to politics, and women's stereotypically highly ethical, "doing what is right for kids regardless of the circumstances" stance causing them to resign in protest (Funk et al., 2002). The data in this study support each of these claims. 
The greatest differences among the women in this study were in the ages when they became superintendents. Although the majority of women were in their 60 s, the age when they became a superintendent spanned 27 years, from 38 to 57 . These findings, divergent from the national average of superintendents, showed the modal age range as 60-65, whereas the 2010 Decennial Study puts the national modal age range at 56-60, which is inclusive of males (Kowalski et al., 2011). The older age range of our female participants can be attributed to the slower career pathway trajectory and to time spent raising children (Grogan \& Brunner, 2005; Kim \& Brunner, 2009). According to Kim and Brunner (2009), men tend to take a speedier and more direct route to the superintendency, with more "line" positions, and women take a slower, less direct route by taking more "staff" positions and by staying in the classroom longer. The findings of the document analysis of the résumés of participating superintendents supported this claim, as it showed lengthy classroom tenures, several supporting staff roles in a central office, and $100 \%$ of the female superintendents raising children.

The large age span at which our female participants had entered the superintendency aligns with the findings of the 2010 Decennial Study (Kowalski et al., 2011), which reported the percentage of both younger and older superintendents has increased. Between 2000 and 2010 the number of superintendents nationally over the age of 60 increased by $126 \%$ (Kowalski et al., 2011). This dramatic increase could partially be attributed to the rising percentage of female superintendents, who tend to come to the position older and later in their careers, which almost doubled, increasing from $13 \%$ to $24 \%$ in the last decade (Kowalski et al., 2011). Although the 2010 Decennial Study 
showed a $50 \%$ increase in the number of superintendents below the age of 46 , none of the present study's women were below the age of 48 , and only 2 began their careers below the age of 46 . Nationally, $56 \%$ of men entered the superintendency below the age of 46 and only $30 \%$ of women. As confirmed by the older age of the majority of this study's participants, a contributing factor to female superintendents failing to achieve parity in numbers to male superintendents is their relative delay in entering the position. Reasons for the delay that are supported subsequently in this study include raising children and tending to other family commitments, lack of or delayed aspiration to become a superintendent because of a focus on learning, rather than selecting an expedient path to the superintendency, and both length of tenure in the classroom and number of administrative roles served before taking the superintendency.

\section{Résumé Document Review Findings and Discussion}

Of the 9 participating female superintendents, 6 provided full curricula vitae (CVs), 1 provided a one-page biography, 1 provided an abbreviated résumé, and 1 did not provide written documentation for analysis (Table 6, “Career Pathway Chart: Curricula Vitae/Résumés," Chapter 3). Key findings surround trends and length of tenure in types of positions held throughout their career paths, education, awards, and emphasis placed on professional development, professional networks, and community affiliations. All résumés and bios provided began with extensive teaching careers in elementary, middle, and high school levels. The average teaching tenure was 9 years, with the shortest at 5 years and the longest at 14 years. This falls within the national average teaching experience of female superintendents, which is 6-10 years, according to the American 
School Superintendent: 2010 Decennial Study (Kowalski et al., 2011). That study also found that overall, women have more teaching experience than men, with $87 \%$ of female superintendents reporting 6 or more years of teaching experience, compared to $72 \%$ of men (Kowalski et al., 2011).

The most common leadership experiences found in the CVs, résumé, and bio were the positions of director of curriculum and instruction and assistant superintendent of educational services, with 7 of the 8 documents submitted listing one or both of the positions for $\mathrm{K}-12$ districts, most commonly both. The next most prevalent positions were vice principal, principal, and program specialist/coordinator at the central office level, with 5 of the 8 documents listing at least one or more of these three positions, and 6 out of the 8 documents citing two of the three. All but 2 superintendents served as principals. Regarding the 2 superintendents who did not list service as a site principal, each served in three or more central office staff positions in more than one district before becoming superintendent. The number of distinctly different titles held related to education before becoming a superintendent was between four and six. Six out of the eight documents listed five or more positions/titles preceding the superintendency. These results align with the Kim and Brunner's (2009) findings that men can more often jump from the principal position straight to the superintendency, and women more often tend to serve in several supporting central office roles regardless of a principalship before entering the superintendency, resulting in a significant delay and shorter tenures as superintendent. 
Five of the $6 \mathrm{CVs}$ cited awards of either teacher of the year of administrator of the year, and 5 of the $6 \mathrm{CVs}$ listed 10 or more professional development experiences, trainings, or certifications; one CV listed as many as 49. Eight out of 8 documents listed membership in professional organizations, the most common being Association of California School Administrators (ACSA) with 6 citations, and Association of School Curriculum Development (ASCD) with 4 citations. Finally, 5 of the 9 superintendents showed that they have earned both a master's and a doctorate. Four of the 8 documents presented affiliations with Rotary and/or the chamber of commerce in the community they serve as superintendent. The document analysis revealed commonalities in the career paths of successful female superintendents in the following areas: robust teaching backgrounds, experience in curriculum and instruction and/or coordinating specific educational programs, honors/recognition for excellence as teachers and/or leaders, extensive training beyond employment requirements and certification, networking and community connections, and advancement through higher education. Overall, these women presented experience, education, and accolades above and beyond basic competency and job experience. The CVs and résumés reveal that successful female superintendent candidates feel they need to present themselves as the best in one or more positions (shown by the awards), as the most educated (shown by layers of certifications and degrees), as needing to be knowledgeable in every function or discipline of an educational organization (shown by the expansive list of trainings covering finance, negotiations, labor law, instruction, etc.), and at the same time as willing to be deeply 
connected in the community in which they serve (shown by the community organization memberships).

Interview Data

Barriers and facilitators to success. The superintendents responded to questions about what had facilitated their successful ascendency to the position of superintendent, and what challenges or barriers they had experienced during their career trajectory or more recently while executing their role as superintendent.

Table 18

Number of Interview Responses Coded as Barriers or Facilitators to Successful Ascendancy to the Superintendency

\begin{tabular}{|lccccccccc|}
\hline \multicolumn{1}{c}{ Barriers/challenges } & & Facilitators/enablers \\
\hline & $\begin{array}{c}\text { Gender } \\
\text { before }\end{array}$ & $\begin{array}{c}\text { Gender } \\
\text { during }\end{array}$ & $\begin{array}{c}\text { Neg. } \\
\text { perception } \\
\text { of supt. role }\end{array}$ & $\begin{array}{c}\text { Family/ } \\
\text { mobility }\end{array}$ & Mentors & Family & Mobility & $\begin{array}{c}\text { Specific } \\
\text { experience }\end{array}$ \\
\hline Patricia Patterns & 0 & 3 & 0 & 0 & 0 & 1 & 0 & 1 \\
\hline Sandy Structure & 1 & 1 & 0 & 0 & 0 & 2 & 1 & 0 \\
\hline Mary Mediator & 0 & 1 & 0 & 0 & 0 & 1 & 1 & 3 \\
\hline Constance Culture & 0 & 0 & 1 & 0 & 0 & 2 & 0 & 1 \\
\hline Terry Teacherfirst & 0 & 0 & 1 & 0 & 1 & 0 & 0 & 1 \\
\hline Elizabeth Engager & 1 & 1 & 0 & 0 & 0 & 0 & 1 & 1 \\
\hline Carrie Community & 1 & 3 & 1 & 0 & 1 & 2 & 0 & 1 \\
\hline $\begin{array}{l}\text { Barbara } \\
\text { Breakingthemold }\end{array}$ & 1 & 1 & 1 & 0 & 0 & 0 & 0 & 0 \\
\hline Susan Systems & 0 & 0 & 1 & 0 & 1 & 2 & 0 & 1 \\
\hline Total responses & 4 & 10 & 5 & 0 & 3 & 10 & 3 & 9 \\
\hline Average & 0.44 & 1.1 & 0.55 & 0 & 0.33 & 1.1 & 0.33 \\
\hline Frequency rank & $4 \mathrm{th}$ & $1 \mathrm{st}$ & $3 \mathrm{rd}$ & $\mathrm{n} / \mathrm{a}$ & 5 th & 1 st & 5 th & 1 \\
\hline
\end{tabular}

Coded response data. Table 18 indicates the number of times interview responses were coded as "barriers or facilitators" to their successful ascendancy to and/or execution of their role of superintendent. Table 18 shows overall more responses coded 
as facilitators to success then coded for barriers. Twenty-five responses were coded to facilitators to 19 responses to barriers. This was anticipated due to the fact these women have achieved great success both during their career path and during their tenure as superintendents. Previous studies placed lack of mobility due to family responsibilities as a top-ranked barrier (Brown, 2011; Kim \& Brunner, 2009). However, none of these women mentioned that as a restraint in their careers. In fact, mobility was mentioned only positively when they spoke of their supportive families and husbands. It should be noted that several related delaying their ascendancy due to raising children, but none depicted this consideration as a challenge or barrier in any capacity. Gender discrimination was coded more strongly as a barrier while females were serving as superintendents than when they were performing jobs previous to the superintendent position. With an average response frequency of 1.1 , it was the top challenge reported by female superintendents. Gender discrimination was reported only minimally as a barrier during their career pathway to the superintendency, with an average response frequency of merely 0.44 . Family scored the highest for facilitating their success before and during their superintendency, with an average response frequency of 1.1. Experience was a close second as a facilitator of success, with an average frequency of 1.0.

Notable findings that emerged during interview data analysis were that the strongest barrier during the pathway to superintendency for women was their own negative perception of the role of the superintendent, which deeply impacted their aspiration. Additionally, contrary to the research on aspiring female superintendents and the importance of mentors to women and women of color, mentors were rarely mentioned 
as keys to their success. Although a few spoke of bosses who advocated for them or tried to push them forward in their careers, their support system was squarely placed within the family structure. Mentors for Susan, Barbara, Carrie, Elizabeth, and Mary were something they wanted to become to others because they lamented that the female networking system is still weak and was mostly nonexistent when they were experiencing the superintendency for the first time. Another notable finding regards the type of experience emphasized as an asset to being hired as a superintendent. When directly referencing reasons for being hired as a superintendent, the experience mentioned were in typically masculine-gendered career roles, such as facilities, construction, negotiations, bond measures, and high schools.

Leadership styles and behaviors for change. All of the superintendents in this study exhibited characteristics and behaviors that were crucial to defining the ethos of their schools. Personal perceptions coming from the highly successful superintendents during the interviews often related to the leadership behaviors described within the "Five Ways Women Lead" as defined by Grogan and Shakeshaft (2011, p. 5):

1. leadership for learning,

2. leadership for social justice,

3. relational leadership,

4. spiritual leadership, and

5. balanced leadership.

The number of responses by successful superintendents coded to Grogan and Shakeshaft's five most common leadership behaviors, plus two additional behaviors, of 
focusing on "systems thinking" and "redefining the role of the superintendent," are presented in Table 19. Much of the following discussion refers to this table. 
Table 19

Responses Coded for Female Leadership Behaviors

\begin{tabular}{|c|c|c|c|c|c|c|c|c|c|}
\hline Superintendent & Learning & Social justice & Relational & Spiritual & Balanced & $\begin{array}{c}\text { Subtotal ("five ways } \\
\text { women lead") }\end{array}$ & $\begin{array}{l}\text { Systems } \\
\text { thinking }\end{array}$ & $\begin{array}{l}\text { Change } \\
\text { leadership }\end{array}$ & Total \\
\hline Patricia Patterns & 5 & 5 & 5 & 3 & 2 & 20 & 18 & 5 & 43 \\
\hline Sandy Structure & 5 & 8 & 9 & 3 & 3 & 28 & 7 & 4 & 66 \\
\hline Mary Mediator & 5 & 7 & 6 & 3 & 3 & 24 & 3 & 5 & 59 \\
\hline Constance Culture & 3 & 5 & 6 & 1 & 3 & 18 & 5 & 9 & 32 \\
\hline Terri Teacherfirst & 5 & 7 & 9 & 2 & 1 & 24 & 6 & 6 & 36 \\
\hline Carrie Community & 4 & 3 & 9 & 2 & 6 & 24 & 5 & 14 & 29 \\
\hline Barbara Breakingthemold & 4 & 7 & 9 & 0 & 4 & 24 & 2 & 3 & 34 \\
\hline Susan Systems & 8 & 12 & 2 & 2 & 1 & 25 & 5 & 4 & 34 \\
\hline Total & 44 & 58 & 62 & 19 & 27 & 210 & 56 & 54 & 376 \\
\hline Average Frequency & 4.8 & 6.4 & 6.8 & 2.1 & 3 & 23.3 & 6.2 & 6 & 42 \\
\hline Ranked Frequency & 5 th & 2nd & Ist & 7 th & 6th & & $3 \mathrm{rd}$ & 4 th & \\
\hline
\end{tabular}

Note: The first five behaviors listed, and subtotaled separately, are the "five ways women lead" described by Grogan and Shakeshaft (2011). 
As noted in Table 19, not all female superintendents exhibited the characteristics and behaviors of the "five ways women lead" to the same degree, and four participants referenced Spiritual Leadership only very indirectly or not at all. However, when analyzing interview responses of the successful female superintendents as a group, evidence for all the "five ways women lead" was found. More of the successful female superintendent responses were coded to relational leadership and there were fewer responses coded to spiritual leadership than for other qualities. More responses were coded to the "five ways women lead" to Sandy, the only recently retired female with multiple superintendencies under her belt, and the fewest responses were coded to Constance, the only female who has spent her entire career in one district.

\section{Grogan and Shakeshaft's "Five Ways Women Lead"}

\section{Leadership for Learning}

Grogan and Shakeshaft's extensive meta-analysis of women administrators, the largest to date on the topic of women in educational leadership, which included superintendents, assistant superintendents, principals, and assistant principals, found that "instruction is central to women," planting leadership for learning firmly in the top five ways women lead (p. 18). Female educational leaders tended to initiate and advocate strong programs in staff development, to support classroom innovation, and to actively explore multiple instructional approaches. "Leadership for learning" means that women stress the importance of instructional competence in teachers and monitor accountability with respect to "task completion within instructional programs" (p. 18). The focus on instruction coincides with the social justice lens of most female administrators. Women 
are likely to push for instructional change that improves learning because they put learning and instruction at the apex of their leadership mission. Because change is now constant within schools due to changing student populations and to the shifting content requirements led by state and federal politics, "changes that women introduce in their organizations most often relate to the improvement of learning," and consequently, according to Grogan and Shakeshaft (2011), female administrators' decision-making practices are often "based on the priorities of student learning" (p. 19).

Coded response data. Below are some examples of coding points to strong evidence of leadership for learning made in interviews from each participant:

1. "I'm a big believer that the superintendent has to be really visible in classrooms and talking to teachers about instruction."

2. "I mean the whole curriculum and instruction package ... major changes to how teachers taught and the assessment and the data they had to inform instruction. It was big curricular stuff."

3. "I'd say academic achievement here would be my number one."

4. "I feel really, really good about ... the work we're doing around projectbased learning and creating culture at schools that empower students."

5. "We're only here for instruction, let's be honest ... instruction has got to be heart and soul of this work."

6. "It's a combination of really very solid instruction, a principal, assistant superintendent, and superintendent who know instruction and leadership." 
7. "My gifts lie in terms of curriculum ... building capacity to support teachers and learning is where my passion was in education."

8. “If you're really looking for change, if you don't understand the instructional program at the very deep level, the question is ... how much change are you going to get out of a $\mathrm{CBO}$ ? If there are any models out there, I'd love to see it."

9. "I'm an avid reader, and I am a lifelong learner, and I believe as a leader if you stop learning, you're done."

Each of these female superintendents acknowledge that in order to manage the district well, they must learn personnel and finance and attend to the politics of the job; however, their passion lies in watching students grow and develop, and they attribute much of their success in raising student achievement in their district to the depth at which they as superintendents understand the academic issues facing the classrooms in their districts. Their collective staunch belief in the importance of instructional leadership has increasingly strong support in the literature and is positively influencing women's likelihood to be hired as superintendents. Since the No Child Left Behind Act (2001) and California's recent adoption of the Common Core State Standards (CCSS) and the Local Control Accountability Plan (LCAP) are pressuring on school districts to improve student achievement, school boards are increasingly turning to women who place a high priority on enhancing student achievement while in the superintendency (Kowalski et al., 201 1; Brunner \& Grogan, 2007). Reciprocally, "the increased focus on academics and accountability should make the job [of superintendent] more attractive to more women 
who tend to have more focus on curriculum, teaching, and learning" (Brunner \& Grogan, 2007, p. 88). A pattern that emerged in the interviews for this study relating to leadership for learning was that the majority of these successful superintendents did not initially aspire to the superintendency because of the fact that the job appeared to be void of responsibilities that directly affected the classroom and was seemingly nothing more than a political figurehead position. The epiphany each experienced as she realized she could reconceptualize the job to fit her leadership for learning focus is discussed subsequently as an emergent theme of "redefining the role of the superintendent."

\section{Leadership for Social Justice}

Grogan and Shakeshaft's "leadership for social justice" theme is grounded in the history of women and their fight for equal rights, as well as in the social context of women's lives. Women's fight for equality and the innate responsibility they possess to raise and protect children provides "a strong overlay to the motivation of women in education" to weave social justice into their mission and vision for their schools (p. 10). According to Grogan and Shakeshaft, "women are likely to report that they entered the field of education because they wanted to change the status quo" and are prone to identify their jobs in education as "social justice work" (p. 11). Female leaders are duty-bound by a strong desire to transform the learning conditions and opportunities for children who have been marginalized by current educational policies and practices (Brown \& Irby, 2006; Grogan \& Shakeshaft, 2011). Leadership for social justice is a deep conviction to work at disrupting the reproduction of social systems that prevent disadvantaged youth from begin served well by the current systems entrenched in traditional hierarchical 
practices. Therefore, "the work," for Grogan and Shakeshaft's female social justice leaders, is often described in an evangelistic tenor and as occurring in partnership with teachers or "in a collaborative relationship" with various stakeholders" (p. 13).

Coded response data. Often the evidence for this characteristic came through during the interviews, as the superintendents talked about their mission and vision for their districts, which often overlapped with their instructional reform initiatives.

Examples of statements made in interview from each participant that were indicative of "leadership for social justice" are as follows:

1. "I can't fix everything. ... I can't buy everyone a home ... but I sure can make sure when they are at school that they feel just as important as anybody else."

2. "A lot of it has to do with my own upbringing with being a poor, disadvantaged kid myself, and my husband was a poor Latino kid, so from a really young age I've just really believed in public education for breaking that cycle."

3. "Kids said by far the number one concern of theirs is [that] there is a lot of racism and marginalization by other children and adults in our schools. That is a huge concern for me."

4. "I see it as one of our greatest accomplishments as a district, being relentless about working on equity. You just have to be relentless. You're going to get a lot of pushback ... you just have to do what's right for all kids." 
5. "We have a Confederate flag flying, and no one is questioning that? And so I felt that we needed to be raising that consciousness here."

6. "I have an intense passion for the underdog and kids that are what I call 'not prepackaged for success.'”

7. "One of our lowest performing schools which was also very high poverty ... they cared for those poor kids to death. All they did was care, but they completely had no expectations. They coddled and babied them, but didn't expect anything, and they go nothing."

8. "I believe in the importance of mixing up the kids. The research is clear about socioeconomically disadvantaged kids having the opportunity to be mixed up with kids who aren't socioeconomically disadvantaged."

9. "You have to be willing to change your professional practice. ... You have to be willing to take risks, and you have to believe that all kids can learn regardless of race or socioeconomic status."

All nine of the participating superintendents provided evidence in their interview that they promoted social justice to further the success of their districts. Table 19 reveals that Susan has the most coded responses for this characteristic. Of note is that Susan is also the only participant to mark an ethnicity other than Caucasian. While three other participants revealed disadvantaged backgrounds as feeding their inherent motivation to help the underserved, Susan is also the only superintendent who discussed experiencing racism, sexism, and prejudice in both her past and while currently serving as superintendent. While all nine of the superintendents referenced the desire to represent 
the underrepresented as a moral imperative, Susan's commentary connected most consistently to profound personal experiences. She revealed had deliberately brought in African American and Latino cultures into her leadership even though it admittedly caused a stir in her mostly white, affluent community. Grogan and Shakeshaft (2011) claim that the strongest examples of social justice leadership are found in the narratives of black women talking about their leadership. This proposition supports the finding in this study that life experiences are the strongest motivators for social justice leadership.

\section{Relational Leadership}

Grogan and Shakeshaft's "relational leadership" is just as much about a women's relationship to power as it is about her relationships with the people themselves. Relational leadership, according to Grogan and Shakeshaft, is "about being in relationship with others in a horizontal rather than a hierarchical sense" (p. 6). They go on to describe relational leadership as defined by how women conceptualize power. Because women tend to express more discomfort with being described as having power or being powerful, they will seek to expand everyone's power. The outcome of this sharing of power presents a more horizontal relationship, and this design is commonly illustrated as women describe achieving success with and through others, opposed to single-handedly pursuing a goal using positional authority.

According to Brunner (2000), as cited by Grogan and Shakeshaft (2011), "women's conceptions of power are closely tied to the importance they place on relationships" (p. 7). Using power to control damages relationships, but the use of power to help others forges bonds. Thus, female leaders will use the power in relationships, not 
simply at the level of individual consideration of the emotional needs of stakeholders involved, but also for the power of collective intelligence, to confront challenge and change. Because women come armed with the relational power to face change, it could easily be viewed as the foundational leadership belief through which all other leadership characteristics and behaviors are carried out. Subsequent discussions in this chapter will reveal the crux of relational leadership is the female's acuity to human dynamics and its impact on an organization's ability to carry out its mission or sustain any positive, measurable change.

Participants often expressed relational leadership in the context of how they were able to achieve goals and trusting relationships between stakeholder groups, whose relations were often expressed as lacking when they first arrived in their superintendent positions and were therefore the aspect most negatively impacting the ability of the district to achieve its goals.

Coded response data. Coding reveals evidence of consensus building, seeking diverse perspectives, sharing and building the leadership capacity in others, and highly collaborative behaviors. Examples of such statements include:

1. "I'm a firm believer that the relationship part matters. The focus of the work is on the kids, but the relational aspect is what's going to help us get there. It's about empowering the people you're with-building strong teams and empowering them." 
2. "I would say the team [is most important] because it is a team effort. I never do anything by myself."

3. "I've invested in the community because I live here ... I'm integrated wholly here. .. I l love that part of it, everywhere I go. I live and breathe, my social events are the schools, so that's who I am."

4. "My problem-solving method is collaborative. ... I really try to get people to push my thinking. I want to look at things from different perspectives. I have no problem making the decision, but I want the best thinking in the room before I make a decision."

5. "It's about relationships really. It's about the people in the room and valuing what they bring, even if it's not something that's in direct alignment with what you have. It's about building capacity in others."

6. "I think at the core of it you have to be a people person. You have to be somebody that genuinely and sincerely cares about the adults and kids in the system and really listens a lot and really can read the system as a whole and have your finger on the pulse."

7. "We hold a very high standard in this district. So that may be counter to the collaborative, but you can be collaborative and you can hold a high standard and create a culture where excellence is expected."

8. "I am always aware of who my audience is and what they're bringing to the table. Principals bring a different need than parents, and that's different than 
my cabinet, so I'm always aware of who I'm speaking to and what their responsibilities are and what some of their challenges are."

9. "It was a lot of conversation. A lot of time talking to individual teachers. ... 'I know you care about kids. Let me show you how this will help you care about the kids.' That was the hook for her."

10. "I believe in the phrase 'you should never ask anybody to do something for you that you don't understand what you're really asking them to do.' You should know what you're asking your custodians to do. You should sincerely know what they value, and you should do as much work as you can to figure that out, because then you'll have an organization they want to work for." As shown in Table 19, evidence for "relational leadership" is seen in all nine participants and very strongly apparent in eight of the nine superintendents, making it the strongest of the five ways women lead. Six out of the nine superintendents had the most codes for relational leadership compared to the other four themes, and two additional participants had relational codes that were a close second in frequency counts. Sandy, Terry, Carrie, and Barbara had the highest number of codes for relational leadership, with nine codes each. Relational leadership was highest in frequency of coded responses. The average number of female superintendent responses coded for this behavior was 6.9.

The examples above coded to relational leadership illustrate the breadth and depth of Grogan and Shakeshaft's meaning of relational leadership. The examples represent "deliberate attempts at coalition-building reflecting the kind of networking approach that contrasts sharply with the idea of command and control," the traditional, masculine 
approach to leadership (Grogan \& Shakeshaft, 2011, p. 10). Relational leadership is about valuing diverse perspectives enough to take the time to learn what those perspectives are and to learn why certain stakeholders bring those perspectives.

In the interviews, most of the female superintendents followed more agenic, topdown male superintendents, and it took much attention to training in shared-decisionmaking protocols and practices for staff to get used to the more open, participative leadership style. Whereas the previous male superintendents were frequently described as making decisions, statements, and presentations as if they were their own, these female superintendents are much more comfortable giving credit to their staff. Previous male superintendents were also depicted as running meetings as merely opportunities to get routine information to the staff, and new information was dismissed if it did not align with decisions already made from the top. The findings of this study emphasized transparency and meetings with open formats, whereby staff members shared ideas, asked questions, and participated in problem solving with each other, promoting more substantive discussion and personal investment. Controlling, agenic leadership style no longer works, according to the perspectives of the leaders in this study, as both staff and community are demanding much more information as they become increasingly sophisticated. Stakeholders want to know what is happening and want to be involved. The findings in this study are supported by the American School Superintendent: 2010 Decennial Study (Kowalski et al., 2011), which found that the "confluence of reform initiative and the realities of the information-based society in which they are pursued have transformed normative communicative behavior for superintendents" (p. 4). 
Administrators must build and maintain positive relationships with a broad spectrum of stakeholder groups because they are now expected to facilitate school improvement by collaborating with school employees, students, parents, and other stakeholders. Thus, the traditional mode of communication has been replaced by the "relational model of communication," which is regular, transparent, reciprocal, and mutually beneficial, which should now be intended to "minimize formal authority and actual power differences" (Kowalski et al., 2011, p. 4).

Two additional aspects of relational leadership were emphasized by the nine female superintendents: building capacity in teams, and being truly a "people person." However, each was sure to always qualify their team-loving and people-loving characteristics with the assurance that they have the toughness and confidence to make the final call when the decision has to be made. These female leaders revealed their keen awareness of the female gender stereotype of fickle, indecisive women who are too timid to take the responsibility for a final decision. Each one emphasized that her definition of "collaborative" did not amount to "soft" or "lowered standards." Each of the nine did not waver in her awareness that the superintendent position includes a tremendous duty to shoulder the responsibility when tough decisions must be made. When referencing tough decisions, a tone of conviction entered their voices as they thought about the inner strength it took to stand firm and never "negotiate or compromise" when it came to "the work" and "the kids." Perhaps the most important understanding that connects these women leaders is the hunger they displayed for substantive change that solves injustice in education. 


\section{Spiritual Leadership}

Spiritual leadership, as defined by Grogan and Shakeshaft (2011), describes female administrators who talk about something bigger than themselves that drives them, and about which they nearly proselytize as the work that needs to be done in schools. These leaders "extend the ministerial aspect of their leadership and combine a spiritual dimension with a belief in social justice" (p. 13). Spiritual leadership tends to be coupled with social justice leadership because it is the "hope, spirituality and belief in God" that helps impel female leaders to change the system and becomes a source of strength to continue the fight when challenges seem too great to burden alone (p. 13). This spirituality found in research on women leaders, most commonly among women of color, was found to be a way to see one's "connectedness to others and to the greater world," allowing them to embrace the responsibility of using their gifts to respond to others "rather than simply [for] our own pleasure or advancement" (p. 14). Spiritual leadership often does not have a religious context; instead, it has been likened to "consciousnessraising" or the continual "search for self-understanding" (p. 14). Spiritual leadership is also a key conduit for relational leadership because it calls one to delve deeply into others" worlds, which is essential to truly appreciating and "loving" them (p. 14). Finally, spirituality, for many women educational leaders, provides hope and resilience to maintain the fight for social change, according to Simmons and Johnson (2008) in their study of African American superintendents.

Coded response data. Evidence for this characteristic came through during the interviews as the superintendents talked about their belief systems, their differentiation 
between the job and "the work," and the extreme challenges of being a superintendent. Examples of statements made in interview from each participant that were indicative of spiritual leadership include:

1. "I could never deny the background it's given me, and it has a lot to do with who I am, just those Christian principles I was raised with. They formed me in ways I can’t get away from.”

2. "It's just refining who you are over the years; trying to figure out who you are [and] what you believe in. We have to keep coming back to who you are. You're figuring that out your whole life."

3. "I believe in predestination ... you are predestined to the spiritualness that you have. How you choose to use that is up to every person, but is part of why Presbyterians believe in predestination."

4. "It's not a job. It's a life. It's a commitment."

5. 'So to me it's about 'the work.' We're here about 'the work.' People who ... work with me ... know that 'the work' means the kids, not all of us adults."

6. "I think ... knowing that in the end things really do work out. I mean, if you really think about the way life works ... something bad happens, but out of the bad always comes something good. . . I've become much calmer. I'm a cancer survivor."

7. “Honestly, it's work. That's why I want to do this, right? I was very excited about the work." 
8. "It's just about values and belief systems and who you are at your core that drives your behavior on a daily basis."

9. "That's always with me, and it helped me. I think I see things from the perspective of the work [that] had to be done. It must be done because we have a moral responsibility. I believe it to my core."

As noted in Table 19, spiritual leadership was the seventh, or least frequently themed response from the female superintendents, with Patricia, Sandy, Mary, and Elizabeth's responses being coded the most often with this behavior/approach. The average number of female superintendents responses coded for this behavior was 2.1.

Just two superintendents referenced a religious context directly in order to establish a backdrop for their core beliefs. The coded responses above illustrate that the spirituality emerges less from a religious foundation and more from the magnitude of responsibility and moral imperative that drives each of them. Differing somewhat from the religiously based spirituality as a support system exhibited mostly by African American female educational leaders in Grogan and Shakeshaft's study, the predominately white participants in this study were coded as referencing spirituality when they intentionally referenced the "work," the "life," and the "core" that drives them, rather than the requirements or demands of the job. The repeated reference to "the work" by the majority of the female leaders was most often contextualized with the struggle for social justice and the extreme challenges of the position. The work, the life, and the core beliefs also defined the depth of their commitment to a legacy of culture change, not quick fixes, and their focus on kids above the adult politics. 
This disposition stood as another juxtaposition against the leadership paradigm they strove to change - the traditional role of superintendent as "statesman" and "business manager" (Kowalski et al., 2011, pp. 2-3). For these women, "the work," in other words, is often code for an almost evangelistic focus on children, the underprivileged, and the core charge of educators in the 21 st century, as being "change agents" for "cultural reconstruction," rather than a transactional figurehead constantly making deals to maintain the status quo (Fullan, 2001; Kowalski et al., 2011, p. 7). Spiritual leadership for these women, comingling with both social justice leadership and leadership for learning, positions their charge as leaders in what Bolman and Deal (2009) would call the district's "highest calling" (p. 58). Rather than simply using religious principles to guide their decisions or withstand personal struggles, this study's participants often discussed core beliefs and values as something they needed to understand from others in the community as well as to identify within themselves. These understandings enabled them to deeply understand the diverse collective of perspectives within their education community and thus affect the culture of their organizations. They understood that changing culture was the only way to leave a legacy of sustainable, positive change in their districts. Bolman and Deal (2009) adeptly define the necessary spiritual element embedded in the culture of a successful organization as "the glue, the hope, and the faith that hold people together" (p. 5). McCain and Salter (2008), as cited by Bolman and Deal (2009), also eloquently describe the spiritual journey of transforming school culture: 
Nothing that is worth doing can be achieved in our lifetime; therefore we must be saved by hope. Nothing which is true or beautiful or good makes complete sense in any immediate context of history; therefore we must be saved by faith. Nothing we do, however virtuous, can be accomplished alone. (p. 5)

In other words, these successful female superintendents who have made substantive change in their school districts, have endeavored to do so by charting their future course to better schools by "reviving the soul and spirit of noble and vital enterprise" (Bolman \& Deal, 2009, p. 5).

\section{Balanced Leadership}

It's commonly reported that the modern career woman struggles to balance work and family. In Grogan and Shakeshaft's (2011) "balanced leadership" paradigm, female leaders not only find balance between work and home, but also see it as an advantage and use it to propel them forward. Although modern women are undoubtedly free to choose to focus primarily on work in the same way a man stereotypically does, most prefer to achieve balance instead of choosing one over the other. Balanced leadership "includes the notions that women are better able to perform their educational responsibilities if they have found ways to manage their home duties as well" (Grogan \& Shakeshaft, 2011, p. 23). Supervising households and caring for family members has brought an aspect to women's leadership that augments performance. Studies support the idea that females perceive that their status as mothers helps when interacting with parents and also that they believe that managing a busy household has given them skills to manage chaos and siblinglike rivalries and other human dynamics among employees (Coleman, 2003). 
Coded response data. Evidence for this characteristic came through during the interviews as the superintendents talked about the importance of family in their career pathway and while performing the duties of superintendent. Examples of statements made in interview from each participant that were indicative of balanced leadership include:

1. "They used to say to me, 'You need to get a life.' And then one day I woke up and I thought, 'Well wait a minute, this is my life, and it's not a bad life.' . . I have a life, and it's this one. Then you stop wishing you had more time or wishing you could be something else, and then you can be yourself. Your best self."

2. “We've always been a great partnership. We've really shared a lot of our lives together. That's part of it, but I put my career on the back burner. I've had this conversation with my daughter. She's getting her master's and had to take a leave of absence. I finally sat her down and said, 'You can be partners all you want, but you're still the mom in the house, and as a mom you probably have to put this master's on hold."”

3. "I was working like 16,17-hour days and we'd already started a family, and I said, 'I just can't do it anymore. I need more balance between my work and my sup life,' so I went to a smaller district up the road."

4. "My family was never going to be the sacrificial lamb. Even though there were times where it felt disproportionate in terms of time, particularly when I 
became a principal.... This job I've been able to manage ... partly from maturity on my part and partly [from] seeing what I've done in other places and being able to create a balance."

5. "I think you need balance for a lot of reasons.... You know I love the quiet of the morning to meditate to center myself. ... You don't see me answering e-mails at 10:00 p.m., at night. . . when I'm done, I'm done. There are things I consciously try to engage that I think my husband can join. I see this as ours, and so he's been a wonderful partner in that."

6. "I couldn't do it without them. Being a mom shaped who I am. I gotta do my teaching at a certain level, and I gotta be a mom at a certain level ... so I kind of layered it. I figured as I weaned them away, and as they weaned me away, probably because I was a very proactive mom, then I was, like, I could let go, and then I needed to fill my time, too."

7. 'They said, 'Once you have a child, you will understand how it feels.' Well, they were right. They were absolutely right. I have been embarrassed by what I've told parents in the past.... I kept advising parents without being a parent myself. ... It added another dimension."

8. “It's going to sound odd, but I don't get off-centered very much. I just don't. When someone says it's a big issue, it's a big problem, it's like, 'It's okay. We'll take care of it. It's just going to be all right.' ... It's like the rocking chair analogy: I can rock and rock, and I can rock faster and harder, but the 
chair is not going anywhere - and that's worry, right? You're not going anywhere with it, so just stop it."

9. “It shouldn't have to be a trade-off. . . I said, 'One day, not now.' My personal life wasn't stabilized enough. I was a single mom, but I said, 'One day maybe I'll be a sup.' . . I think that's where the female thing comes in, because I was not going to be a 'less than parent,' either."

As noted in Table 19, balanced leadership was the sixth most frequently themed response from the female superintendents, with Carrie's responses being coded the most often with this behavior/approach. The average number of female superintendents' responses coded for this behavior was 3.0. Eight out of the nine superintendents in this study are married with children and described long-term healthy relationships with both their spouses and children. Only one, Elizabeth, described difficulty in maintaining a marriage amid the demands of being a school superintendent. However, a strong relationship with her daughter seemed to compensate for this void. Balanced Leadership for the other eight meant not choosing between family and work, but rather making career decisions based on family situations, so that they could be equally successful as both an educator and a mother and spouse. Sandy, Mary, Terry, Carrie, and Barbara deliberately steered their careers around raising children or delayed pursuing career advancement. Balancing the needs of work and family in the extreme $24 / 7$ job of school superintendent may be accomplished both by "making more time" and by combining or "integrating" work and family roles (Cheung \& Halpern, 2010). 
When referencing family, each of the eight superintendents who were married with children spoke of ways they would integrate their family into their work by including them in events or becoming deeply involved in the community in which they raised their children. Mary bikes and jogs with her husband and son; Susan snowboards with her family; Patricia golfs avidly with her family, and Carrie strategically planned her community event attendance around some of her husband's preferences. They also discussed routines, such as early morning meditation or exercising with family, in order to combine necessary attention to personal health with spending time with family while also giving them the emotional and physical stamina to juggle both roles authentically.

All nine alluded to an emotional equilibrium they possessed that was foundational to their success. All nine credited their family (all nine have children) as their major source of long-term support. While several mentioned mentors and parents as advocates who nudge them or have "kicked" them forward in their careers, their children and husbands were attributed with ongoing emotional support and stability. They told triumphant stories of their marriages as equal partnerships and their children as staunch supporters and cheerleaders when the shadows of self-doubt entered their minds during tough challenges. All nine gave credit to their children (and all eight who were married for the husbands as well) for their success. Therefore, balancing family was not a skill developed to compensate for a deficit or detractor, but rather being a mother and a wife gave them strength, courage, sage advice, and a cadre of loyal backers.

An emergent element within the theme of balanced leadership goes beyond "balance" in the sense of maintaining poise while juggling multiple "occupations" such 
as head of household, mother, and superintendent - it can refer to emotional stability as well. When asked about their leadership characteristics, Patricia used "calm" and "steady" to describe herself, while contrasting it with a "rocking chair analogy" that represented needless stress. Constance used "solid" and "dependable" and contrasted it with not being "needy" or "high maintenance." Carrie called herself "centered" and described achieving "balance" through "meditation" and "experience." Sandy described being "grounded." Susan used the word "sane" when describing how she attends to her mental and physical health. Barbara used the word "stabilized" when describing where she is and needs to be mentally in order to pursue the superintendency. Finally, Elizabeth, who expressed the most difficulty with juggling a marriage with the demands of the superintendency, used a vivid metaphor of a ship collecting barnacles as it sits in the water to illustrate her career path and possibly her marriages and how she's achieved inner peace and calm from coming to terms with her purpose in life and what's she's "predestined" to do. The "barnacled ship" metaphor represents a leader who picks up a barnacle with each difficult decision. As the barnacles accumulate, the ship glides through the water less swiftly, just as with each critical decision, a superintendent picks up political baggage until, at some point, the superintendent becomes the firebrand detracting from the mission itself. It is at this time that the ship (the superintendent) needs to pick up and move to fresh waters.

Mental health and emotional stability is an important factor of balanced leadership for the successful female leaders in this study. Additionally, for the eight participants who have maintained long-term marriages and strong family connections, a 
link could be hypothesized between the ability to maintain healthy personal relationships and the ability to employ relational leadership strategies effectively. Put another way, the key skills necessary to effectively engage in relational leadership have helped them maintain healthy relationships in their personal lives. These skills, which include the ability to "really hear the input from others" and the conceptualization that the "use of power to help others strengthens relationships, while power used to control damages relationships" has afforded them the ability to normalize a marriage as an egalitarian "partnership," a word used by multiple participants to describe their spouses.

It could therefore be argued that successful female leaders, who are given stronger scores in emotional intelligence and transformational leadership traits than men in leadership studies, are "social animals" with acuity to human dynamics allowing them to bond with others and connect to large ideas (Brooks, 2012; Eagly, 2007; Vinkenburg et al., 2011). In The Social Animal (2012), David Brooks debunks the bias in modern culture that overemphasizes individualism, IQ, and learning certain skills and the right techniques to get ahead; he posits that successful leadership is rooted in the

unconscious mind ... where most of the brain's work gets done. This is the realm of emotions, intuitions, biases, longings, genetic dispositions, personality traits, and social norms; the realm where character is formed and where our most important life decisions are made. The natural habitat of The Social Animal. 


\section{Two More Ways Women Lead}

As interview data were analyzed, two additional behaviors displayed by female superintendents emerged. These noteworthy behaviors-systems-thinking leadership, and changing role of the superintendent to lead change - are therefore added to the five identified by Grogan and Shakeshaft (2011).

\section{Systems-Thinking Leadership}

In traditional leadership literature, the word leader has come to refer largely to positional authority and is a synonym for an executive manager (Senge, 2006). Therefore, the bulk of the findings in leadership research focus on the essential managerial elements of leadership that rely on formal organizational authority and power. An example drawn from the world of business is Jim Collins's "level 5 leader." (2001). A "level 5 leader" has a series of qualities, such as a "duality of professional will and personal humility," "compelling modesty," and "unwavering resolve," to name just a few. Gray and Streshly (2010) connected Collins's traditional "great man" scholarship to education in their study on highly effective principals. With the addition of building relationships, their principals generally fit the profile of the exemplary business model.

In contrast to the traditional leadership literature, Grogan and Shakeshaft's (2011) research on women in educational leadership points us in a new direction, in which leadership is "considered a collective rather than an individual capacity" and is demarcated as a "relationship or process, not a person" (Gauthier, 2006, cited in Grogan \& Shakeshaft, 2011, p. 42). Grogan and Shakeshaft (2011) have found that women "gravitate towards various forms of collective leadership" that redefine relational 
leadership as more about seeking to expand everyone's power by sharing power-by leading with and through others as a cohesive unit-than by simply developing a meaningful relationship with each person they encounter (p. 42).

Coded response data. Table 19 indicates the number of times interview responses were coded as "systems thinkers." Examples of such statements expressing the importance of approaching their work from a systems perspective include:

1. "We began to work together in a way that modeled what it meant to be a professional learning community, not just talked about it, because that's ‘conblaboration' vs. collaboration. One is make-believe, and one is authentic. The catalyst for growth has been about building leadership capacity in a very thoughtful and intentional way. ... I'm trying to move towards sustainable change ... we're looking to create an infrastructure that is sustainable over time."

2. "I'm really into organizational development... I love people like Peter Senge and Peter Drucker; in fact, we're working with Peter Senge right now. We went to this thing called 'systems thinking' ..."

3. "It's a system ... we would be mistaken if we think we can change things a little like 'one piece here, one piece there.' We look at everything as a system and see how everything we do is connected. When I make a decision over here, it is going to impact everybody else in our system, so we need to get everybody on board to see what we need to do to support them." 
4. "We had to start with management, because if the managers are not going to make that shift and didn't understand, and I go into a meeting and don't know how to head towards a decision of an area and identify a problem for that adaptive action, then we're all in trouble, right? Then we're all going to spin."

5. "People want to help make decisions, but actually when you turn that over to people, all of a sudden you get, 'Why can't you just tell us what to do?' Right? Because there's that fear of 'Why do I have to do this?' And they discover it's actually more work. . . . It's been quite a journey . . . all 90 managers I had certified in what is called human systems dynamics, which is a change process."

6. "Through this process we learned how to deal with change. How to approach it in ways that [are] adaptive. ... We no longer sit back ... everything that happens is an organization. Every minute of every day we are part of. If I don't change my behavior or I don't initiate a shift, no shift will happen . . . the question we now ask is, 'What part are you playing in it?"'

7. "So that's when I started to be able to make the link to systems. I really started to look at it and say, 'Okay, this is a systems issue. It's not me. It's not them. It's not a union issue.' It's the systems, and part of dealing with that are the structures that are in place for us, and structures force our function... Sometimes people stay in the same spot all the time, and they can't see anymore; they stop seeing the patterns." 
8. "There's the need for stakeholders to know how decisions get made and for principals to have some defined autonomy. . . For me, human systems dynamics was a way to help that happen. ... In order to move from a paternalistic, very top-down culture, they need to learn how to have input in collaboration, but to also accept responsibility ... this is a bit of a process from HSD."

9. "You need a structure of collaboration and consensus building in order to make it effective. It's not really just a tacit agreement that everybody agrees to be collaborative. You have to have processes in place so they allow collaboration."

10. “Changing their attitudes and beliefs wasn't enough. We needed to give them the structure and the supports and the systems so that they could deliver the instruction to the kids. ... [ [ $\mathrm{am}]$ a person who could bring structure and systems into our program."

As noted in Table 19, systems thinking was the third most frequently themed response from the female superintendents, with Patricia's responses being coded the most often with this behavior/approach. Coding reveals evidence of a focus on human dynamics within the system as a whole, a strong value placed on training managers to collaborate among the cross-functional disciplines and to facilitate shared decision-making processes, and using outside consultants to help administrators lead the change process while including diverse perspectives. The average number of female superintendents' responses coded for this behavior was 6.2. 
An emergent theme in this study surrounds female leaders who value organizations as living systems and approach their work differently because of it. They grasp they can create new metrics, formal roles and processes, or innovative meetings, but it is what happens when people use the artifacts or processes, or participate in the meetings, that matters. Systems organizational leadership studies, supporting this recent shift, are refocusing the conceptualization of leadership from a capacity of an individual to a "capacity or a process residing in relationships between people across the organization linked to the external environment" (Grogan \& Shakeshaft, 2011, p. 42). In other words, a main focus of leadership should be on the structure of an organization and the human dynamics that operate within it. The "fifth discipline" that integrates and "fuses" the five disciplines of a learning organization, according to Peter Senge's seminal work on organizational management The Fifth Discipline (2006), is "systems thinking" (p. 11). Systems thinking is based on the principle that "structure influences behavior," both mechanically and socioemotionally (p. 385). According to Senge (2006), the dynamics of human behavior are fundamentally tied to the organizational structure in which they are placed.

Our female leaders often referenced systems thinking in contrast to or as a replacement for traditional top-down management, which placed the decision making solely in a hierarchical structure of individuals. These decisions were often described by our participants as quick, intractable fixes by their predecessors (former superintendents) to immediate complaints or problems that often caused more harm over the long run. In his latest volume, Schools that Learn, Peter Senge explains that being overly reactive and 
changing practice only when problems surface contributes to an "attention-deficit culture in the school systems" (Senge, Cambron-McCabe, Lucas, Smith, \& Dutton, 2012, p. 124). Moving hastily from "one issue to the next, people grow highly skilled at solving crises instead of looking for ways to prevent them" (p. 124). Patricia, the most prolific and enthusiastic on the topic of systems thinking, explained this problem-preventing approach as the ability to see patterns as opposed to isolated problems or events:

You're paying attention to patterns. That's our job as leaders, to see, understand, and influence patterns. Everything is a pattern. Trust is a pattern. It's not a thing. So we say fidelity doesn't exist here. We're creating a coherent environment, not a compliant environment. Being given a frame doesn't mean you don't have choice. The whole idea in the system is coherence and not boundaries that are too tight and too small and you tell people what to do inside your boundary, now you're asking for compliance and compliance is bad. Compliance is a destroyer for all systems.

The discipline of systems thinking offers a distinctive way of considering problems and goals - not as singular events, but as factors of larger, but less discernible structures that affect each other. To appreciate a system "is to understand those interrelationships and how they recur and change over time" (Senge et al., 2012, p. 124). This study found our successful female superintendents, like most children, are "natural systems thinkers, highly attuned to the interrelationships among nature, other people, emotions, thoughts and themselves" (p. 125). 
Change Leadership: Redefining the Role of Superintendent to Lead Change

A theme emerging from this study was the notion that these women did not want to lead the way their predecessors had led. Peter Senge summarizes this urge to redefine the role of the superintendent as a leader of change:

I also now believe that many of the most important leaders in the coming decades will not be those we have been assuming they would be. A new order of things must be brought forward by a new order of leaders. It is not a surprise that wherever we see a new system of management starting to take root, we see leaders emerging from the periphery - people who do not come from the traditional centers of power but from the cultural, economic and demographic periphery: women, the poor, and the young. (Senge, 2006, p. 367)

The cornerstone of the traditional leadership model places the charismatic, heroic leader at the pulpit during crisis. Inversely, these women often shared being adamantly against being a superintendent if it meant taking on this sovereign persona so removed from the egalitarian work of educators - engaging collaboratively with teachers, parents, students, and site-level personnel about issues surrounding teaching and learning. Whereas the first few generations of women leaders felt like they had to lead more like men to be taken seriously, women leading as women by default reconceptualized the role of the superintendent in this study.

Coded response data. Table 19 indicates the number of times interview responses were coded as "redefining the role of superintendent—women leading as 
women." Coding revealed evidence of a negative perception of the role and/or the person in it; reversing the traditional role of prioritizing politics, facilities, and budget; expressing differences in their leadership style with that of their predecessor; and wishing to disrupt the status quo leadership paradigm within their district. Examples of such statements expressing the need to change the function and/or how they serve in the role include:

1. "I think seeing that juxtaposition from a bad administrator, who maintained the status quo, to a good administrator, who wanted to change things [to being] about the kids, not the adults. It's really what made me go into administration. And then, as an assistant superintendent, [I had] a horrible superintendent."

2. "I never set out to be a superintendent. I love teaching. 'Who's the superintendent, and how are they affecting me?' It was the sense of the role and whether it could have an impact, or 'Is that role a figurehead?' I didn't get it. . . It was because some of the people as I moved up the ladder, I didn't see that part of their desire."

3. "I could not do a political speech if my life depended on it. But if you ask me to teach somebody about something, I know how to do that. . . . So when I finally learned that instead of speaking, I was teaching, it was like turning on a light switch. ... That's exactly how I see my role with the board.”

4. "Stephan, right before me, his example was 'I want to be a superintendent because I want to carry the ball.' Like in football? I want to be the 
'quarterback'? I don't care about carrying the ball ... that sounds very unappealing to me. . . None of that mattered to me, but I think I didn't understand the job under those people."

5. "Their past superintendent was more of a top-down kind of leader . . . but the focus groups said, 'Well we'd kind of like someone who is a little more collaborative,' . . . and that was me. . . All the board members thought they were looking for a collaborative superintendent, but they really weren't used to a collaborative superintendent. They were used to someone who set the course and said 'This is the way you're going to do it."'

6. "We had a superintendent for like 25 years. We were solid, right? Very topdown management structure. We were growing. ... He passed it on to his successor, and then it got passed on to my predecessor, and he didn't do anything about it. ... They didn't do anything! . . So now it's on my shoulders to say, 'It's gotta change."”

7. "Giving the principals some voice and getting them more active in the conversations and decision making ... some of my cabinet members struggled with [this] because they, too, have come up in this system that is very top down, and they're comfortable there, right?"

8. "I may not fit the mold that some of you think is the superintendent or what you have pictured. But that tells you more about me as a person. Because I am a contender with those people. Nothing's ever been handed to me. I'm not 
prepackaged or destined to be great. That's probably what I would become, breaking the mold."

9. "I found working with him [my predecessor] to be very oppressive. You could see his whole methodology; his style felt anti-women. I mean top down. He was very autocratic ... I was in the curriculum role. The sup loved that I was there because he knew I had deep knowledge, and he had none. He had been a coach, [a] counselor, but he had no interest [in instruction] at all. His superintendency was about getting ... facilities."

As noted in Table 19, the average number of highly successful female superintendent responses coded as "redefining the superintendency-women leading as women" was 6.0. The superintendent with the highest frequency of response coded to this theme was Carrie, and the fewest coded responses came from Barbara.

The findings of this study disclose that these female superintendents who have successfully moved their district toward positive change found the top-down approach neither comfortable nor effective. Therefore, in order to change this management structure, the superintendent needed to model the way she wanted her people function in their schools. For over two decades, leaders in the field of student achievement and educational reform, such as Dufour (2005) and Fullan (1992), have been touting the indisputable facts surrounding the impact of teachers working as "professional learning communities" on student achievement and the importance of "interrelationships of the main components of a system, which equates to tending to the deeper issue of culture of a system" in order to enact sustainable school reform. Yet superintendents themselves, 
according to our participants' reflections about their predecessors, remained in a rather hypocritical stance, talking about collaboration while seemingly doing little to adjust their own leadership practices to match the work done within the teaching ranks of their organizations.

The previous role of a superintendent, praised for its individuality, decisiveness, and vision in order to maintain the stability of an American institution, has been reconceptualized by these women in order to allow them to lead sustainable change projects, particularly with "challenges to the status quo on behalf of marginalized populations that have not been well served" (Grogan \& Shakeshaft, 2011, p. 44). Ospina, El Hadidy, and Hofmann-Pinilla (2008), as cited by Grogan and Shakeshaft (2011), stated "shared-leadership strategies are emblematic of social justice organizations, and women are likely to define schools as social justice organizations" (p. 41). Grogan and Shakeshaft (2011) explain that social action organizations are more likely to function in an egalitarian format that relies on common interests and the ability to deal with diverse perspectives and the change process. The main shifts in the role of the superintendent by the participating females centered around opening up and redesigning their systems to harness a collection of ideas and knowledge, focusing on the social justice motivation to bring a sense of urgency to the change and focusing the deep discussions on kids and learning to promote "sense-making that allows a change in the thinking of the constituencies and in the perceptions of the problems and its possible solutions" (Grogan \& Shakeshaft, 2011, p. 55). These women, as a collective, understood that leading long- 
term, sustainable change starts with leading that change differently and comporting their roles as superintendents differently than their role models, mentors, and predecessors.

\section{Chapter Summary}

This chapter represented the findings of the study. The chapter commenced with an introduction, followed by presentation of the data from the demographic questionnaire, the document review of participant résumés, and then the coded responses with respect to interview data that revealed barriers and facilitators to success, and leadership styles as they relate to Grogan and Shakeshaft's (2011) "five ways women lead." The chapter closed with a demonstration of promising female leadership behaviors residing beyond these primary, foundational themes, which emerged from the rich interview experiences with these dynamic women. The study's major findings included the following: 1) More barriers were perceived as a sitting female superintendent than during their career path. 2) Strong family support was emphasized over finding mentors. 3) All nine participants exhibited evidence of all five of Grogan and Shakeshaft's leadership styles, plus two additional leadership themes of systems-thinking and changing the role of the superintendent. 4) The strongest or most commonly coded leadership behaviors, in descending order, were relational leadership, social justice leadership, systems-thinking leadership, and changing the role of the superintendent to model their leadership paradigm.

1. The average profile of participants is white, heterosexual, married with children, and between 50-65 years old--older on average than males when entering the role of superintendent, possibly due to a decision to raise children 
first and a lack of early aspiration due to negative perception of image and traditional role of superintendent.

2. Relatively long tenures as teachers (averaging 9 years), and most common leadership positions held were director of curriculum and instruction, assistant superintendent of educational services, and principal.

3. Participants as a whole did not feel they experienced external barriers on their path to superintendent, nor did they mention mobility as a challenge, which is contrary to current research. The strongest barrier was internal-the negative perception of the image of superintendent as not working with teachers in classrooms, but rather above them and far away from the instructional arena as political statesman or front man.

4. Contrary to research on aspiring female superintendents, mentors were rarely mentioned as pivotal to success.

5. Though not to the same degree, evidence for all five ways women lead were found in all women, except in one area for one woman-spirituality.

6. Relational and social justice leadership were the strongest leadership themes.

7. Two themes emerged as new trends in female leadership: systems-thinking and change leadership_ changing the role of superintendent from statesman to teacher, facilitator, liaison, and chaos diviner in order to lead change. 


\section{CHAPTER 6. CONCLUSIONS AND RECOMMENDATIONS}

Introduction

Exploring the experiences of several women in their successful ascendancy to the position of $\mathrm{K}-12$ superintendent and successful execution of this role was the purpose of this multiple case study. This study is designed to build upon Hanson's (2010) and Grogan and Shakeshaft's (2011) work by identifying the common experiences and leadership behaviors of women that contributed to their success in attaining and effecting positive change in the position of superintendent. Because women remain underrepresented in the superintendency, it was valuable not only to look at the experiences of women who are superintendents, to better understand the barriers, if any, and the leadership behaviors used to overcome these barriers, but also to add to the discourse on educational leadership by examining female leadership characteristics and behaviors that lead to system-wide positive outcomes for students.

When the researcher began this exploratory study, she wanted to see if highly successful female superintendents exhibited many of Grogan and Shakeshaft's (2011) descriptors of the "five ways women lead." The two questions that provided the foundation for my analysis of the data collected were:

1) How do female educational leaders who succeed in attaining the $\mathrm{K}-12$ superintendency describe barriers and facilitators to their success? 
2) How do women superintendents describe leadership styles and behaviors that have enabled them to attain a superintendent position and to facilitate positive, measurable change in their school systems?

The interviews produced compelling stories describing the characteristics and behaviors of successful school superintendents. However, the reader should be cautioned not to make generalizations about superintendents based on the findings of this study.

First, the researcher will summarize study findings as related to these questions. Second, the researcher will address limitations of the study. Third, the researcher will offer recommendations for improving district hiring procedures and administrator preparation programs based on the results of this exploratory study to suggest how these findings might have a practical application. Finally, she will present recommendations for further study in the area of superintendent leadership.

\section{Findings: Question 1}

This multiple case study, in which the female superintendents are the units of study, is an empirical inquiry that explores a "contemporary phenomenon within its reallife context" (Yin, 2003, p. 13). Because a multiple case study often has many more variables of interest than data points, the research design relied on multiple sources of evidence, with "data needing to converge in a triangulating fashion" (p. 14). Therefore, three forms of data were collected to determine the factors that helped or hindered the success of our female superintendents: a demographic questionnaire, document review of 
participant résumés, and interview questions asking about perceived challenges and advantages throughout their careers and during their tenure as superintendents.

\section{Demographic Questionnaire}

The strongest commonalities among female superintendents with respect to demographics centered on race, marital status, children, and sexual orientation. The overwhelming majority of female superintendents were heterosexual, white, and married with children. Only one superintendent was divorced and only one identified as other than white. The average tenure as superintendent was a relatively short four years, and most were at or near retirement, with an average age of 58.

\section{Document Review of Résumés/Curricula Vitae}

All participants had strong backgrounds in teaching, with an average of nine years in the classroom. All but one had site administrative experience that included assistant principal, principal, or both, and all but two had been principals. All had central office experience that included assistant superintendent or director of curriculum and instruction, with an average of eight years of central office experience. All had administrative certification and held masters degrees, and $55 \%$ held or are due to attain a doctorate within the year. Of note was that five of the nine participants achieved significant honors, such as teacher of the year or administrator of the year, and five of the nine participants listed a significant number of certifications (between 10 and 49) and studied at academies and institutes as continuing professional development before and during their tenure as superintendents. These successful superintendents relied heavily on varied leadership experiences and ongoing education and certifications. 


\section{Barriers and Facilitators to Success}

Overall, participants perceived they had more advantages than challenges. The most common perceived facilitators were family support (mainly in the form of supportive husbands and older children) and experience. Although raising children most often delayed their decisions to move into administration, it was more strongly associated with career advantages, such as providing them with an important perspective when interacting with parents and supervising employees with children. Additionally, with respect to experience, while extensive and varied site-level and district-level experience facilitated career advancement in educational administration, experience or knowledge of traditionally male gendered roles, such as budget, labor negotiations, bond measures, and construction/facilities, were emphasized when interviewing for superintendent positions and were perceived as decisive factors for school boards when hiring them. Finally, of note were individual responses that pointed toward perception of likeability as a factor in their success. Reasons for perceived likeability ranged from being "engaging" and "unemotional" to being able to relate to men because they could talk sports and "play with the boys" or become their "buddy."

\section{Findings: Question 2}

This multiple case study, in addition to relying on multiple sources of evidence to triangulate contemporary phenomena in a real-life context, also benefited from the "prior development of theoretical propositions to guide data collection and analysis" (Yin, 2003, p. 14). A theoretical framework is a systematic explanation of phenomena related to variables within a given theory. The theoretical framework supporting this study is social 
role theory, which posits that due to gender role expectations in the workplace, differences have a emerged between men and women in their leadership behaviors. In Women in Educational Leadership (2011), Margaret Grogan and Charol Shakeshaft, two of the most prolific researchers on the topic of women in educational leadership, distinguished five ways women approach leadership. Their five themes of female leadership were used to guide data collection and examination.

Table 20

Ranked Frequency of Leadership Themes

\begin{tabular}{|lcc|}
\hline Rank & Leadership theme & Frequency \\
\hline 1 & Relational & 6.8 \\
\hline 2 & Social justice & 6.4 \\
\hline 3 & Systems thinking & 6.2 \\
\hline 4 & Change leadership & 6.0 \\
\hline 5 & Learning & 4.8 \\
\hline 6 & Balanced & 3.0 \\
\hline 7 & Spiritual & 2.1 \\
\hline
\end{tabular}

When analyzing all nine of the highly successful female superintendents individually and as a group (Table 20), evidence for all of the "five ways women lead" as defined by Grogan and Shakeshaft were found, except in one theme by one participantspirituality, by Barbara.

Five Ways Women Lead

Leadership for Learning. All nine participating superintendents exhibited evidence of leadership for learning in the interview conversations. The résumé review also showed all nine superintendents with extensive classroom instruction, curriculum 
and instruction experience, and/or continuing professional development in areas of instruction. Leadership for learning had the most evenly distributed response frequency, with seven of the nine respondents coded 4-5 times for leadership for learning behaviors. Susan and Constance were outliers, with 8 and 3 respectively.

Social Justice Leadership. All nine participating superintendents exhibited evidence of social justice leadership in the interview conversations. Social justice leadership was the second most frequently coded leadership behavior with an average of 6 coded responses per participant. Susan, who was the only superintendent who identified as nonwhite, had the highest number of coded responses with 12, and Carrie had the fewest, with 3 behaviors coded to social justice leadership.

Relational Leadership. All nine participating superintendents exhibited evidence of relational leadership. Relational leadership was the most frequently coded leadership behavior, with an average of 7 coded responses per participant. Sandy, Terry, Carrie, and Barbara were most frequently coded for relational leadership with 9 each, and Susan had the fewest with 2 .

Spiritual Leadership. This was the only leadership theme of which not all nine participants displayed evidence. Of the eight respondents who exhibited evidence of spiritual leadership, the average response frequency was only 2 . Two respondents were coded for spiritual leadership because of religious foundations, and the other six exhibited evidence of spiritual leadership because of their references to the "work" as a mission, a service above self, and/or a core belief that drives them. 
Balanced Leadership. All nine participants displayed balanced leadership through their use of healthy family or other personal relationships to enhance work relationships and interpersonal interaction. This they accomplished in part by being cognizant of exerting efforts to maintain emotional/physical well-being and ensuring that their family is not "the sacrificial lamb" for the job. Balanced leadership had the second lowest coded frequency, with an average response rate of 3. Carrie had the most coded responses with 6, and Terry and Susan had the lowest with 1 each.

\section{Emergent Themes}

Systems-Thinking Leadership. Interview responses from all nine participants indicated their belief and focus on training management in how to facilitate change in an open, collaborative, more egalitarian system. All nine participants also exhibited the desire to focus on the interpersonal dynamics within their organization and redesigning those systems to function more effectively with attention to accountability in a highly collaborative system. Systems-thinking leadership had the third highest frequency rate, with an average of 6 coded responses per participant. Patricia Patterns was an outlier with 18 coded responses, and Barbara was an outlier with the lowest rate of 2 . The mode of response toward systems thinking was between 5 and 7 .

\section{Women Leading as Women-Redefining the Role of Superintendent in}

Order to Lead Change. This female leadership theme transpired from a confluence of factors: 
1. Multiple participants remarking that they did not aspire to be superintendents specifically because of how they viewed the role, most often occupied and executed by men,

2. Multiple respondents viewing the perception of the role expressly as not being focused on students or education,

3. Openly discussing leadership style differences with their predecessors,

4. Expressing opposition to or the general ineffectiveness of top-down management, and

5. Wanting eventually to disrupt the status quo in favor of better serving underrepresented populations.

With an average coded frequency rate of 6 (which ties for second place with social justice and systems-thinking leadership), this second emergent leadership theme stands among the strongest leadership behaviors of the successful female superintendents in this study. The reconceptualization of the role of the superintendent, one that reverses traditional priorities of politics, money, and facilities to kids, classrooms, and teachers, and focuses on being the chief communicator, model educator, and culture builder for the entire community, has implications for leadership programs and school boards alike.

Whereas the first few generations of female leaders learned to lead like men in order to compete for top leadership positions, these women have brought the "ways women lead" to bear on the challenges of sustainable reform in their respective districts, and they have seen positive results. These women, leading as women, have brought to the forefront a "sensibility regarding sustainability issues"; this is because, according to Peter 
Senge (2006) in his influential theory on learning organizations that lead effective change, "women gravitate toward longer-term issues that lie at the periphery of most businesses' [and, by extension, business-minded leaders'] attention, like sustainability, and approach these from a standpoint of collaboration and discovery rather than solutions, plans," and quick wins (Senge, 2006, p. 368). These women are connecting with the core value and ritual of schooling in America, which originally inspired the hopes and dreams of a democracy. These women are also unabashedly tapping their innate desire to be more directly involved in the lives of children. This is not to say that all women lead this way, nor is the researcher positing that there are not men who utilize many of these leadership behaviors framed in the study. Rather, successful female superintendents leading as women can positively inform the discourse on leadership and effect positive change in school systems.

\section{Limitations of the Study}

Grogan and Shakeshaft (2011) conducted a meta-analysis of more than 50 studies that compare female and male approaches to leadership in order to coalesce five approaches that characterize women's educational leadership preferences. The successful female superintendents interviewed in this study represent a sample of others in the state that might meet the criteria for a broader study. Just nine superintendents are studied, and including more female superintendents who fit the criteria from more than the five counties in this study by expanding the participant pool beyond the borders of California and the West Coast would provide additional data from which to find more generalizable characteristics and behavior commonalities and differences. 
The main criterion for selecting the female superintendents for the study was district-wide improvement on the California Standards Test (CST), which was officially frozen in the spring of 2013 in preparation for the new state-adopted accountability measurement, the Smarter Balanced Assessment Consortium (SBAC) set, to be given for the first official scoring in the spring of 2015. Utilizing additional factors, such as school achievement awards, professional honors, and recommendations from board members, cabinet members, or community members about the success of the superintendent might enhance validity of the study.

Districts of the successful superintendents in this study improved by a minimum of 6 points over a minimum of two years during the tenure of the superintendent. A longer period of sustaining student achievement growth would most likely have produced a different set of successful superintendents. On the other hand, because the average tenure of a female superintendent is relatively short, not only would it be difficult to find a larger sample, but also it could potentially rule out some effective superintendents who retired or changed districts.

The participants were selected and labeled from the beginning of the study as successful based on their district's student performance gains. A blind study, where I did not have that knowledge beforehand, would have prevented any assumptions I might have had about the participants.

Data for analysis were limited to information collected from a demographic questionnaire completed by the superintendents, a 2-3 hour interview session, and a 
document analysis of their self-generated résumés. Triangulation of data for this multiple case study occurred only within analysis of these three data sources. These self-reported perceptions given by the superintendents during their interviews may be validated by additional data collected from interviews with people who work with the superintendents and observations of the superintendents in their work environment.

\section{$\underline{\text { Recommendations for Practice }}$}

Revise Administrator Preparation Programs

These programs have an important function in preparing school administrators. However, revisions to the programs must occur before they can be viable tools for shaping school leadership. Recommendations are as follows:

Revise the core leadership curriculum to include gender-inclusive leadership theories, such as Synergistic Leadership Theory.

Administrative credentialing programs are often taught by practitioners who are mostly retired school administrators teaching about leadership through the lens of their past experiences and within their traditional leadership paradigms. Traditional leadership paradigms are further perpetuated by mentors advising aspiring superintendents according to their perceived past successes. This study suggested that female superintendents who have successfully led their districts toward positive, measureable change, have up to seven commonalities to varying degrees in the way they prefer to lead, five of which are supported by research from the most prolific writers of women in education administration, Margaret Grogan and Charol Shakeshaft, yet administrative 
preparation programs and tier 2 administrative credentialing curriculum does not generally include gender-inclusive leadership theories nor recognize them as such.

Synergistic Leadership Theory (SLT) is a 21 st-century leadership theory that provides a framework to examine and reflect on the feminine voice in educational leadership (Irby et al., 2009). Synergistic Leadership Theory frames four main, interconnected components of leadership: a) organizational structure, b) leadership behaviors, c) external forces, and d) beliefs, attitudes, and values. According to Leonard and Jones (2009), "dispersing power within an organization is a portion of the SLT model and has been the focus of studies on women in leadership" (p. 26). Using Synergistic Leadership Theory (SLT) as a frame to examine modernist leadership theory empowers one to understand that women can lead successfully without having to behave aggressively or in a "manly" manner to be effective. Female administrators are stimulated to take a stance when having to make difficult decisions while being attentive to all who are affected by the resolution. Similarly, female administrators are encouraged to employ a collaborative approach to decision making when possible, never losing sight of the emotional needs of individual members on the team, nor the organizational structure that impacts the human dynamics and culture within an organization (Irby et al., 2009; Leonard \& Jones, 2009).

Revise the core leadership curriculum to include significant literature in theories of organizational management, leading complex systems, systems thinking, and leading without control. 
This study suggested that successful superintendents understood the importance of training their management teams in how to facilitate change in a system that included a diverse collective of voices. They understood that in order to change the leadership design in a complex, political system such as education, from the traditional top-down management system to a more horizontally structured decision-making system, multiple layers of management must understand systems thinking. Systems thinking, according to Senge et al. in Schools That Learn (2012), combines a) the ability to recognize the hidden dynamics of complex systems (patterns) with b) engagement-facilitating a safe place for listening as well as speaking - and c) a "learner-centered" as opposed to an "authoritycentered" approach to all problems inside and outside the classroom (pp. 418-419). An example of the kind of curriculum and/or training needed for superintendents who are expected to manage whole districts that are composed of multiple systems of people, is available at the website of the Human Systems Dynamics (HSD) Institute (http://www.hsdinstitute.org; Eoyang, 2011). HSD is based on the science of chaos theory, complex systems, and complex human systems in particular, and it trains business leaders and educational leaders alike to recognize and "help make sense of patterns that emerge from chaos when people work and play together in groups, families, organizations, and communities" (Patterson, Holladay, \& Eoyang, 2012). Grounded in the theory that self-organizing systems operate under short sets of rules that emerge from the system and subsequently influence the system going forward, HSD trains leaders in adaptive action, which is a reflective inquiry process of recognizing and understanding the patterns created by human interdynamics within an organization in order to respond 
appropriately and build better coherence and generative capacity for change. Finally, core administrative preparation curriculum must include training on facilitating stakeholder engagement over often-emotional issues and learner-centered leadership as a competence of educational leaders.

Structured Support for the Aspiring and Sitting Superintendents

Include the superintendent position in a "tier 3 " coaching requirement to attain and maintain certification.

Currently, there are no specific requirements, only preferences and highly desirable qualifications as designated by school boards, to serve as superintendent in the public school system in California. Some superintendents currently serving districts in California have no formal experience as an educator, no formal experience as a CEO, and do not possess any certification for teaching or administrative services. Additionally, there currently exists no standard leadership curriculum or preparation program for the job of school superintendent.

Currently, the bulk of administrative preparation training occurs before one acquires an administrative position, which is referred to as the "tier 1" requirement for a preliminary administrative services credential. When an administrative job such as assistant principal is secured, one is eligible to begin "tier 2" training to satisfy the requirement to clear one's credential. Therefore, administrative training programs often cover only entry-level leadership positions. Some districts have recognized the need for executive leadership training and have begun offering coaches to new principals. 
However, executive coaching for central office personnel, assistant superintendents and superintendents is still exceedingly rare.

In this study, several respondents valued having a mentor, coach, and/or a network of trusted confidents of fellow superintendents while serving as superintendent, regardless of their career experience before entering the position. Moreover, the findings that the female educators possess an overall negative perception of the role of superintendent hold significance when examining the minimized or delayed aspiration and subsequent shorter tenure of female superintendents. A lack of awareness of what the job of superintendent entails combined with little or no perceived support once the job is secured could considerably weaken or delay the aspiration of many of our female leaders. Therefore, a "tier 3" coaching requirement that covers a uniform set of standards designed by experts in the field of educational leadership and organizational management would satisfy the leadership preparation void that exists for assistant superintendents and superintendents alike. It would also satisfy the need, expressed by this study's participants, for a confidential coach and mentor. By definition of the position, a superintendent has precious few to none whom she or he can reach out to for guidance on often confidential and sensitive matters, other than district-hired attorneys. The cost of the "tier 3" coach can be recommended to school boards as a standard contract obligation for the superintendent and cabinet.

Design a K-12 Executive Leadership program as a separate cohort of candidates for Doctorate of Educational Leadership (Ed.D.) in the CSU system. 
Outside of the purview of California teacher and administrative credentialing, which is entirely housed in the Commission on Teacher Credentialing (CTC) branch of the Department of Education, are the leadership degrees offered by California's universities. The current curriculum for Doctorate of Education in Educational Leadership at San Francisco State, while possessing many important components of leadership, is missing curricula vital to leaders pursuing executive-level positions. Critical curricula absent from an Ed.D. at San Francisco State, for example, are many of the skills housed in human resources, such as constructive supervision and evaluation, negotiations and collective bargaining, labor law and employee mediation, and organizational psychology and human systems dynamics. Curricula absent for the fiscal services include fund-raising and foundations, parcel tax and bond elections, facilities and construction management, and the bidding process. Overlooked areas from the Educational Services branch include guidance counseling and student services, analyzing student assessment data, building a Local Control Accountability Plan (LCAP) aligned to the Local Control Funding Formula (LCFF), and assessing curriculum and instructional programs; that is, "What is a common viable curriculum, and how does one go about leading a system to backwards-map new curriculum standards across core disciplines, align assessments, and monitor student benchmarks at regular intervals?" Finally, a cohort model emphasizes a cooperative, team approach to learning, where one extends learning by interaction with one's like peers. However, a broad cohort comprising mostly non-K-12, non-executive-level participants reduces the positive effects of sharing likepractices at the "systems" level. 
Promote the "cosuperintendent" model to the California School Boards Association.

The findings of this study show that these successful women are able to do it alllead as women in 7 different effective leadership behaviors, balance work and family expertly, play with "the boys" on demand, and excel at curriculum and instruction, as well as master all the traditionally masculine roles such as overseeing construction, budget negotiations, parcel tax campaigns, safety, high schools, and facilities. Although deeply awe inspiring, it is of concern in what it implies to future female aspirants to the superintendency. Women have to show high levels of competence in every component of a district's system before they enter the superintendent's seat, and they have to do it really well. This is not to say that men do not have to, because they should and sometimes do, but the women in this study are cognizant of needing to fill any perceived experience gap before applying to be superintendents when, in reality, most leaders have many experience gaps. Traditionally, according to Kim and Brunner's (2009) analysis of gender differences in superintendents' career pathways, male superintendents who followed a speedier trajectory stepped over many positions. For example, a traditional path for men commonly went from teacher/coach to vice principal of discipline/athletics to principal to superintendent in about four steps. This career path differed from the female path, which more often included, in addition, to the aforementioned line positions, more staff positions, such as department chair, content specialist, guidance counselor, central office administrator, assistant superintendent of personnel or educational services, and many other positions in a K-12 system (Kim \& Brunner, 2009). 
In order to gain additional career experiences perceived as necessary by these women for advancement, such as is evidenced in the career paths of our nine participants, the route to superintendent is delayed, resulting in older female superintendents on average than male. This slower route, which raises the average age of females entering the superintendency and possibly contributes to the shorter average tenure of female superintendents, underwrites the disproportionally low rates of women in the superintendency comparative to men.

A solution that is worthy of further consideration and research is the concept of a "cosuperintendency" to attract more aspirants to this daunting job. If the role of the superintendent is all encompassing, including "collective bargaining, personnel, budget and finance, policy development and implementation, effective communication with stakeholders, strategic planning, and instructional leadership," then logic would hold that at present most candidates and holders of the position alike do not have firsthand experience in more than half of these qualifications (Callan \& Levinson, 2011, as cited by Wallace, 2014, p. 52). Although the model has been debunked in the past due to board members worrying about whom to hold accountable, participants in a recent study of female school superintendents felt the job to be big enough for two people regardless of the gender of the superintendent. Therefore, to help both male and female superintendents serve their districts more effectively, a cosuperintendency model should be piloted and endorsed by the California School Boards Association (CSBA).

The cosuperintendency model should also be considered as an avenue to increase the attraction of a position to more leaders from the periphery. Overall, the homogeneity 
of this study's participants was of concern-white, married, with children. Where do single, childless, gay, transgendered, or female candidates of color sit in the eyes of California's school boards, especially ones who serve high-paying, affluent, stable districts in highly desirable locations? A cosuperintendent model may help in two possible areas to alleviate the extreme disparate outcomes to talented, potentially highimpact educators who fall outside of the mainstream social markers:

1. A single candidate may feel like she or he does not have the family support structure to handle the emotional strain of such a large, highly political job alone.

2. A school board may feel better about "pairing up" a nontraditional candidate with a more traditional candidate with a different skill set.

\section{$\underline{\text { Recommendations for Further Study }}$}

This study was an exploration of behaviors and leadership preferences of successful female school superintendents. Recommendations for further study in this area follow.

Conduct a more in-depth exploration of the characteristics and behaviors of each of the superintendents in this study set. Triangulate the data collected in superintendent interviews with teacher, school board, parent, and district administrator interviews and through multiple observations of the superintendent working with teachers and students at the school. 
Conduct a study exploring school board members' perceptions of female leadership and female leadership from the periphery, such as unmarried, childless, gay, transgendered, and/or minorities underrepresented in school leadership, such as Latino, African American, Asian, Pacific Islander, and Middle Eastern. The job of the school superintendent is the only position not hired by educators, but rather by elected officials. Therefore, a female's viability for a position of superintendent is inextricably tied to local politics and a community's perception of specific demographics, and the perception of how each demographic may impact on the leadership of the community. Reducing the underrepresentation of women in the superintendency needs to include school boards and search firms.

Conduct a study on efficacy of superintendents who employ a coach within the first two years of theirfirst superintendency. Responses from participants pointed to the critical nature of having a coach as a superintendent.

Conduct a study exploring the influence of human systems dynamics (systems thinking/adaptive action) training in school districts on student achievement. Since almost half of respondents (four out of nine) provided unsolicited responses specifically to this form of administrator training as being transformational in their efforts to change the leadership paradigm in their districts, it seems prudent to examine this type of training more closely.

Conduct a study exploring the influence of labor relations and contract negotiations on school leadership. Responses from the superintendents outlined the 
importance of reforming traditional ways of collective bargaining in order to improve both the overall culture of the district and student achievement.

Conduct a study exploring successful gay superintendents, male and female. The superintendency has long been "configured to resemble male roles in conventional heterosexual marriages," and in many ways schools still serve as "extension[s] of the heteronormative family" (Blount, 2003). Examining experiences of gay superintendents will be vital to informing young gay educational leaders on how to a prepare for and be seen as a desirable candidate for a position that has been so masculinized and representative of heteronormative families in America.

Conduct a study of male and female of superintendents that more closely examines why females continue to have shorter tenures on average than males. The findings of this study point to career delays due to raising children and taking more lateral positions than men because of the need to compensate with experience, resulting in women being older candidates. However, evidence in this study also hints at the possibility that social justice activists (change agents), to which all these women strongly coded, have shorter tenures due to the inherent elements of protest and unrest in their leadership style.

This study's examination of female superintendents who have successfully moved their systems of schools toward greater equity and superior student achievement has provided valuable evidence about how these women achieved such successes, why it is important that gender parity is achieved in the $\mathrm{K}-12$ superintendent position, and why 
more women like them should be encouraged to lead our schools. Important conclusions for aspiring female superintendents include:

1. Successful female superintendents transform the role of superintendent to fit their leadership style: Barriers are minimal and are more internal than external on the path to a superintendent position. The strongest barrier was a negative image of the traditional role of superintendent because it was seen as more political than educational, and therefore undesirable.

2. Superintendent networking and coaching should be encouraged and supported: Gender discrimination and isolation was experienced most strongly as a sitting superintendent.

3. Family and long-term, egalitarian relationships, not mentors, scored most prominently in providing guidance, strength, support, and encouragement: All participants had supportive older children, and all but one had supportive husbands and long-term, stable, egalitarian marriages. Those who can sustain healthy relationships, it appears, transfer those skills to successful leadership roles.

4. Relational and social justice leadership took center stage: Although instructional leadership, commonly associated with female leadership, was coded for all participants, negotiating complex interpersonal dynamics in the workplace and being the voice of underserved kids fueled their resilience, grit, and determination as they described their proudest accomplishments and successes. 
5. Leading successful change in culture and equity were their collective cornerstones: They accomplished and sustained their grand visions via extensive training of their management teams in effective human dynamics management/systems thinking and facilitating adaptive action combined with changing the perceived role of the superintendent from "removed statesman" to one that models "boots on the ground instructional leadership." ("I could still be a teacher!'”)

\section{$\underline{\text { Conclusion }}$}

Our female change leaders, fueled by a higher calling for social justice, learn to live with tension and challenge. They have moral courage and unabashedly claim their activism. While this study clearly provides profiles and shows the leadership propensities of successful female superintendents, it's important for school boards and recruiting firms to begin to do their part in disrupting the status quo and the traditional leadership structures that have failed our most vulnerable populations across California. Each of the change leaders profiled herein concentrated not simply on improving test scores, but on founding changes in the educational setting of their schools-systems, culture, and educational practices - that resulted in more inclusive and more unbiased experiences for all students. Each superintendent implemented processes that surpass traditional approaches and goals of organizational effectiveness central to transformational leadership. They committed time and resources to helping their teachers and administrators recognize and comprehend how many of their current assumptions and beliefs about teaching, learning, and leading constitute barriers to the success of all 
children. Consequently, each focused on generating new understandings that critiqued methodologies that preserve the opportunity of some to the marginalization of others. At the same time, they used their influence as community leaders to level the playing field for the submerged underclass in their whitewashed suburban communities. In other words, our change leaders took into account the ways in which the inequities of the outside world affect the outcomes of what occurs internally in educational organizations.

This study has demonstrated the potential of change leadership as a way forward and a way out of stasis. Change leaders, who collectively employ social justice, relational, instructional, spiritual, balanced, and systems-thinking leadership, do more than lament current political challenges and play along the edges of profound and significant transformation. Truly, they act fearlessly and unceasingly to ensure more equitable learning environs and instructional practices for all children. The evidence here demands that we call on California school boards and superintendent recruitment agencies to demand new possibilities of leadership rather than continue the practice of simply asking the community power brokers what kind of traits they want in a leader. Hiring practices based on traits of individuals inevitably squash reform; they lead to people recalling descriptors of past individuals in traditional organization structures who made them feel comfortable or fearful, or else they lead to the hiring of persons who would be a "good fit" in the current culture, inexorably maintaining the hierarchical structures already in place in their municipalities.

Public education in America is a lesson in paradox when theory and practice intersect. It is a launch pad for many of America's young dreamers while it stealthily 
maintains a parallel alleyway leading to a destination of poverty and untapped dreams. Whether schools continue to function as a vehicle for social reproduction perpetuating inequity for the majority of our students of color ultimately depends upon educational leaders within the school systems acknowledging the duality and committing to merge our tracked worlds into one of equal access and opportunity for all students.

It is the role of the superintendent to define and defend the humanist vision of critical consciousness, social justice, and student-centeredness staunchly enough to make this vision become everyone's reality across a system of schools. As a superintendent begins to struggle against oppressive conditions, he or she must start with Freire's (1970/2000) love of humanity and retain an optimistic attitude that the struggle for freedom for others will ultimately succeed. 


\section{REFERENCES}

Ardovini, J., Trautman, H. D., Brown, G., \& Irby, B. (2010). Including female leadership experiences and behaviors: A qualitative validation of synergistic leadership theory. International Leadership Journal, 2(3/4), 22-52.

Avolio, B. J., Bass, B. M., \& Jung, D. I. (1999). Re-examining the components of transformational and transactional leadership using the Multifactor Leadership Questionnaire. Journal of Occupational and Organizational Psychology, 72(4), $441-462$.

Bezy, K. G. (2011). An operational definition of spiritual leadership (Unpublished doctoral dissertation). Virginia Polytechnic Institute and State University, Blacksburg.

Björk, L. G., Glass, T. E., \& Brunner, C. C. (2005). Characteristics of American school superintendents. In L. G. Björk \& T. J. Kowalsky (Eds.), The contemporary superintendent: Preparation, practice, and development (pp. 19-44). Thousand Oaks, CA: Corwin.

Blount, J. M. (1998). Destined to rule the schools: Women and the superintendency, 1873-1995. Albany, NY: SUNY Press. 
Blount, J. M. (2003). Homosexuality and school superintendents: A brief history. Journal of School Leadership, 13(1), 7-26.

Bogdan, R. C., \& Biklen, S. K. (2006). Qualitative research for education: An introduction to theories and methods (5th ed.). Boston, MA: Pearson.

Brandt, R. (1992). On rethinking leadership: A conversation with Tom Sergiovanni. Educational leadership, 49(5), 46-49.

Brooks, D. (2012). The social animal: The hidden sources of love, character, and achievement. New York: Random House.

Brown, A. R. (2011). The freedom to be: African American women as public school superintendents (Unpublished doctoral dissertation). University of North Carolina, Greensboro.

Brown, K. M. (2004). Leadership for social justice and equity: Weaving a transformative framework and pedagogy. Educational Administration Quarterly, 40(1), 77-108.

Brown, G., \& Irby, B. J. (2006). Expanding the knowledge base: Socially just theory in educational leadership programs. In F. L. Dembowski \& L. K. Lemasters (Eds.), Unbridled spirit: Best practices in educational administration (pp. 7-13). Lancaster, PA: DEStech Publications.

Brunner, C. C., \& Grogan, M. (2007). Women leading school systems: Uncommon roads to fulfillment. Lanham, MD: R\&L Education/American Association of School Administrators. 
Brunner, C. C., \& Kim, Y. L. (2010). Are women prepared to be school superintendents? An Essay on the Myths and Misunderstandings. Journal of Research on Leadership Education, 5(8), 276-309.

Burns, J. M. (1998). Transactional and transforming leadership. In G. R. Hickman (Ed.), Leading organizations: Perspectives for a new era (pp. 133-134). Thousand Oaks, CA: Sage.

California Department of Education. (2015). CAASPP description—CalEdFacts. Retrieved from http://www.cde.ca.gov/ta/tg/ai/cefcaaspp.asp.

Catalyst. (2014, January). Knowledge center: Women in S\&P 500 Companies. Retrieved from http://www.catalyst.org/knowledge/us-women-business.

Cheung, F. M., \& Halpern, D. F. (2010). Women at the top: Powerful leaders define success as work + family in a culture of gender. American Psychologist, 65(3), $182-193$.

Coleman, M. (2003). Gender in educational leadership. In M. Brundrett, N. Burton, \& R. Smith (Eds.), Educational management: Research and practice: Leadership in education (pp. 36-51). London: Sage Publications.

Collins, J. C. (2001). Good to great: Why some companies make the leap-and others don't. New York: Random House. 
Copeland, S. M., \& Calhoun, D. W. (2014). Perceptions of mentoring: Examining the experiences of women superintendents. International Journal of Educational Leadership Preparation, 9(2), 28-46.

Creswell, J. W. (2013). Research design: Qualitative, quantitative, and mixed methods approaches. Sage Publications.

Dantley, M. E. (2005). African American spirituality and Cornel West's notions of prophetic pragmatism: Restructuring educational leadership in American urban schools. Educational Administration Quarterly, 41(4), 651-674.

Deal, T. E., \& Peterson, K. D. (2010). Shaping school culture: Pitfalls, paradoxes, and promises. John Wiley \& Sons.

Denzin, N. K., \& Lincoln, Y. S. (Eds.). (2008). Collecting and interpreting qualitative materials (Vol. 3). Thousand Oaks, CA: Sage Publications.

Derrington, M. L., \& Sharratt, G. (2009). Female superintendents: Breaking barriers and challenging life styles. Delta Kappa Gamma Bulletin, 75(2), 8-12.

DeRue, D. S., \& Ashford, S. J. (2010). Who will lead and who will follow? A social process of leadership identity construction in organizations. Academy of Management Review, 35(4), 627-647.

DuFour, R. (2004). What is a "professional learning community”? Educational leadership, 61(8), 6-11. 
Dunbar, D. P., \& Kinnersley, R. T. (2011). Mentoring female administrators toward leadership success. The Delta Kappa Gamma Bulletin, 77(3), 17-24.

Duncan-Andrade, J., \& Morrell, E. (2008). The art of critical pedagogy. New York: Peter Lang.

Eagly, A. H. (2007). Female leadership advantage and disadvantage: Resolving the contradictions. Psychology of Women Quarterly, 31(1), 1-12.

Eagly, A. H., \& Carli, L. L. (2009). Navigating the labyrinth. School Administrator, $66(8), 10-16$.

Eagly, A. H., \& Johannesen-Schmidt, M. C. (2007). 13 Leadership style matters: The small, but important, style differences between male and female leaders. Handbook on women in business and management, 279.

Eagly, A. H., Johannesen-Schmidt, M. C., \& van Engen, M. L. (2003). Transformational, transactional, and laissez-faire leadership styles: A meta-analysis comparing women and men. Psychological Bulletin, 129(4), 569-589.

Eagly, A., \& Johnson, B. T. (1990). Gender and leadership style: A meta-analysis. Psychological Bulletin, 108, 233-256.

Eagly, A. H., \& Karau, S. J. (2002). Role congruity theory of prejudice toward female leaders. Psychological review, 109(3), 573-598.

Ed-Data (Education Data Partnership). (2014). County reports of fiscal, demographic, and performance data on California's K-12 schools: Countywide profiles, fiscal year: 
2013-14. Retrieved from http://www.ed-data.k12.ca.us/App_Resx /EdDataClassic/fsTwoPanel.aspx?\#!bottom=/_layouts/EdDataClassic /profile.asp?Tab=1\&level=05\&reportnumber $=16$.

Ely, R., Ibarra, H. \& Kolb, D. M. (2011). Taking gender into account: Theory and design for women's leadership development programs. Academy of Management, Learning and Education, 3(10), 474-493.

Ely, R. \& Rhode, D. L. (2010, January). Women and leadership: Defining the challenges. In N. Nohria \& R. Khurana (Eds.), Handbook of leadership theory and practice: A Harvard Business School centennial colloquium on advancing leadership (pp. 377-410). Boston, MA: Harvard Business Review Press.

Eoyang, G. H. (2011). Complexity and the dynamics of organizational change. In P. Allen, S. Maguire, \& B. McKelvey (Eds.), The Sage handbook of complexity and management (pp. 317-332). London: Sage Publications.

Foldy, E. G., Goldman, L., \& Ospina, S. (2008). Sensegiving and the role of cognitive shifts in the work of leadership. The Leadership Quarterly, 19(5), 514-529.

Friere, P. (1998). Pedagogy of freedom: Ethics, democracy, and civic courage (P. Clarke, Trans.). Lanham, MD: Rowman and Littlefield.

Freire, P. (2000). Pedagogy of the oppressed (30th anniversary ed.) (M. B. Ramos, Trans.). New York: Continuum. (Original English edition published in 1970.)

Fullan, M. G. (1992). Visions that blind. Educational leadership, 49(5), 19-22. 
Fullan, M. [G.] (2002). The change. Educational leadership, 59(8), 16-20.

Fullan, M. [G.] (2010). The moral imperative realized. Thousand Oaks, CA: Corwin Press.

Garcia-Retamero, R., \& López-Zafra, E. (2009). Causal attributions about feminine and leadership roles: A cross-cultural comparison. Journal of Cross-Cultural Psychology, 40(3), 492-509.

Gilligan, C. (1982). In a different voice: Psychological theory and women's development. Cambridge MA: Harvard University Press.

Giscombe, K., \& Mattis, M. C. (2002). Leveling the playing field for women of color in corporate management: Is the business case enough? Journal of Business Ethics, 37(1), 103-119.

Glass, T. E., \& Franceschini, L. A. (2007). The state of the American school superintendency: A mid-decade study. Lanham, MD: Rowman and Littlefield Education.

Gray, S. P., \& Streshly, W. A. (2010). Leading good schools to greatness: Mastering what great principals do well. Thousand Oaks, CA: Corwin Press.

Greenleaf, R. K. (1977). Servant leadership: A journey into the nature of legitimate power and greatness. New York: Paulist Press.

Grogan, M. (1996). Voices of women aspiring to the superintendency. Albany, NY: SUNY Press. 
Grogan, M., \& Shakeshaft, C. (2011). Women and educational leadership: Vol. 10. Jossey-Bass Leadership Library in Education. San Francisco, CA: Jossey-Bass, Wiley.

Hanson, K. M. (2011). An exploratory study of the ascendancy of women to the position of $K-12$ superintendent. California State University, Fullerton.

Heilman, M. E., \& Okimoto, T. G. (2007). Why are women penalized for success at male tasks? The implied communality deficit. Journal of Applied Psychology, 92(1), 81.

Ibarra, H., Ely, R. J., \& Kolb, D. (2013). Women rising: The unseen barriers. The Harvard Business Review, (9) 62-66.

Irby, B. J., Brown, G., \& Yang, L. (2009). The synergistic leadership theory: A 21 st century leadership theory. In C. M. Achilles, B. J. Irby, B. Alford, \& H. Perreault (Eds.), Remember our mission: Making education and schools better for students, (pp. 93-105). Lancaster, PA: Pro-Active Publications.

Jackson, K. M., Chiu, C.-C., Lopez, R., Simmons, J. M. C., Skral, L., \& Warner, L. S. (2013). An Exercise in tempered radicalism: Seeking the intersectionality of gender, race, and sexual identity in educational leadership research. In L. C. Tillman \& J. J. Scheurich (Eds.), The handbook of research on educational leadership for equity and diversity (pp. 327-354). New York: Routledge. 
Kanter, R. M. (1976). The impact of hierarchical structures on the work behavior of women and men. Social Problems, 23(4), 415-430.

Kim, Y.-L., \& Brunner, C. C. (2009). School administrators' career mobility to the superintendency: Gender differences in career development. Journal of Educational Administration, 1(47), 75-107.

Klein, S. S. (1985). Handbook for achieving sex equity through education. Baltimore, MD: Johns Hopkins University Press.

Kowalski, T. J., McCord, R. S., Petersen, G. J., Young, P. I., \& Ellerson, N. M. (2011). The American school superintendent: 2010 decennial study. Lanham, MD: R\&L Education.

Kowalski, T. J., Petersen, G. J., \& Fusarelli, L. D. (2007). Effective communication for school administrators: An imperative in an information age. Lanham, MD: Rowman and Littlefield Education.

Leithwood, K., \& Mascall, B. (2008). Collective leadership effects on student achievement. Educational Administration Quarterly, 44(4), 529-561.

Lemasters, L., \& Roach, V. (2012). 3-Dimensional Portrait of the Female CEO. International Journal of Educational Leadership Preparation, 7(1), 1-12.

Leonard, N., \& Jones, A. (2009). Synergistic leadership theory. In 21st century theories of education administration (pp. 25-29). Houston, TX: Connexions, Rice University. Retrieved from http://cnx.org/content/coll0727/1.1. 
Louis, K. S., Dretzke, B., \& Wahlstrom, K. (2010). How does leadership affect student achievement? Results from a national US survey. School Effectiveness and School Improvement, 21, 315-336.

Louis, K. S., Leithwood, K., Wahlstrom, K. L., Anderson, S. E., Michlin, M., \& Mascall, B. (2010). Learning from leadership: Investigating the links to improved student learning. Minneapolis: University of Minnesota Center for Applied Research and Educational Improvement, and Toronto: Ontario Institute for Studies in Education/University of Toronto.

Lincoln, Y. G., \& Guba, E. E. (1985). Naturalistic inquiry. Newbury Park, CA: Sage.

Lopez-Zafra, E., \& Garcia-Retamero, R. (2012). The relationship between transformational leadership and emotional intelligence from a gendered approach. The Psychological Record, (62) 97-114.

Mahitivanichcha, K., \& Rorrer, A. K. (2006). Women's choices within market constraints: Re-visioning access to and participation in the superintendency. Educational Administration Quarterly, 42(4), 483-517.

Marshall, C., \& Rossman, G. B. (2010). Designing qualitative research (5th ed.). Thousand Oaks, CA: Sage.

Miller, S. K., Washington, Y. C., \& Fiene, J. R. (2006). Female Superintendents: Historic Barriers and Prospects for the Future. Journal of Women in Educational Leadership, 4(4), 219-242. 
Moskowitz, D. S., Suh, E. J., \& Desaulniers, J. (1994). Situational influences on gender differences in agency and communion. Journal of Personality and Social Psychology, 66(4), 753.

National Center on Educational Statistics (2012). Digest of education statistics: Table 209.10: Number and percentage distribution of teachers in public and private elementary and secondary schools, by selected teacher characteristics. Retrieved from http://nces.ed.gov/programs/digest/d13/tables/dt13_209.10.asp.

Ospina, S., El Hadidy, W., \& Hofmann-Pinilla, A. (2008). Cooperative inquiry for learning and connectedness. Action learning: Research and practice, 5(2), 131147.

Patterson, L., Holladay, R., \& Eoyang, G. (2012). Radical rules for schools: Adaptive action for complex change. Circle Pines, MN: Human Systems Dynamics Institute.

Pfaff, L. A., Boatwright, K. J., Potthoff, A. L., Finan, C., Ulrey, L. A., \& Huber, D. M. (2013). Perceptions of women and men leaders following 360-degree feedback evaluations. Performance Improvement Quarterly, 26(1), 35-56.

Robinson, V. M., Lloyd, C. A., \& Rowe, K. J. (2008). The impact of leadership on student outcomes: An analysis of the differential effects of leadership types. Educational Administration Quarterly, 44(5), 635-674. 
Rosette, A. S., \& Tost, L. P. (2010). Agenic women and communal leadership: How role prescriptions confer advantage to top women leaders. Journal of Applied Psychology, 95(2), 221-235.

Saldana, J. (2013). The coding manual for qualitative researchers. Thousand Oaks, CA: Sage Publications.

Salleh-Barone, N. (2004). Asian American women educators: Narrations of their career paths to leadership (Unpublished doctoral dissertation). State University of New York, Buffalo.

Sanchez, J. E., \& Thornton, B. (2010). Gender issues in K-12 educational leadership. Advancing women in leadership journal, 30(13), 2-15.

Sanders-Lawson, R., Smith-Campbell, S., \& Benham, M. K. (2006). Wholistic visioning for social justice: Black women theorizing practice. In C. Marshall \& M. Oliva (Eds.), Leadership for social justice: Making revolutions in education (pp. 3163). New York: Pearson Education.

Seidman, I. (2013). Interviewing as qualitative research. Teachers College. Columbia University (4th ed.).

Senge, P. M. (2006). The fifth discipline: The art and practice of the learning organization. New York: Currency, Doubleday. 
Senge, P. M., Cambron-McCabe, N., Lucas, T., Smith, B., \& Dutton, J. (2012). Schools that learn: A fifth discipline fieldbook for educators, parents, and everyone who cares about education. New York: Crown Business.

Sergiovanni, T. J. (1992). Moral leadership: Getting to the heart of school improvement. San Francisco, CA: Jossey-Bass.

Shakeshaft, C. (1989). Women in educational administration. Newbury Park, CA: Sage Publications, Corwin Press.

Shakeshaft, C., Brown, G., Irby, B. J., Grogan, M., \& Ballenger, J. (2007). Increasing gender equity in educational leadership. In S. S. Klein (Ed.), Handbook for achieving gender equity through education (2nd ed), (pp. 103-129). New York: Routledge.

Shields, C. M. (2010). Transformative leadership: Working for equity in diverse contexts. Educational Administration Quarterly, 46(4), 558-589.

Simmons, J. C., \& Johnson, W. Y. (2008). African American female superintendents speaking the language of hope. Improving Schools: Studies in Leadership and Culture, 7, 223.

Skrla, L. (2000). The social construction of gender in the superintendency. Journal of Education Policy, 15(3), 293-316.

Staines, G., Tavris, C., \& Jayaratne, T. E. (1974). The queen bee syndrome. Psychology Today, 7(8), 55-60. 
Tyack, D., \& Hansot, E. (1982). Managers of virtue: Public school leadership in America. New York: Basic.

Vinkenburg, C. J., van Engen, N. L., Eagly, A. H. \& Johannesen-Schmidt, M. C. (2011). An exploration of stereotypical beliefs about leadership styles: Is transformational leadership a route to women's promotion? The Leadership Quarterly, 3 (22), 10 21.

Wallace, T. (2014). Increasing the proportion of female superintendents in the 21 st century. Advancing Women in Leadership, 34, 48-53.

Wickham, D. M. (2008). Female superintendents: Perceived barriers and successful strategies used to attain the superintendency in California (Unpublished doctoral dissertation). University of the Pacific, Stockton, CA.

Wiseman, L. (2014). Rookie smarts: Why learning beats knowing in the new game of work. New York: HarperBusiness.

Yin, R. K. (2003). Case study research: Design and methods (3rd ed.). Thousand Oaks, CA: Sage.

Yin, R. K. (2009). Case study research: Design and methods (5th ed.). Thousand Oaks, CA: Sage. 
APPENDICES 


\section{APPENDIX A: PROTECTION OF HUMAN AND ANIMAL SUBJECTS}

\section{SAN FranCisCo}

STATE UNIVERSITY

OFFICE OF RESEARCH AND SPONSORED PROGRAMS HUMAN AND ANIMAL ProteCtIONS

INSTITUTIONAL REVIEW BOARD

Date: May 8, 2014

To: Mary Streshly

Re: Change Leadership and the Female Superintendent

The Institutional Review Board Chair at San Francisco State University has reviewed and approved the use of human subjects in the above protocol. You may proceed with your research as described in your protocol and as modified in any subsequent correspondence.

Protocol Number: $\mathbf{X 1 4 - 1 2}$

Approval Date: May 8, 2014 Expedited

Expiration Date: This approval expires on May 7, 2015.

If the project is to be continued, it must be renewed by the expiration date. Please allow at least six weeks for processing of a renewal application. Data cannot be used in the research if collected after the expiration date, before the protocol has been renewed.

Completion: Upon completion of the project, a Study Completion Form must be submitted to the IRB.

Adverse Event Reporting: All unanticipated or serious adverse events must be reported to the IRB within ten working days.

Modifications: Prior IRB approval is required before implementing any changes in any of the approved documents. Data cannot be used if collected before any changes in the research are approved.

Recordkeeping: You must retain all signed consent forms for at least 3 years after all research activity is completed.

Questions: Please contact ORSP - Human and Animal Protections and the Institutional Review Board at (415) 338-1093, or at protocol@sfsu.edu

Sincerely,

Institutional Review Board

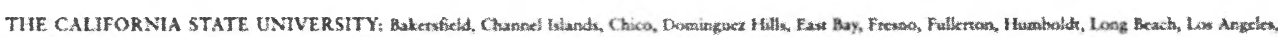

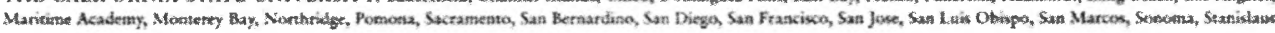




\section{APPENDIX B: INFORMED CONSENT FORM AND LETTER OF \\ INTRODUCTION/E-MAIL LETTER TEXT}

\section{San Francisco State University}

\section{Change Leadership and the Female Superintendent}

\section{PURPOSE AND BACKGROUND}

My name is Mary Streshly. I am a Doctoral Student in the Educational Leadership Program at San Francisco State University and an Assistant Superintendent for Educational Services in Campbell Union High School District in Santa Clara County.

I am currently conducting a dissertation research study to examine the barriers and facilitators experienced by female educational leaders who succeed in attaining the $\mathrm{K}-12$ superintendency. I also wish to explore leadership behaviors they attribute to making positive change in the position as superintendent.

I am requesting your participation in this study. You were selected because you are a female superintendent currently serving a public school district in California with an ADA larger than 1,000 students and have served in the position of superintendent 6 months or longer. All female superintendents meeting these criteria have been invited to participate.

\section{PROCEDURES}

If you agree to participate in this dissertation research study, the following will occur:

1. You will be asked to participate in a personal interview lasting no longer than 90 minutes, to be conducted at a time and place convenient to you. Although in person is preferred, a phone or Skype interview can be accommodated if requested.

2. At the onset of the interview, you will be asked to fill out a demographic questionnaire.

3. To assure accuracy of the data, the researcher would request permission to make an audio recording of the session.

4. Following the completion of the interview, the researcher would request a copy of your curriculum vitae.

5. The researcher may contact you later to clarify your answers for approximately fifteen to thirty minutes.

6. Total time commitment will be 90 minutes. 


\section{$\underline{\text { RISKS }}$}

This study may make you conscious of your leadership style and experience which may be something you might not have recognized before your participation in the study thereby adding discomfort in the style and manner in which you previously exhibited leadership practices or in remembrance of past experiences associated with barriers in your career path.

\section{CONFIDENTIALITY}

Throughout this study, the researcher will practice confidentiality that will be maintained to the extent allowed by law. Each participant will be given a pseudonym known only to the researcher to ensure anonymity. Results will also be aggregated for confidentiality. Data will be kept under locked cabinet of the researcher and only the researcher will collect and analyze the data. You will have the opportunity to edit written transcripts of the interview, if you choose. The researcher will destroy the audio recordings and the data transcribed into a written format within 3 years of the publication of the study.

\section{BENEFITS}

There are no direct benefits for your participation in the study.

\section{PAYMENT}

There will be no direct compensation for you other than snacks or beverages that may be offered during interview session.

\section{$\underline{\operatorname{COSTS}}$}

There will be no costs to you to participate in the study.

\section{ALTERNATIVES}

The alternative for you is not to participate in the study or to opt out at any time during the study.

\section{OUESTIONS}

You have spoken with Mary E. Streshly about this study and have had your questions answered. If you have any further questions about the study, you may contact Mary by email at mestreshly@gmail.com or you may contact her faculty advisor, Dr. Darlene Yee-Melichar, at dyee@sfsu.edu. Questions about your rights as a study participant, or 
comments or complaints about the study, may also be addressed to the Office for the Protection of Human Subjects at 415-338-1093 or protocol@sfsu.edu.

\section{CONSENT}

You have been given a copy of this consent form to keep. PARTICIPATION IN THIS RESEARCH IS VOLUNTARY. You are free to decline to participate in this research study, or to withdraw your participation at any point, without penalty. If you agree to participate, please sign and return this consent. I will then contact you to arrange the interview appointment.

I have carefully read and/or I have had the terms used in this consent form and their significance explained to me. By signing below, I agree that I am at least 18 years of age and agree to participate in this project. I also agree to the audio recording of the session.

Signature

Date:

Research Participant

Signature

Date:

Researcher 
June 20,2014

Dear Superintendent

My name is Mary Streshly. I am a doctoral candidate in Educational Leadership at San Francisco State University. My dissertation concerns the experiences of female superintendents during their ascendency to the position of $\mathrm{K}-12$ superintendent and execution of this role. Your input will help educational leaders understand the commonalities among female superintendents in the areas of leadership style, career pathway, perceptions of barriers to ascendency and personal motivating/inspirational factors. This information will be valuable to aspiring female superintendents as they prepare for a career in a position that has been historically masculinized and largely male-dominated.

This study also anticipates that deeper insight into the experiences and perspectives on leadership from the vantage point of successful female superintendents, like you, will accomplish the following two supplementary objectives:

1) expanding the appreciation of female ways of leading schools, thus leading to decreased underrepresentation of women in the K-12 superintendency (currently less than 1 in 4 superintendents are female nationwide)

2) encouraging all leaders (males and females alike) to lead as you do because of the increasing evidence showing linkages between elements of the most common female leadership behaviors, elements of transformational leadership and improved school culture and increased student achievement.

You were selected because you are a female superintendent of a public school district in one of five Bay Area counties in California selected with an ADA of 1,000 students or larger, you've held the position of superintendent for two years or more and your school system has achieved positive, measureable change during your tenure. All female superintendents fitting these criteria in the five selected Bay Area counties, which include San Mateo, Santa Clara, Alameda, Contra Costa and Marin, will be invited to participate.

I hope that you will decide to participate in this study. The requirements on your time will be a personal interview and a brief demographic questionnaire lasting from 60-90 minutes, to be conducted at a time and place convenient to you. To assure accuracy of data, I would request permission to make an audio recording of the session. 
I also would request a copy of your curriculum vitae/résumé. The information that is shared during the study will be anonymous and remain confidential.

Thank you for your consideration. If you are interested in participating or have further questions about the study, please call me@650-678-7516 or email me at mestreshly@,gmail.com.

Sincerely,

Mary E. Streshly 


\section{APPENDIX C: SEMISTRUCTURED INTERVIEW QUESTIONS}

1. At what point did you decide you wanted to become a superintendent? Please speak to the factors that contributed to your perception that this was a viable option for you.

2. What personal behaviors, characteristics or beliefs do you ascribe to your successful ascendancy?

3. What key life experiences, relationships or events do you see as pivotal to attaining key roles on the path to the position of superintendent?

4. Where do you see your greatest advantages and disadvantages lie now and while following your career path to superintendent?

5. How would you characterize your leadership? Can you think of any examples that illustrate your leadership?

6. What approaches do you use? Have you always approached leadership that way? Why? Why not?

7. Can you tell any stories to help explain what you mean?

8. What values or beliefs influence the way you lead? What have you learned about leadership or life that made you choose those values?

9. How do others respond to your leadership approaches?

10. Are there certain conditions or situations that influence your approach to leadership tasks? For example?

11. What are some challenges that you have dealt with as a woman in a leadership position?

12. You were invited to participate because your district made significant 
improvement in academic achievement while you served or are currently serving as superintendent. What changes did you implement that you attribute to having the biggest impact on improving student achievement? Explain how any of the above leadership behaviors (list them again) played a part in the change process.

13. As superintendent, what changes to district policies or practices have you helped to make that better serve underrepresented minorities in your district? How did those changes get made? Can you tell the story of one process that you used? Who was involved?

14. When reflecting about your career, what is your proudest accomplishment as a superintendent, and what advice would you give a fellow female superintendent or aspiring superintendent who wanted to accomplish the same goal? 
APPENDIX D: DEMOGRAPHIC INFORMATION: SUPERINTENDENT

\section{BACKGROUND QUESTIONNAIRE}

1. Your age now:

2. Your age when you first attained a position as superintendent:

3. Your Race or Ethnicity:

$\begin{array}{lll}\text { Asian } & \text { African American } \\ \text { Hispanic } & \text { Native American } & \text { Middle Eastern } \\ \text { Caucasian } & \text { Two or more ethnicities } & \text { T Decline to state }\end{array}$

4. Your relationship status:

single never married single divorced married domestic partnership married same sex decline to state

5. Family:

I have children I do not have children decline to state

6. Sexual Orientation:

$\begin{array}{cl}\text { heterosexual } & \text { homosexual } \\ \text { transgender } & \text { decline to state }\end{array}$

7. Length of tenure as a superintendent in current district:

District type:
$\mathrm{K}-5$
$\mathrm{K}-8$
$\mathrm{K}-12$
$9-12$

District size:

$3,000-5,000$

$5,000-10,000$

$10,000-20,000$

larger 